\title{
DISCLAIMER
}

This report was prepared as an account of wotk sponsored by an agency of the United States Government. Neither the United States Goverument ror eny arency shereof, nor any of theis employees, makes any wurranty, express or implied, or asumes any lecal liability or responsibility for the accuracy, completener;, or usefuloes of any information, epperatus, product, or process disclosed, or cpresents that its ase would aor infringe ptivately owned riehth Reference herein to any specilic combercial product, proses, or service by trade name, trademark, menufacturer, or otherwise does not neceasarily constitute or imply it ectorsement, recommendation, or favoring by the United States Govemment or any seacy thefoof. The views and opinions of authors expresed hereir do rot necessarily state or reflect those of the United States Government or any agency thereof.

\section{Mirror Advanced Reactor Study (MARS): Executive Summary and Overview}

\author{
B. G. Logan \\ L. J. Perkins \\ J. D. Gordon*
}

Manuscript date: July 1984

* TRW Energy Development Group,

Redondo Beach, California

\section{LAWRENCE LIVERMORE NATIONAL LABORATORY University of California - Livermore, California - 94550}




\section{Contributing Authors}

B. G. Logan. C. D. Hennıng, L. J. Perkins, G. A. Carlson. R. W. Werner Lawrence Livernore National Laboratory livermore, California

1. D. Gordon

TRW Energy Development Group

Redondo Beach. Califormia

G. I. Kulcinski

Lniversity of limeomin

Madiam, Wincorasn

1. F. Parmer

General Diname Compair Divinion

San Dienge. California

1. 1. Ribs

Liniversily al Wa-kengtom

Seattle. Wioningteri

R. I Herherminn

Cirumman Acromple Corporatuon

Bellopage. Sew tork
J. R. Bilton

Ebasco Services, Inc.

New York, New York

H. Gurol, J. E. Glancy

Science Applications, Ine.

l.a jolla. California

L.. C. Ërown

GA Technologies

San Diego. California

N. I. Hoffman

Eriergy Technology Engincering Center (ETEC)

Canoga Park, California

R. W: Conn

University of Califorria

l.om Angeles. California

O. K. Kueton

( notano Hydro

Miamisaluga, Ontario, Cankala 


\section{Contents}

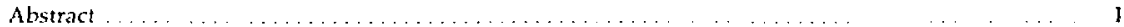

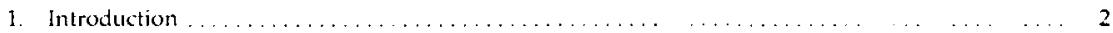

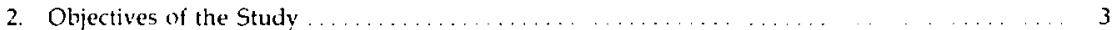

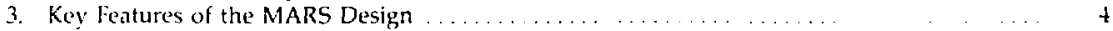

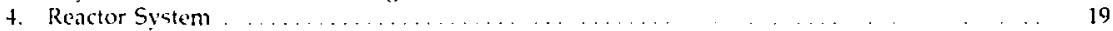

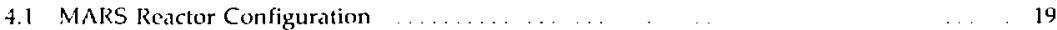

4.2 Plasma Engineering Design . . . . . . . . . . . . . . . . . 31

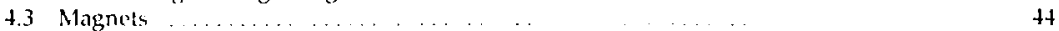

4.4 Microwase Heating Systems .............. 48

4.5 Lon-Cyoitron Resonamt Heating Systoms ... . . . . 52

4.6 Neutial Beam Sistem . . . 54

4.7 End Plasma Technology . . . . . . . . . . . . . . . . .

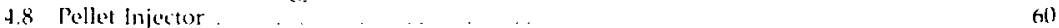

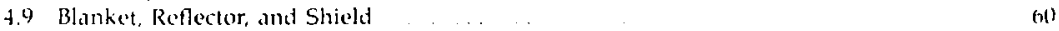

4.10 Heat Transport and Energy Consersien

4.11 Tritiun Sintems . . . . . . (n)

4.12 Crvogenic Sistem 69

5. Balance of Plant . Tl

6. Plant Cinstructum _. . .

7. Plant (iperations.

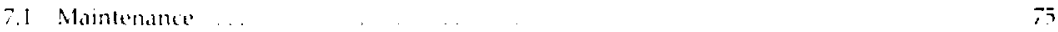

7.2 Reaclor ()peration

7.3 Arailatility $\quad-8$

8. Enviromment and Safety . . . . B

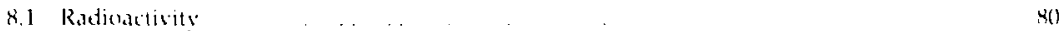

8.2 Normal Radioactivity Release?

8.3 Safutr $\mathrm{kP}$

4. Eacumemic Analinis

10. Power llow and cost scaling. . Xo

11. Conclusion of the MARS Studs...

11.1 Accomplishments 92

11.2 MARS R\&D Noeds. . . . . . . 11.3

11.3 Future Directions.

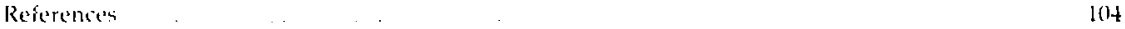




\title{
Mirror Advanced Reactor Studv (MARS): Executive Summary and Overview
}

\begin{abstract}
This report provides an executive summary and overview of the Mirror Advanced Reactor Study (MARS), which is a comprehensive conceptual design of a deuteriumtritium-fucled commercial fusion reactor. Its operation is based on the tandem nirror principle exemplified by the Tandem Mirror Experiment-Upgrade (TMX-U) and the Mirror Fusion Test Facilit: (MFTF-B), two experiments currently being conducted by the 1. awrence livermore Cational Laboratory (LLNL). Two self-consistent MARS configuratiuns are discushed - a $12(1)$-MWe commercial electricity-generating plant and a synfuelsgenerating plant that produces hy drogen with an energy equivalent to 26,000 barrels of oil per day: The MARS machine emphasizes the attractive features of the tandem mirror concept, including steady-state operation, a small-diameier high-beta plasma, a linear central cell with siplo low-maintenance blankets, low first-wall heat fluxes (<10 $\mathrm{W} /$ $\left(\mathrm{m}^{2}\right)$, no driven plasma currents or asscciated disruptions, natural halo impurity diversion, and direst conversion of end-loss charged-particle power. The MARS electric plant produces $20(10) \mathrm{MW}$ of fusion power in a 130 -m-long central cell. Advanced tandemmimot plasma-engineering concepts, a high-efficiency licjuid lithium-lead $\left(\mathrm{Li}_{1}, \mathrm{P}^{\mathrm{B}} \mathrm{b}_{83}\right)$ blanket, and efficient direct electrical conversion of end loss power conbine to produce a high not plant efficiency of $36 \%$. With a total capital cost of $\$ 2.9$ billion (constant 1983 dollars), the MiRS elictric plant produces busbar electricity at $-75 / \mathrm{kW}$ hour. The MARS synfuels plant produces $3500 \mathrm{MW}$ of fusion power in a 150 -m-long central cell. A helium-gas-conled silicon carbide pebble-bed blanket provides high-temperature $\left(100()^{\circ} \mathrm{C}\right.$ ) heat to a ther mochemical water-splitting cycle and the resulting hydrogen is catalytically conserted to methanol for distribution. With a total capital cost of $\$ 3.6$ bilion (constant 1983 dollars), the synfuels plant produces methanol fuel at about $\$ 1.7 /$ igal. The major features of the MARS resctor inciude sloshing-ion thernal barrier plugs for efficient plasma confinement $\rightarrow$ high efficiency blanket, high-field (24-T) choke cells, drift punping for trapped plasma species, quasi-optical electron-cyclotron resonant heating (ECKH I) systems, and a compact gridless direct converter. We have placed spe'ial empinasis on fusion's potential for improved safet:" lower activation, and simpler radiuactive waste disposal as compared with fission. In particular, the $\mathrm{Li}_{17} \mathrm{Ph}_{\mathrm{y}}$ blankct concept affords a low blanket tritium inventory $(<8 \mathrm{~g})$, passive con!ing during loss of flow or coolant accidents, and activated materials that can be disposed of using criteria established for near-surface burial of radioactive waste.
\end{abstract}




\section{Introduction}

The Mirror Advanced Reactor Study (MARS) was a two-year study of a commercial tandem-mirror fusion reactor combining the current plasma confinement concepts used in Lawrence Livermore National Laboratory's (LLNL) Tandem Mirror Experiment-Upgrade ${ }^{l}$ (TMX-U) and Mirror Fusion Test Facilit $y^{2}$ (MFTF-B) with advanced engineering design concepts for efficient production of electricity and synfuels. The MARS program was conducted by LLNL for the U.S. Department of Energy (DOE), with TRW as the prime industrial partner; General Dynamics, EBASCO Services, Inc., and Science Applications, Inc., as subcontractors; and the University of Wisconsin as a university partner Grumman Aerospace Corp. also contributed a significant portion of the engineering effort, and additional support to the study was provided by the University of California-Los Angeles and Ontario Hydro. Finally, the University of Washington and GA Technologies provided input to the synfuels portion of the program. This report is an executive summary and overview of the MARS Study and is an abstraction from the Final Report, ${ }^{3}$ which is a comprehensive design document providing detailed reports on all aspects of MARS; the Final Report consists Volume I-A and I-B (MARS Commercial Fusion Electric Plant) and Volume 2 (MARS Commercial Fusion Synfuels Plant).

Since its inception in 1976, the tandem mirror concept 4,5 has evolved rapidly--both experimentally 6,7 and theoretically 8,9 -to the poinc that in 1981 it became possible to envision tandem mirror reactors with woth high power density (neutron wall load $\Gamma_{\mathrm{n}}>2 \mathrm{MW} / \mathrm{m}^{2}$ ) and high power gain ( $\mathrm{Q}=$ plasma fusion power/plasma heating power $>25) .10,11$ with these advances, a commercial fusion power reactor based on the tandem mirror concept exhibits the following attractive features:

- Steady-state operation (no pulsed loads or cycling fatigue);

- Simple, "low-technology" central cell region with linear geometry locating the higher-technology items in the end ce?ls results in a simple, easy-to-maintain power-produciag system in the central cell);

- Low charged-particle heat fluxes to the first wall $\left(\leqslant 10 \mathrm{~W} / \mathrm{cm}^{-2}\right)$;

- No reguired driven current and no ideritifiable plasma disruptions; 
- Direct electrical conversion of charged-particle end-loss power;

- Natural impurity diversion via plasma halos;

- High-beta operation as a result of the machine's linear geometry.

In this study we completed and costed a single, self-consistent MARS design, performed some limited cost optimization, and examined alternative parameter vanges. It is important to note that because the MARS study provides only limited parameter surveys, we expect that the tandem mirror reactor can be further refined with respect to performance and cost. The present MARS design represents a major advance in the tandem-mirror reactor concept: the physics and engineering are self-consistent, and they demonstrate that efficient production of electricity and synfuels is feasible at nearcompetitive costs.

\section{Objectives of the Study}

The MARS study began in fiscal year (FY) 1981 and was motivated by several developments in tandem mirror physics and technology. As a result of successful electrostatic plugging demonstrated in the earlier TMX experiment, 6 the MFTF machine (a single, minimum-B mirror experiment) was approved in 1980 for conversion to a large tandem-mirror device ${ }^{2}$ capable of a confinement equivalent to $Q>0.5$. Therefore, there was a need to fully assess reactors with these design features. There was also a need to design a stable end plug for a reactor configuration that would incorporate advances in tandem mirror microstability and magnetohydrodynamic (MHD) stability with thermal barriers. 12 A complete tandem mirror reactor design was needed with comparable detail in reactor plant equipment and balance of plant, as in the Starfire tokamak study, 13 to gain a more accurate perspective on the cost of designing and constructing an entire tandem mirror power plant. In adoition, in 1980 there was increased interest in the use of high temperature heat from fusion to produce synfuels as well as electricity, plus an increased interest in finding ways to improve fusion reactor safety and reduce the amount and longevity of fusion-generated radioactive waste. 
Therefore, the general objectives of the MARS study were:

- To design efficient tandem-mirror reactors, both for electricity and synfuels production, that are consistent with aforopriate physics and technology constraints;

- To identify key new physics concepts and feasible technologies that could be developed to improve the reactcr's economics;

- To exploit the potential of fusion for improved safety, lower activation, and simpler disposal of radioactive vastes, compared with fission.

Additianal guidelines were provided as the result of some programmatic assumptions and groundrules. First, we made technology and cost assumptions for first-generation, but tenth-of-a-kind, commercial reactors circa the year 2020. We included plug physics concepts that incorporated the basic elements of thermal barrier, quadrupole-type plugs to be tested in TMX-U and MFTF-B. Although we allowed for additional shysics and te: hology concepts to improve reactor performance, we specified that they should be developable by the 2020 time frame. We were also required to select structural steels that satisfy the Nuclear kegulatory Commission's (NRC) rules (10CFR61) for near-surface burial of Class $C$ low-level radioactive waste. In addition, the reactor blankets were to have a iow tritium inventory $(<1 \mathrm{~kg}$ ) and were not to use flanmable liquid metals. Finally, the size of the MARS reactor was to be comparable to Starfire and today's largest nuclear fission plants.

\section{Key Features of the MARS Design}

The MARS commercial fusion electric plant, described in Ref. 3, Vols. $1-A$ and $1-B$, is shown in Figs. 1 and 2 . The reactor has a 130-m-long cylindrical central cell producing $2600 \mathrm{MW}$ of fusion power in steady state. Neutron energy multiplication (1.36) in a liquid lithium-lead ( $\mathrm{L}_{17} \mathrm{~Pb}_{83}$, hereafter referred to as $\mathrm{Li}-\mathrm{Pb}$ ) blanket ( $\mathrm{Fig}$. 3) increases the reactor's thermal power to $3349 \mathrm{MWth}$, and efficient direct conversion of the plasma exhaust out the ends (Fig. 4) leads to a high ret plant efficiency of $36 \%$ and a high net electrical power production of 1200 MWe. Table $l$ summarizes key 


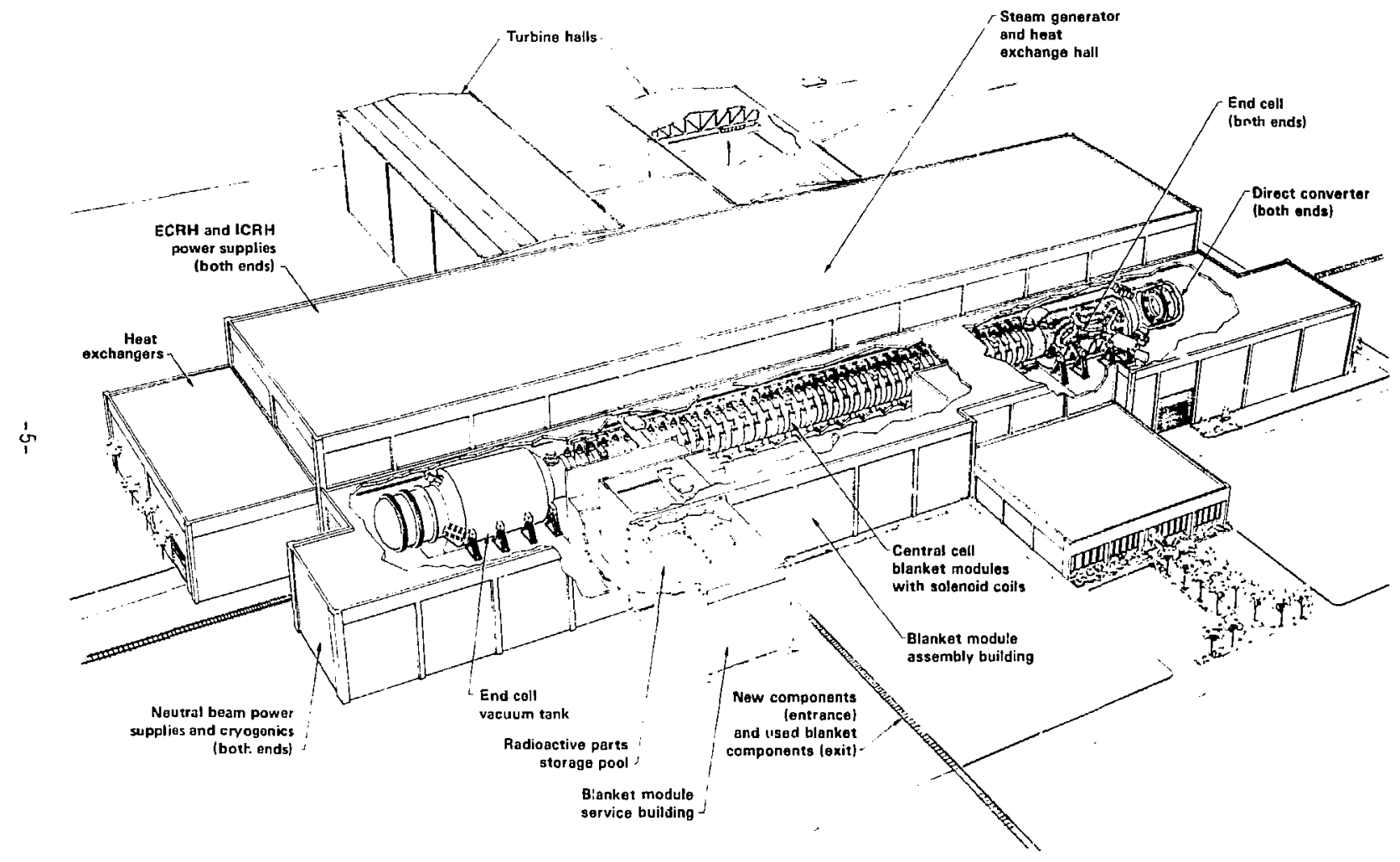

Fig. 1. General view of the MARS tandem mirror reactor plant. 


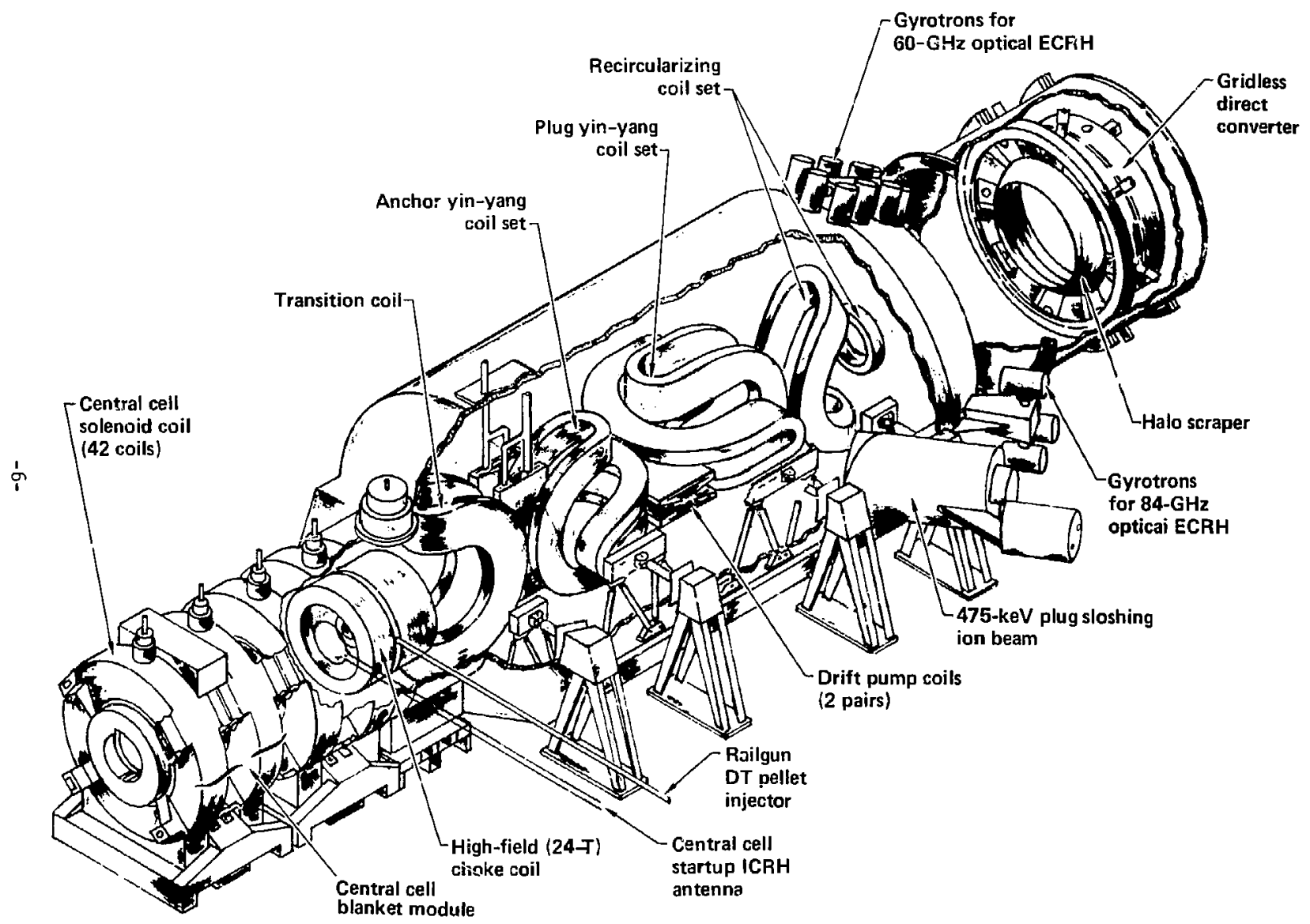

Fig. 2. View of one end of the MARS reactor. 


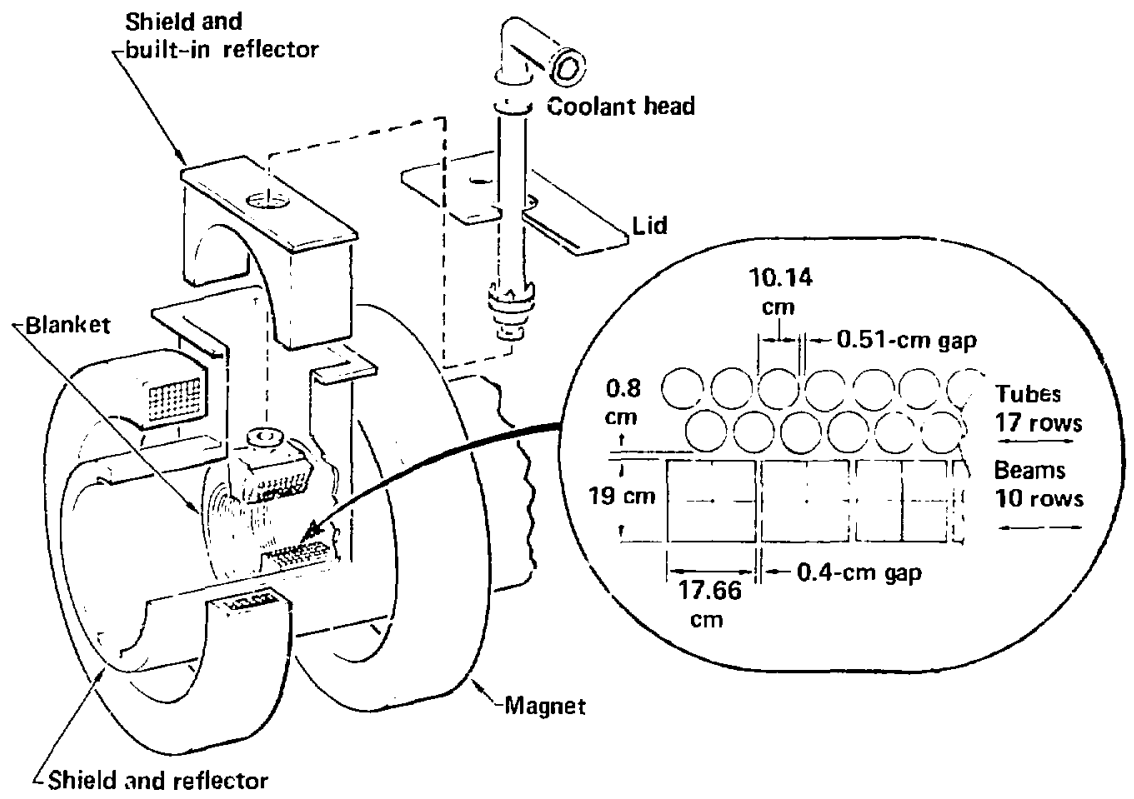

Fig. 3. A section of the MARS central cell (commercial electric reactor). The method for removing one of thie $\mathrm{Li}-\mathrm{Pb}$ blanket modules is shown.

MARS reactor parameters for electricity projuction. With a total capital cost of $\$ 2.9$ billion (constant 1983 dollars), a 15\% fixed charge rate, 6 years of cunstruction, $10 \%$ inflation rate, and $73 \%$ predicted plant -railability, the MARS electric power plant produces busbar electricity at about $7 t$ per kW hour, competitive with new eleciricity costs in many parts of the U.S. today. Table? summarizes MARS reactor costs.

Improved safety arld reduced enviromental hazards will facilitate siting and licensing of MARS fusion reactors compared with today's fission reactors. The HT-9 ferritic steel structure used in the MARS Li-Pb blanket (Fig. 3) will not melt in any loss-of-coolant accident and will last at least 5 years before 


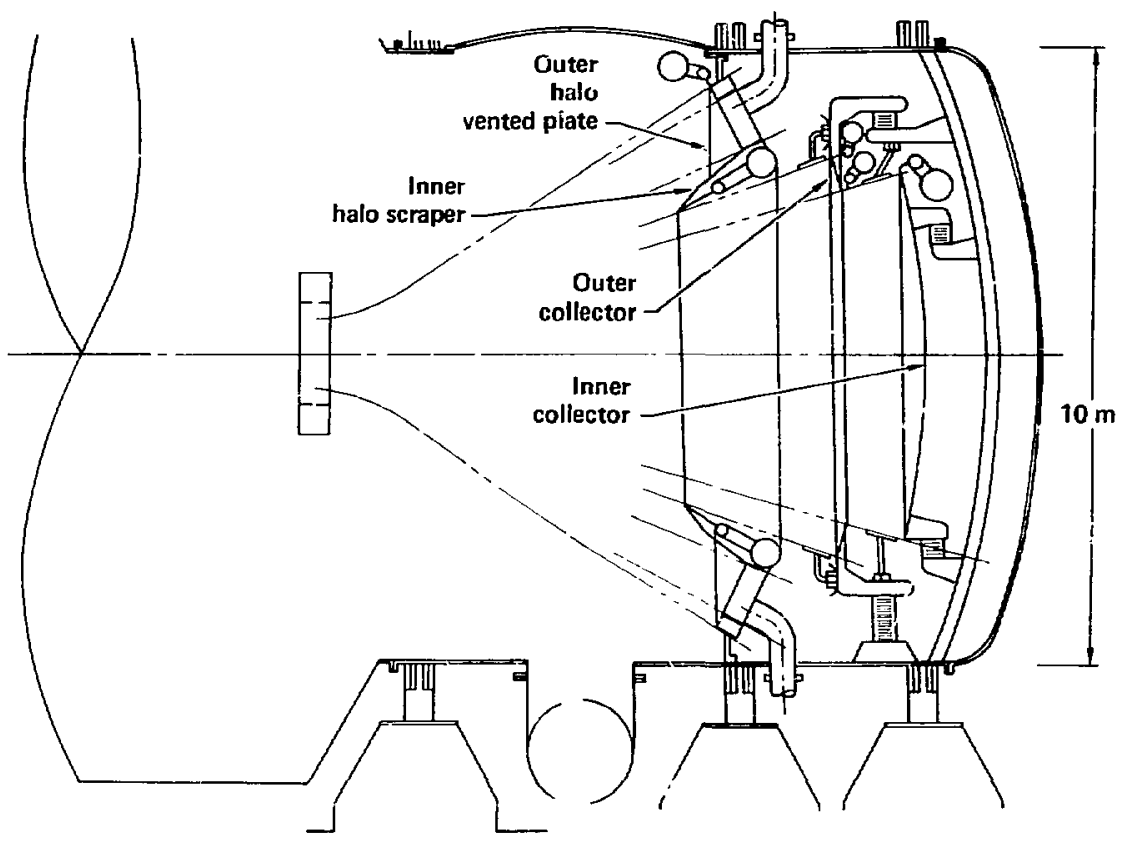

Fig. 4. Cross section of the end-plasma technology system locateo in each end cell. The central, gridless, direct zonverter coriprises an inner and outer collector and is surrounded by the inner halo scraper and the outer halo vented plate.

schedujed replacement. Because nearly all the radioactivity in the steel has less than a 5-year half-li:e, the spent blanket moduler can be simply filled with concrete and safely disposed of using near-surface burial according to NRC regulations for Class $C$ low-level waste. In addition, the liquid $L i-P b$ coolant wil? not burn in air or water and contains extremely low concentrations of tritium--less than $8 \mathrm{~g}$ in the entire coolant inventory.

The MARS commercial fusion synfuels plant, described in Ref. 3, Vol. 2, uses a slightly longer central cell (150 vs $130 \mathrm{~m}$ ) and produces more fusion power (3500 vs $2600 \mathrm{MW}$ ) compared with the electricity-producing design. A helium-gas-cooled, si icon-carbide, pebble-bed blanket (Fig. 5) provides high temperature heat $\left(1000^{\circ} \mathrm{C}\right)$ to a thermochemical water-splitting cycle (Fig. 6), producing hydrogen with an energy equivalent to 26,000 barrels of oil per day. 
Table 1. Major parameters for the MARS comercial electric plant.

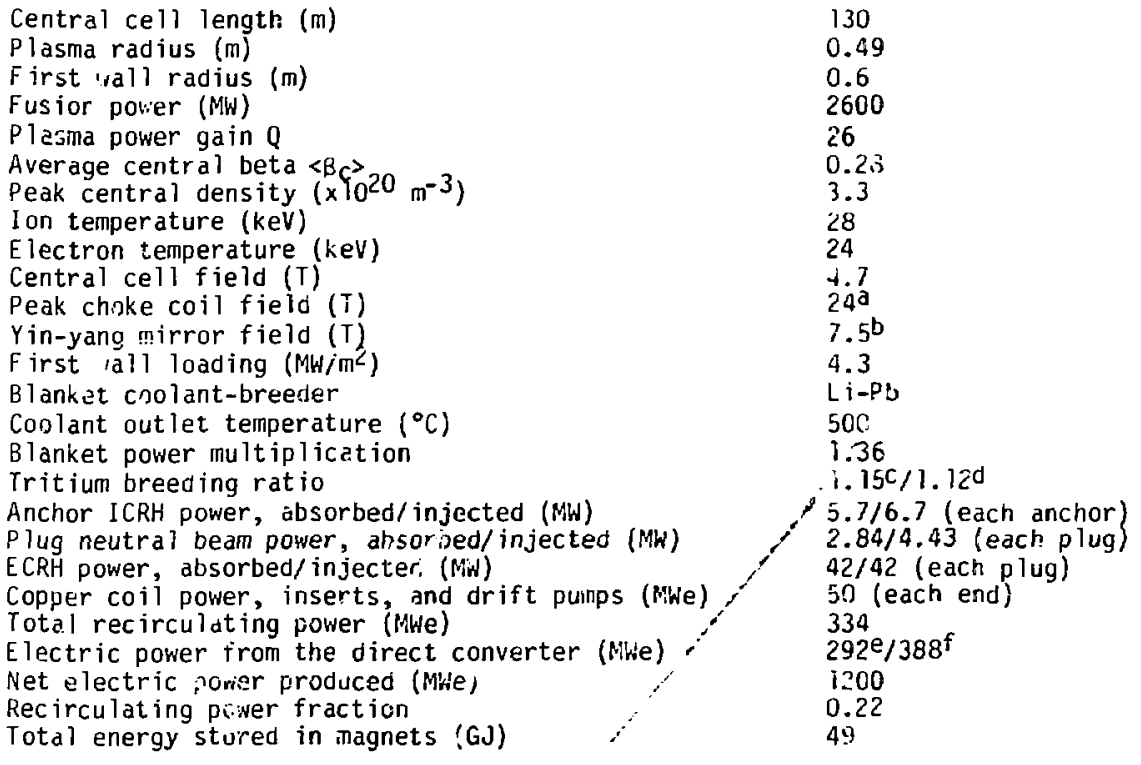

Efficiencies

Direct converter

475-kV sloshing-ion be zms

$0.519 / 0.68^{h}$

ECRH

0.70

AlIchor ICRH

0.70

Thermal cycle

0.55

Overall system (plant)

0.40

0.36

al6 T from suter superconducting coil plus $9 \mathrm{~T}$ from copper insert coil.

$b_{10} T$ on conductor.

$C_{B}$ lanket local tritium hreeding ratio.

doverall reactor tritium oreeding ratio.

eNet direct electric conversion.

fotal electric power from the end loss plasma conversion.

9Net direct electric conversion efficiency

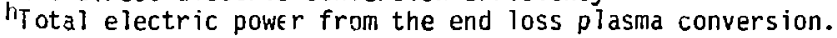


Table 2. Summary of capital costs for the MARS electric plant.

\begin{tabular}{llr}
\hline Account & \multicolumn{1}{c}{ Title } & Cost (M\$)a \\
\hline 20 & Land and land rights & 5.0 \\
21 & Structures and facilitias & 249.8 \\
22 & Reactor system & $1,517.3$ \\
23 & Turbine plant & 275.0 \\
24 & Electrical plant & 160.0 \\
25 & Other & 33.2 \\
26 & Special materials & 124.9 \\
91 & Construction equipment & 240.0 \\
& and services & 189.0 \\
92 & Engineering and management & 118.0 \\
93 & Other & $2,912.2$ \\
& &
\end{tabular}

amilitions of dollars.

This represents a $43 \%$ conversion efficiency of fusian energy to hydrogen energy. The hydrogen is catalytically combined with 1000 tons of coal per day to produce 38,000 barrels per day of liquid methanol fuel for pipeline distrioution. The MARS synfuel plant, with $\$ 3.6$ billion total capital cost (constant 1983 doilars), $10 \%$ interest during construction, 6 years of construction, and $73 \%$ maximum capacity factor, would produce methanol fuel for a cost cf about \$1.7 per gallon. The need for liquid synfueis-producing MaRS reactors is expected to increase when both world oil reserves and low-cost, near-surface coal deposits begin to be depleted some decades afier fusion electric plants are introduced.

The MARS electricity and synfuel reactors use similar end cells at each end of their respective central cells (see Figs. 1 and 2 ). Figure 2 depicts four distinct types of end cell magnets: (1) the transition coil to match the magnetic flux bundle from the choke coil to the subsequent end cell magnets; 


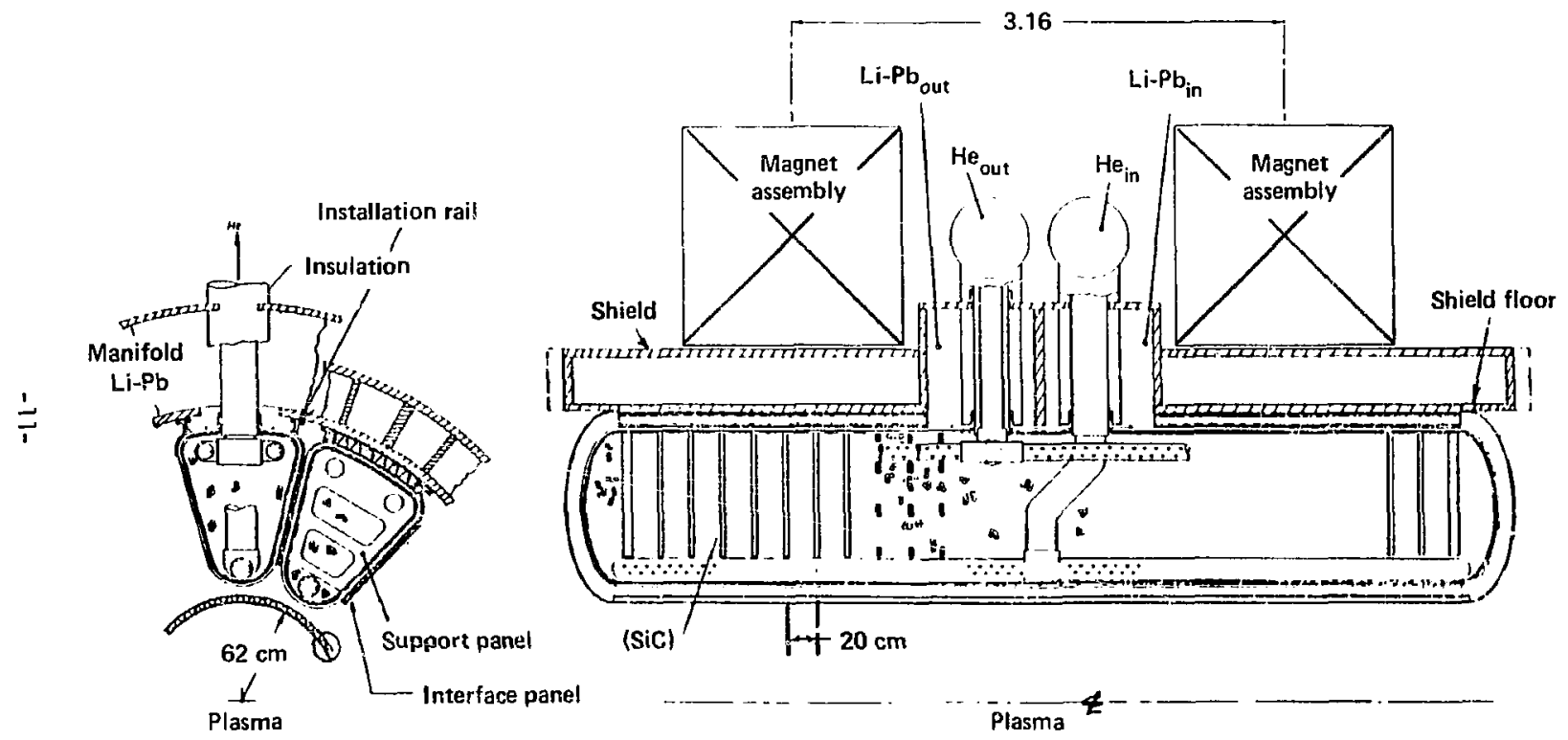

Fig. 5. Design of the high-temperature blanket for synfuels production. 


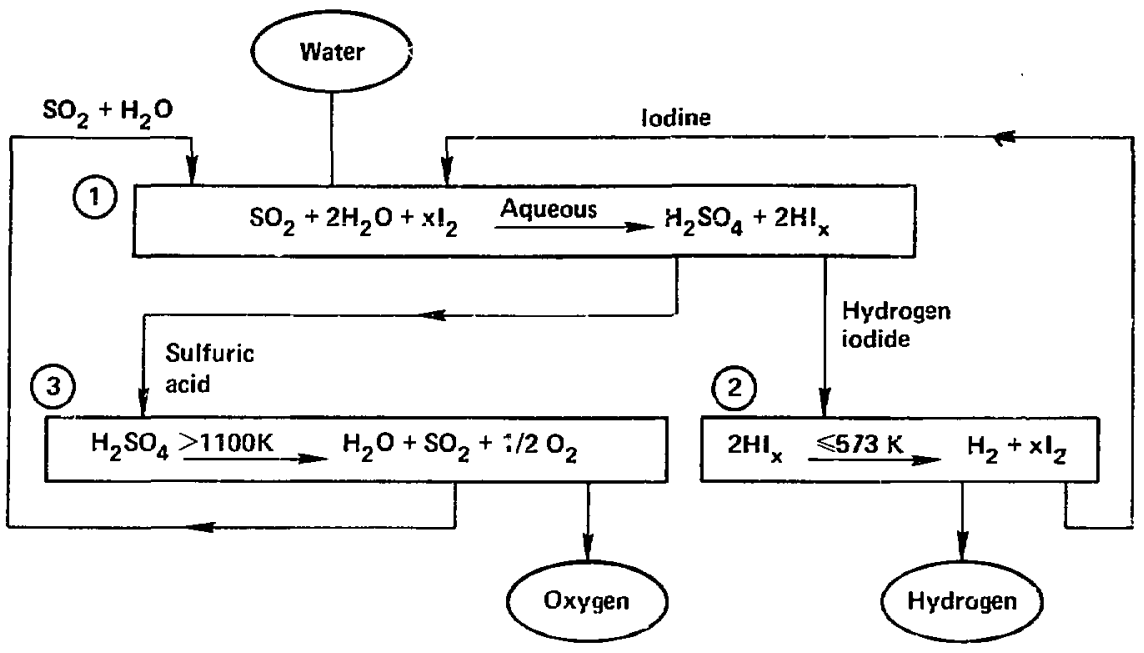

Fig. 6. GA Technology's sulfer-iodine cycle for MARS synfuels roduction.

(2) the anchor minimum-B yin-yang coil set; (3) the piug minimull-B yin-yang coil set; and (4) the recircularizing coil set designed to present a magnetic flux bundle of circular cross section to the direct converter. With in the plug region, continuous injection of neutral beams and microwave heating generate electrostatic potential barriers to confine the steady-state deuterium tritium (DT) plasma in the central cell.

The central cell fusion plasma is fueled with high-velocity $(20 \mathrm{~km} / \mathrm{s})$ pellets of DT ice near one of the ends. The required injection rate is 6.5 pellets/s. Nearly all 3.5-MeV fusion alpha particles are born mirror-trapped by high-field (24-T) mirrors ("choke coils") at each end, permitting most alpha energy to be transferred to the DT fuel ions and electrons. With positive plug potential barriers ( $\phi_{\text {plug }}-\phi_{\text {central cell }}>150 \mathrm{kv}$ ), the central cell ion end loss is reduced enough to allow alpha heating to sustain the residual axial and radial energy losses of the central cell, i.e., the central cell plasma is ignited. Thus, the only auxiliary central cell heating needed is 5 to $10 \mathrm{MW}$ of ion-cyclotron resonant heating (ICRH) for $120-\mathrm{s}$ periods during startup. The power gain factor $Q \equiv$ plasma fusion power/plasma heating power then increases roughly linearly with the central celi length. We chose the 
length of the MARS central cell $(130 \mathrm{~m})$ to produce 1200 Mhe of net power, which yields a $Q$ of 26 .

The "thermal barriers" 8 required to moderate end plug heating power are maintained by inducing radial loss of ions trapped in the thermal barrier with low frequency $(50-\mathrm{kHz}) \mathrm{rf}$ fields, called drift pumping. ${ }^{14}$ Because drift pumping of central cell ions that collisionally trap in the plugs represents a loss to the central cell, central cell ignition burn can be controlled by feedback modulation of the drift-pump rf current. Because of the orift-pumping and high plugging potentials, nearly al? of the unburned DT fuel, thermalized alpha ash, and other impurities escape by radial diffusion to the plasma edge, or "halo," in the end cell. This diverts the plasma exhaust into annular halo dumps in the end tanks (see Figs. 2 and 4). The unplugged plasma halo, together with drift pumping, acts as an impurity diverter and high-speed vacuum pump, minimizing first wall surface heating and sputtering in the central cel?. The plasma electrons are left to escape along the field lines, and are collected by negatively biased end plates inside the halo dumps. The electrons collected at $167-\mathrm{kV}$ negative voltage directly generate enough dc electricity (approximately 300 MWe) to match nearly all plug heating and plant auxiliary power requirements (see Table 1). Radial loss of end-plugged ions eliminates the need for grids, ${ }^{15}$ permitting the compact, high-power electron direct converter to fit within an MFTF-size (10-mdiameter) vacuum tank (Fig. 4).

Many of the MARS plasma confinement and magnet design features are derived from related past and present tandem mirror experiments. The MARS end cell magnets (Fig. 2), in the shape of "C" coils or yin-yangs, are similar to those used in $2 X I I B,{ }^{16}$ TMX-U, ${ }^{1}$ and MFTF-B to obtain high-beta MHD stability. In 1975, the $2 X I I B$ experiment ${ }^{16}$ demonstrated near-unity beta in a neutral-beam-sustained plasma with reacto. - level plasma pressure (10 kev, $10^{14} \mathrm{Cm}^{-3}$ ion temperature and density). The MARS yin-yang magnets are designed and costed in accordance with MFTF-B's successfully tested riobiumtitanium superconducting yin-yang magnet. Only modest extrapolations in size are neeaed to attain the MARS reactor scale; thus, technical risk is minimized. The plasmia mode ${ }^{17}$ used to design the MARS end cell has successfully predicted much of the experimental behavior recently observed in the TMX-U: microstable sloshing ions with loss rates ralculable with Fokker-Planck codes, enhanced 
potential barrier formation with ECRH, reduction of ion end losses by plugging until residual radial ion losses dominate, net electron current collection on end wall plates, and improved vacuum pumping by the plasma halo. Unique MÁRS features such as high-field choke coils and drift pumps are planned for testing in TMX-U in the near future.

Several new, but developable, technologies in the MARS aesign are keys to its performance. The Li-Pb blanket itself ( $\mathrm{Fig} .3$ is very simple and rugged, and blanket modules for remote replacement weigh only 2.7 tons each when drained. Scheduled module replacement every 5 years requires only 11 days of downtime. Critical technologies for this blanket design are double-walledtuje heat exchangers to reduce tritium permeation into the steam cycle to less than $10 \mathrm{Ci} / \mathrm{day}$, and cold traps to control deposition of corrcsion products within the main heat transfer loop. Most of the tritium vulnerable to release as $T_{2}$ is in the tritium purification and separation system ( $2160 \mathrm{~g}$ ) and in the pellet injector system ( $20 \mathrm{~g})$.

The MARS magnet et consists of 42 central cell solenoids spaced $3.16 \mathrm{~m}$ apart, followed by an end cell coil set at each end containing a circilar nighfield choke coil ( $F$ ig. $7 a$ and $b$ ), a series of 6 C-shaped coils, and a final circular rim coil. All coils use a ductile NbTi superconauctor except for the inner layers of the superconducting part of the choke coil, which use $\mathrm{Nb}_{3} \mathrm{Sn}$ (doped with $T i$ ) where the local field is $16 \mathrm{~T}$. As maximum wall loading $\Gamma_{n}$ and $Q$ both increase strongly with the choke coil field $B_{\text {mlax }}$, there is a strong incentive for the hignest practical $B_{\max }$. To increase $B_{\max }$ beyond the Timits of practical superconductors ( $16 \mathrm{~T}$ at $r=1.4 \mathrm{~m}$ ), a water-coolea, high-strength copper alloy coil is inserted inside the choke coil shiald (see Fig. $7 b$ ) to increase $B_{\max }$ to $24 \mathrm{~T}$ at $r=0.3 \mathrm{~m}$. The electricity consumed by the resistive inserts ( 80 MWe for two inserts) is more than compensated for by reductions in plug heating power, particularly in electron-cyclotron resonant heating (ECRH). The lifetime of the small replaceable insert coils is expected to be about four years with the use of inorganic (ceramic) insulation. ihe water-cooled copper coils used for the 50-kHz orift pumping ( $F i g .8$ ) are expected to last for the operating lifetime of the reactor.

riasma heating in MARS is summarized in Table 1 in terms of the power each system delivers to the plasma. The large majority of the total heating power is needed to inaintain the hot electron thermal barrier $(38.5 \mathrm{MW}$ of $60-\mathrm{GHz}$ ECRH power at each erry). Such a large ECRH power requirement necessitates 
(a)
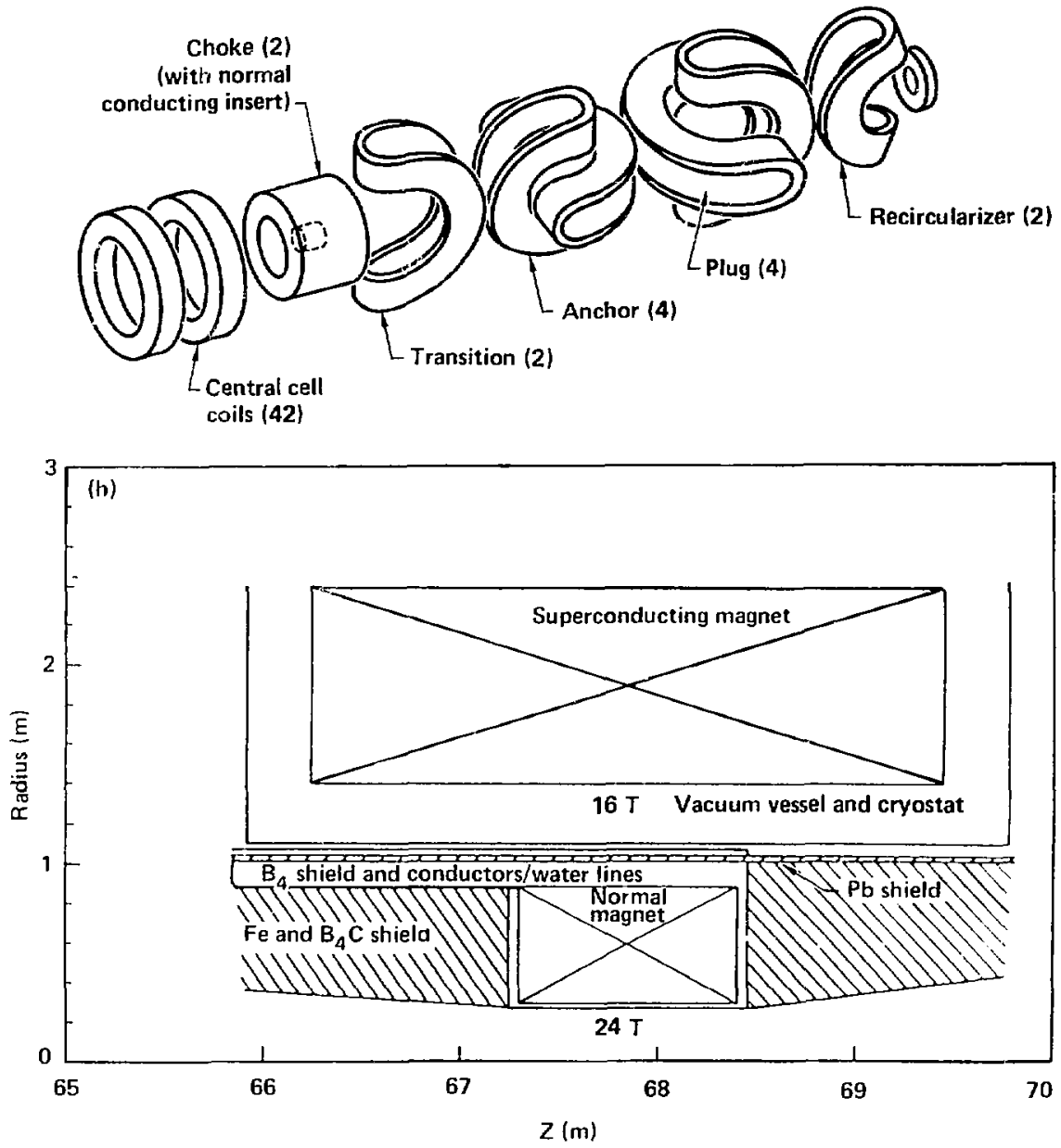

Fig. 7. (a) The MARS magnet system. (b) Cross section of the 24-T chcke coil showing the outer superconducting solenoid and the normal conducting insert solenoid (also see Fig. 22). 


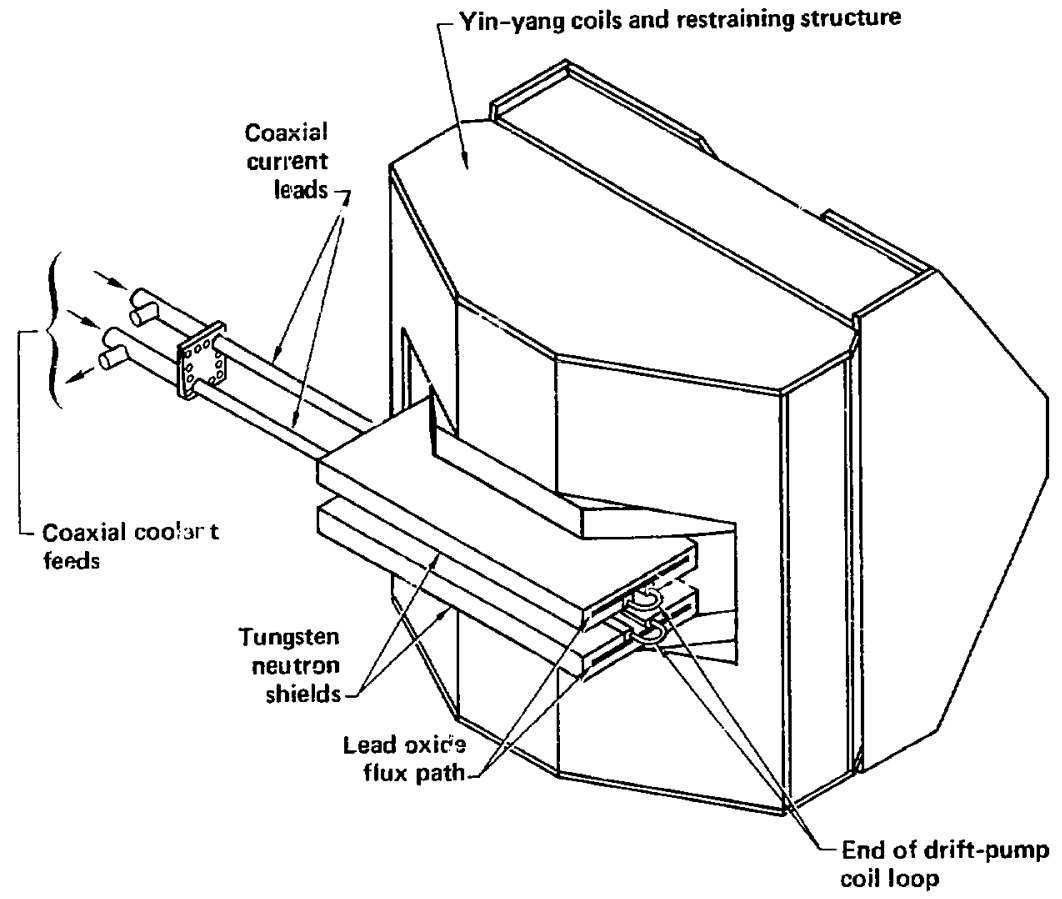

Fig. 8. Location of the drift pump coils within the yin-yang coil structure.

gyrotrons in unit sizes larger than present-day models, i.e., at least 1 to 'MW/tube. Figure 9 is a conceptual design of a 2.5-MW tube with a large transverse cavity. Parabolic mirrors reflect the 30-cm-diameter microwave beams from arrays of 20 gyrotron tubes ( 18 operating +2 spares) into slots in the yin-yang coil shielding. No microwave windows are required; and, to minimize neutron damage and activation, the demountable gyrotrons are placed outside the line-of-sight to the plug plasma.

Two ICRH systems are used in MARS (Fig. 2). The first-- $12 \mathrm{MW}$ delivered, $10 \mathrm{MW}$ absorbed--is used only to did startup in the central cell. The second-6.7 MW delivered, 5.7 MW absorbed at each end--is used to maintain hot ions in 


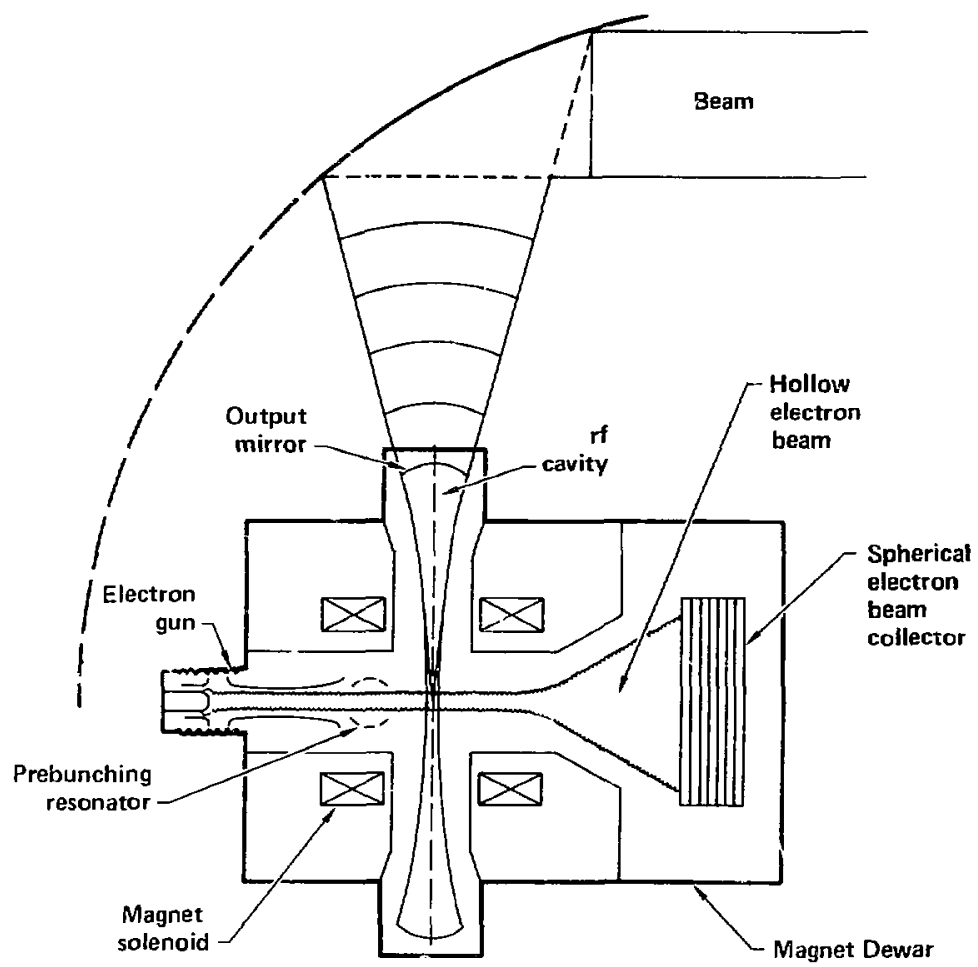

Fig. 9. Schematic cross section of a high-power quasi-optical gyrotron.

each anchor yin-yang for MHD stability. Thus far, experiments in TMX-U have succeeded in producing startup without the aid of ICR:A, but we specify $10 \mathrm{MW}$ (absorbed) of ICRH for the added ability to heat the MARS central cell to ignition (see Sec. 4.5). The ICRH frequencies needed ( 250 to $120 \mathrm{MHz}$ ) are typical of those used in tokamaks.

Although the sloshing-ion beam power trapped in the MARS plugs is relatively small (2.34 MW absorbed at each end), the sloshing ions require a large size negative-ion beamline for steady-state injection at $475 \mathrm{kV}$ (Fig. 10). After acceleration to $475 \mathrm{keV}$, the unneutralized negative ion 

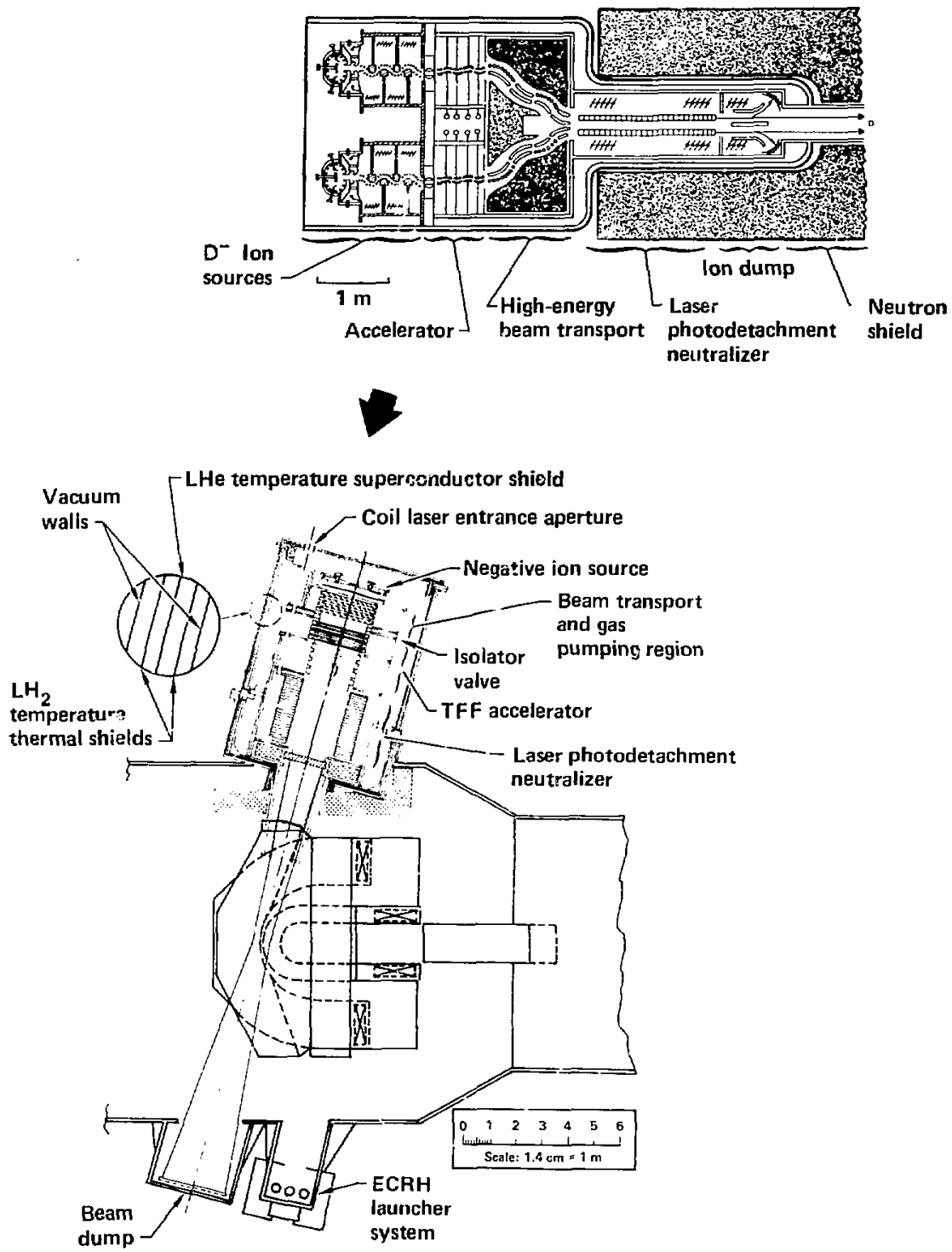

Fig. 10. The 475-keV negative-ion neutral beam system for sloshing-ion production in the end cell. The insert at the top of the figure illustrates the neutron shielding for the ion solirce and accelerator. 
beam, in the shape of a wide ribbon, is bent by electrostatic transversefield-focusing electrodes around neutron shielding to protect the negative ion source and accelerator from streaming neutrons. The advantage of this beamline design is that the high-voltage components are shielded from neutron damage and are easier to access for remote maintenance. A laser photodetachment scheme is used for neutralization.

\section{Reactor System}

\subsection{MARS Reactor Configuration}

The MARS reactor configuration. (Fig. 11) was selected to incorporate the key features of thermal barrier plugs in the TMX-U (Fig. 12) and MFTF-B (Fig. 13) mirror facilities. Thermal barrier plugs generate the electrostatic potential barriers that axially confine the central cell plasma. Thermal barriers are the primary common element in TMX-U, MFTF-B, and MARS. The special groups of not ions and electrons that create the themal barrier in TMX-U have recently been experimentally measured and their respective roles in forming the potential profile shown in Fig. 12 have been experimentally verified. 7 The positive electrostatic plugging potential at point "a" virtually elimirates axial loss of central cell ionj. This plugging potential is generated and controlled by a small amount of ECRH power heating the electrons at point "a" to a temperature well above the central-cell electron temperature. The largest plug plasma heating requirement is ECRH power at point "b," forming mirror-trapped hot eiections and a local dip iil putential near the midplane. The potential dip thermally insulates the outer electrons at "a" from the central cell electrons (hence the term "thermal barrier").

The axial pressure of the plugged central cell plasma is confined in steady-state equilibriur ristly by the 24-T choke coil fields at each end of the central cell. The small fraction (<70\%) of central cell ions in the loss cone pass into the end cell, reflect off the electrostatic potential peak in the plug, and return to pass through the centrai ceil. The plasma models used to predict the thermal barrier plasma parameters in TMX-U and MFTF-B are essentially the same models ${ }^{17}$ used to calculate the MARS plasma parameters. Whereas axial confinement in the MARS central ce 11 is provided by choke coils and electrostatic potential plugs, radial confinement in the central 


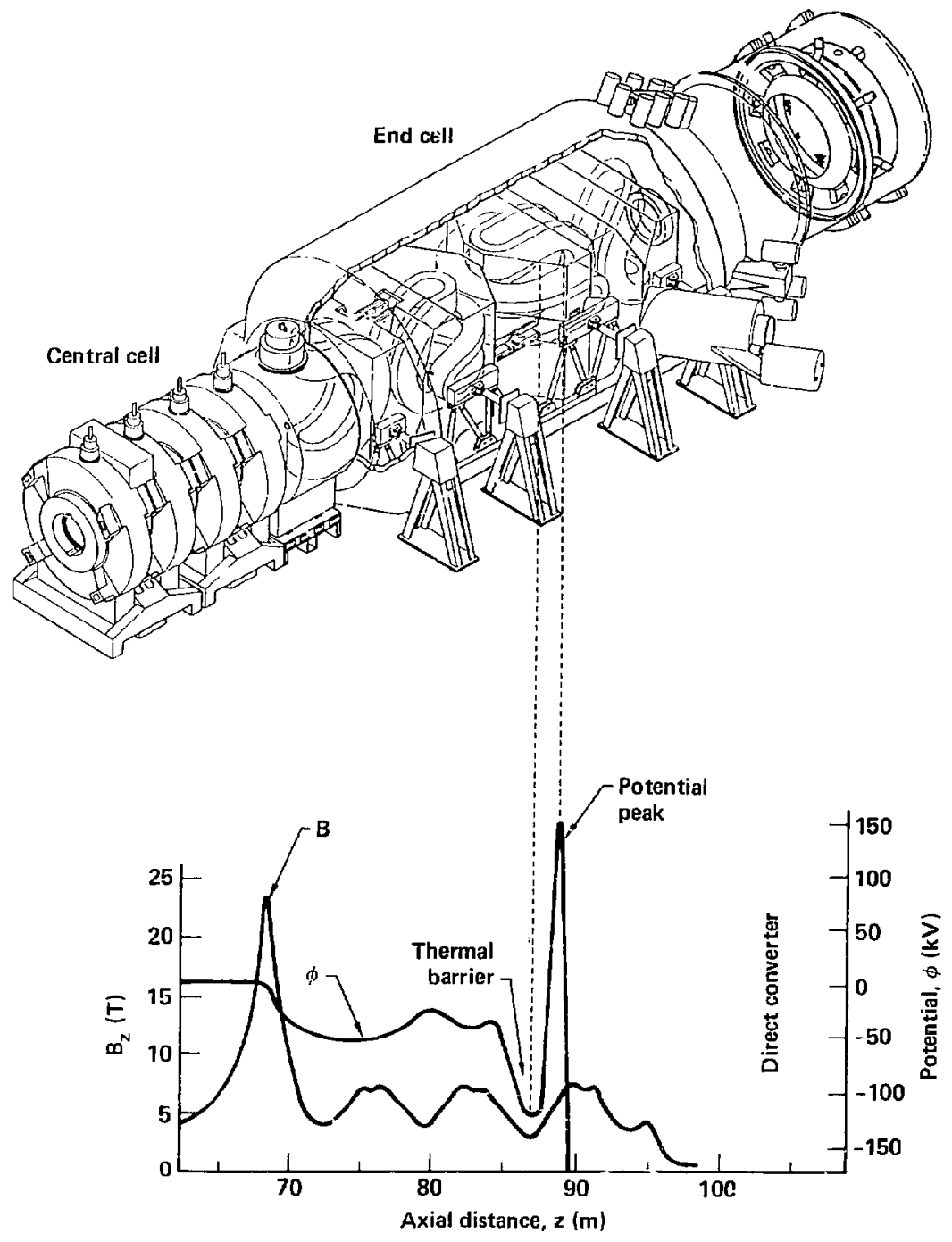

Fig. 11. Magnetic field and electrostacic potential profiles as a function of the axial (z) distance from the center of the central cell. The positions of the thermal barrier and electrostatic potential peak are indicated relative to their location in the plug yin-yang. 


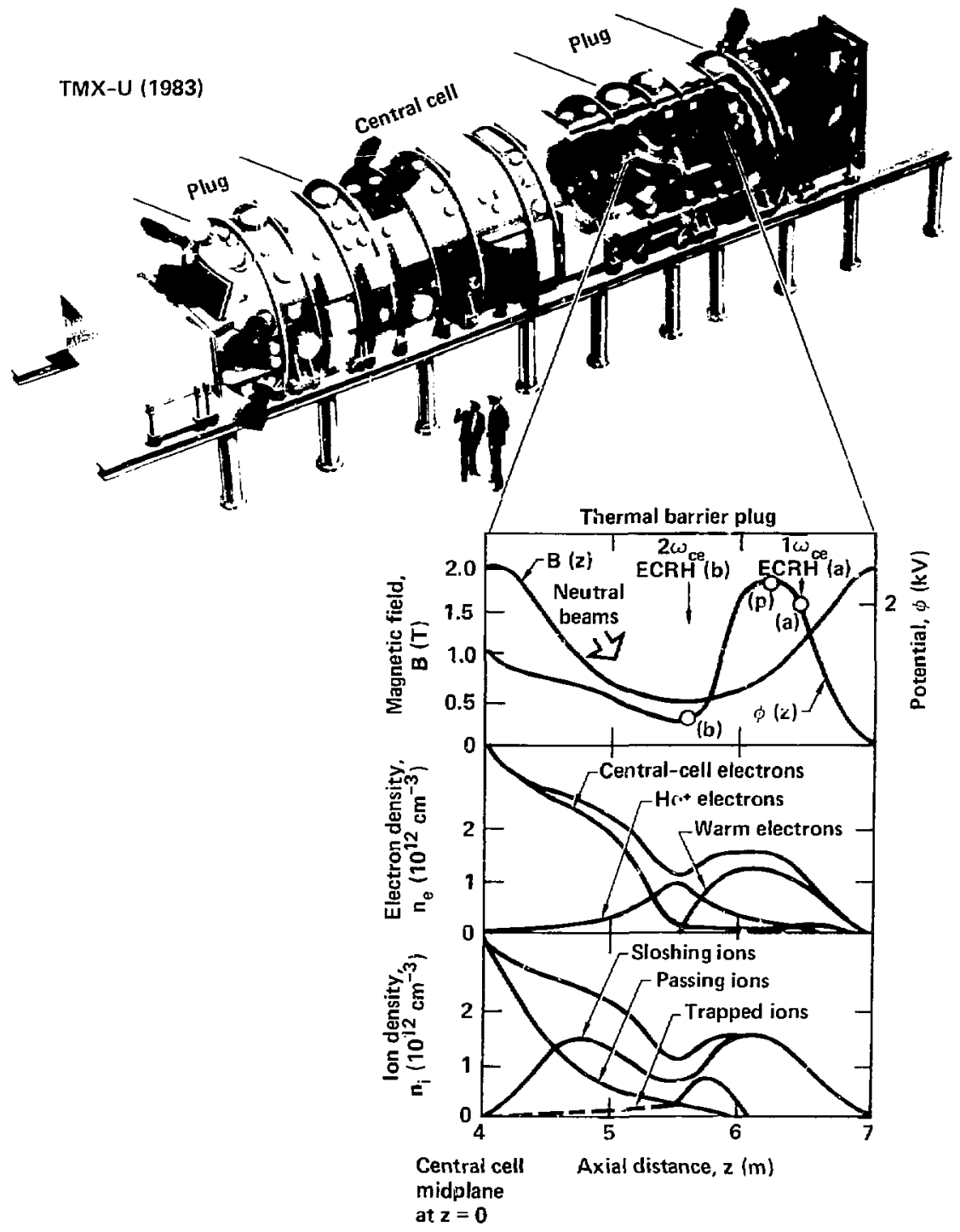

Fig. 12. Plasma parameters as a function of axial distance for the end cell of TMX-U. 


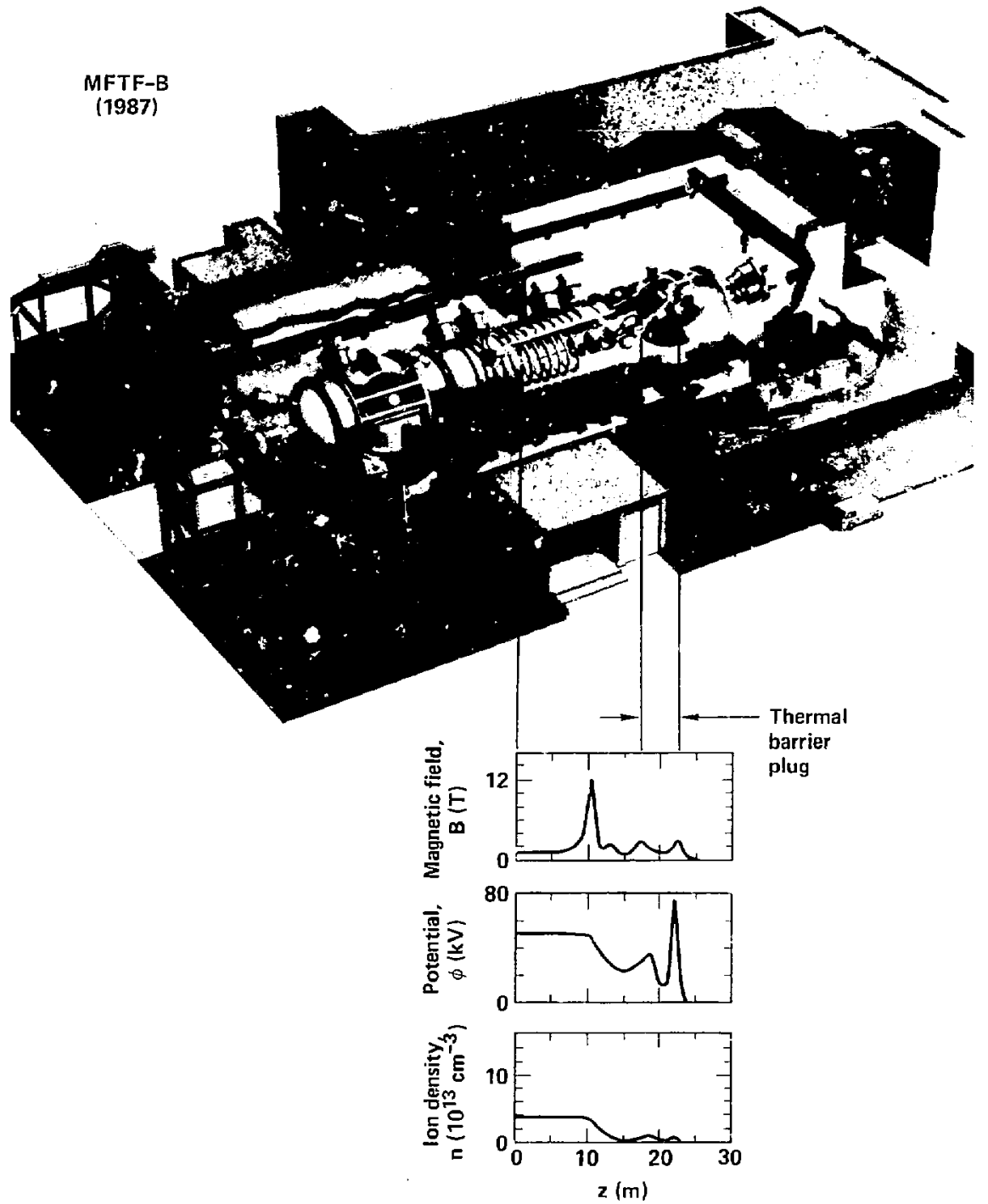

Fig. 13. Plasma parameters as a function of axial distance for the end cell of the METF-B facility currentiy under construction at LLNL. 
$c e^{7} 1$ is provided by a 4.7-T solenoidal magnetic field. The high fusion power density in the MARS central cell plasma $\left(27 \mathrm{MH} / \mathrm{m}^{3}\right)$ requires a significant ratio (beta) of plasma pressure to field pressure $\left(\left\langle B_{c}\right\rangle=0.28\right)$, averaged over the central cell plasma volume. Accordingly, the second key consideration in selecting the MiRS crnfiguration was the design of end plug magnets that could provide MHB stablity for the MARS plasma at the $r$ in beta values required. To allow for both WHD stability and to counter trapped-particle instability ${ }^{18}$ (a predicted fast-growing mode that first came to 1 ight during the early part of the MARS study), the reccmmended location of the thermal birriers was within mirimum-8 magnetic wells, ${ }^{19}$ as in TMX-U. Accordingly, during the study, the MARS (and MFTF-B) end plug designs were changed from having thermal barriers in: axisymmetric mirror celis (called "TARA" configurations; ${ }^{20}$ in favor of placing the thermal barriers in additional minimum-B regions, as is shown in Figs. 14 and 15, respectively.

To enhance stability and allow higher central cell beta values compared with MFTF-B, the MARS design adds ICRH to increase the plasma pressure weighting in the pesitive-curvature region of the transition. Local mirror confinement of the ICRH-heated ions in the positive-curvature transition region (called the "anchor") favors the use of a second yin-yang coi pair for MARS in place of the larger, baseball-shaped cransition coil used in MFTF- 8 . The resulting plasma shape in MARS, however, is nearly identical to the shape in MFTF-P (Figs. 14 and 15), except that an additional C-shaped coil is added to each end of MARS to recircularize the plasma field lines so that they map into a compact, circular, direct converter.

After MHD plasma equilibrium and stability come requirements for controllable plasma transport in the MARS configuration. Geodesic curvalure is the component of field-line curvature that projects along the plasma surface, orthogonal to the local normal curvature component. Geodesic and normal curvatures for both MARS and MFTF-B can be ceen in Figs. 14 and 15 , respectively. Radial diffusion and transport depend mainly on the integral of geodesic field-linz curvature seen by central ceil ions as they reflect off the potential harriers in the plugs. As Figz. 14 and 15 show, MARS and MFTF-B are each designed with equal ano opposite geodesic curvature spikes, so that radial drifts of ions passing througii these regions are canceled out. $A$ certain ariount of residual plasma transport is desired in MARS to cleanse the plasma of thermalized alpha ash and other impurities, and to simultaneously 


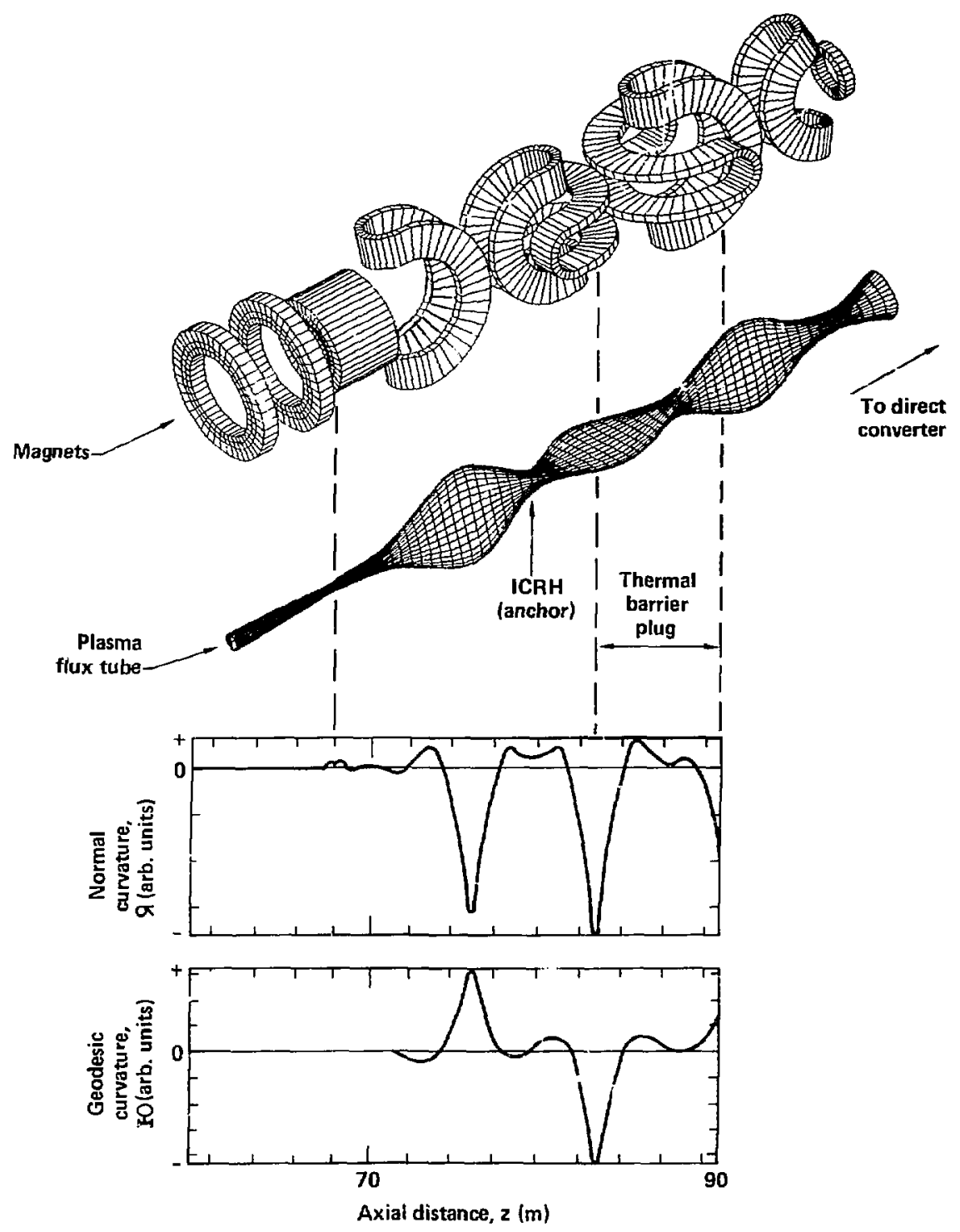

Fig. 14. Axial variation of the normal and geodesic curvature components of the MARS plasma bundle. 


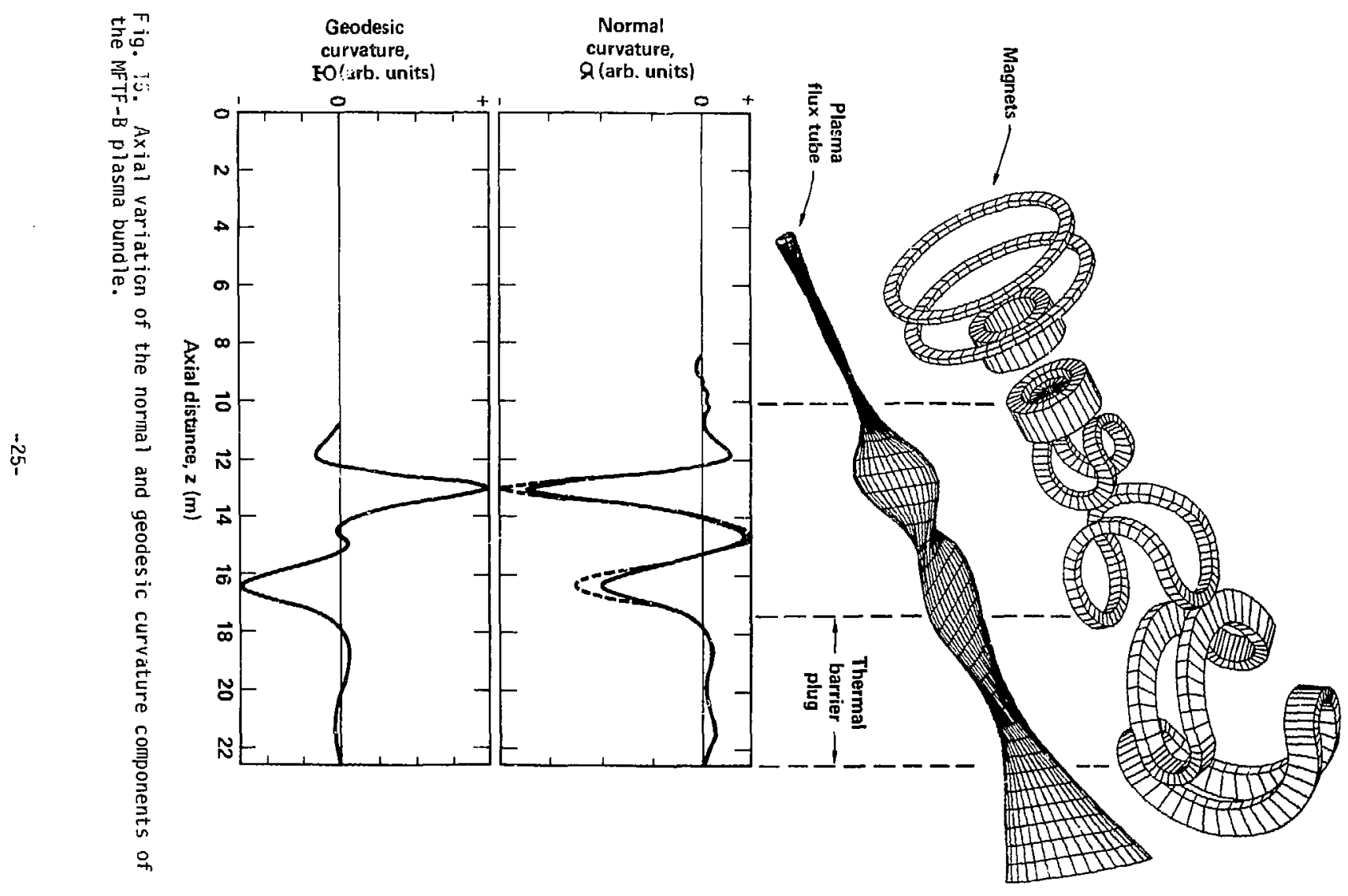


remove DT fuel ions that become trapped in the thermal barrier potential dip as a result of collisions. This desired residual radial transport is achieved by "drift pumping." Here, a small dc magnetis field perturbation, oscillating at the trapped ien bounce frequency, is applied by arift-pump coils above and below the plasma fans in the end cells, thereby producing a slight nonzero cancellation of the geodesic curvature.

Another key element in both the MARS and MFTF-B configurations is a highfield circular choke coil (see Figs. 2 and $7 b$ ) whose function is to allow steady-state operation with much higher plasma density in the central cell than in the transition regions and thermal-barriers. With the removal of the majority of trapped ions in the end cell by drift puming, the allowed ratio of central cell density to end cell density is roughly the ratio of maximum choke-coil field to the end cell fields; that is, the density profile follows the field profile to the right of the coil, as illustrated in Figs. 11, 12 , and 13. To maximize central cell fusion power density while minimizing end cell auxiliary heating power density, we desire the maximum central cell-toplug density ratio, hence the need for the maximum practical choke coil mirror fielo. Thus, a normal resistive insert coil is used in the MARS choke coil to boost the maximum field beyond that possible with superconducturs aione.

The equipmerit for plasma fueling, heating, and exhaust in MARS is illustrated in Fig. 2, which shows one end of the reactor. At the end of the central cell by the high-field choke coil, a high-velocity $(20 \mathrm{~km} / \mathrm{s})$ oT pellet injector for fueling the central cell can be seen. The pellecs are injected near one of the choke coil mirrors because the plasma radius is smaller ir that region (allowing easier penetration) and the number density of $f$ ast alphas is small (for reouced pellet ablation). Also, near the choke coils at one end of the central zell, ICRH antennas deliver a total of $12 \mathrm{MW}$ for $120 \mathrm{~s}$ to heat the central cell ions to ignition temperature during startup. Once steadystate conditions are attained, the plasma heating required to maintain equilibrium is that required to maintain the thermal-barrier for potential plugging--38.5 $\mathrm{MW}^{\star} \mathrm{ECRH}$ at each end at $60 \mathrm{GHz}, 3.3 \mathrm{MW}^{\star} \mathrm{ECRH}$ at each end at $71 \mathrm{GHz}$, plus $4.43 \mathrm{MW}^{\star}$ sloshing-ion neutral beäms at each end at $475 \mathrm{kV}-$ and to maintain the anchor--6.7 $\mathrm{MW}^{\star}$ ICRH at each ena at $55 \mathrm{MHz}$. Impurity removal and

*Injected powe:s (i.e., delivered power from heating system). 
plasma exhaust are accomplished by two sets of drift-purnp coils, which cause nearly all ions to diffuse radially to the plasma edge (halo), where they are diverted along the outer field lines into an annular dump, called a halo scraper. The halo scraper is connected to mechanical vacuunı pumps. The plasma electrons escape along the field lines and are received at $-167 \mathrm{kV}$ negative potential by a gridless direct converter plate.

The remote maintenarce design philosophy in MARS exploits the linear MARS geometry to minimize reactor downt ime required for scheduled and unscheduied remote maintenance of critical reactor components. The maximum staile plasma beta is high because the magnetic axis is straight, reducing the average field line curvature. High beta allows high plasma-fusion power density and small radius plasmas, which in turn reduce the size and weight of the blanket sections (2.7 tons each when drained) that need periodic replacement (Fig. 16). The MARS plasma equilibrium requires no driven plasma current, permitting steady-state operation with blankets and magnets subjected to usually only one thermal and mechanical stress cycle per year (during the annual maintenance shutdown period).

The modular MARS central cell configuration (Fig. 17) capitalizes on the small blanket module size by providing for their scheduled replacement through periodically spaced service ports, leaving in place the reflector, shield, and magnets, which are designed to last the life of the plant. To minimize reactor downtime for minor maintenance operations, enough shielding is provided to permit hands-on maintenance to be performed outside the shield within two days after shutdown. In the unlikely event of failure of any reflector, shield, or magnet, the central cell is divided into $6.4-\mathrm{m}$ segments, each with two central cell coils. Each segment can be removed as a whole unit by transhaulers mounted on floor rails and can be replaced by a spare unit.

In a similar fashion, the remote maintenance design philosophy for the MARS end cell is to provide for replacement of all critical end cell components, such as choke coil inserts, orift-pump and ICRH antennas, gyrotrons and neutral beam sources, and the halo scraper portion of the direct converter. These items are designed to be replaceable without moveing any of the magnets. However, provision is still made for removing the end cell magnets on a transhauler/rail system, similar to the system used in the central 


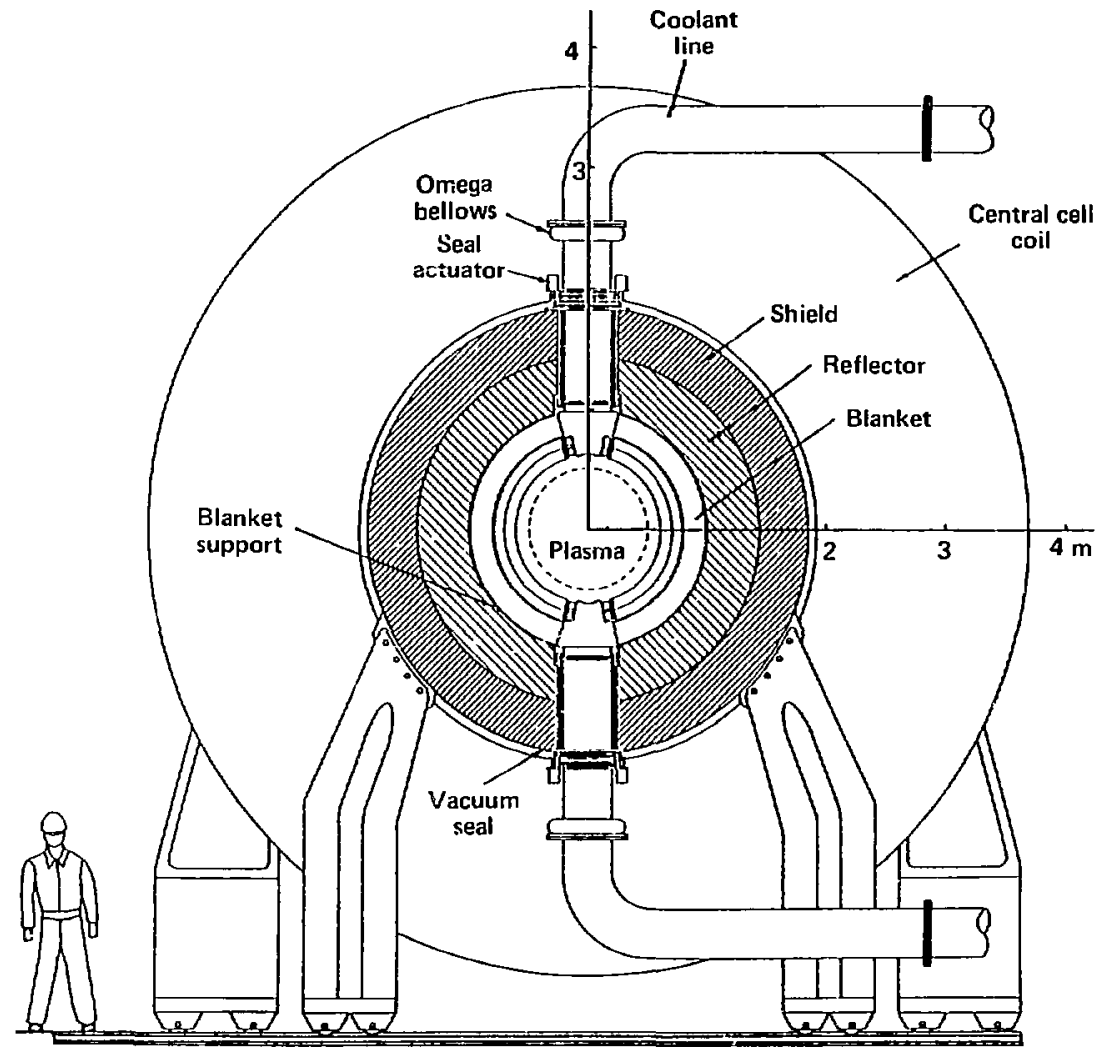

Fig. 16. Cross section of the MARS central cell showing the Li-Pb blanket.

cell, to minimize reactor downtime in the unlikely event of failure of any end cell magnet or shieid. As illustrated in Fig. 18, the linear MARS gemetry avoids interlinking any of the magnets by windings or massive structures, so that individual magnets can be replaced if necessary. 


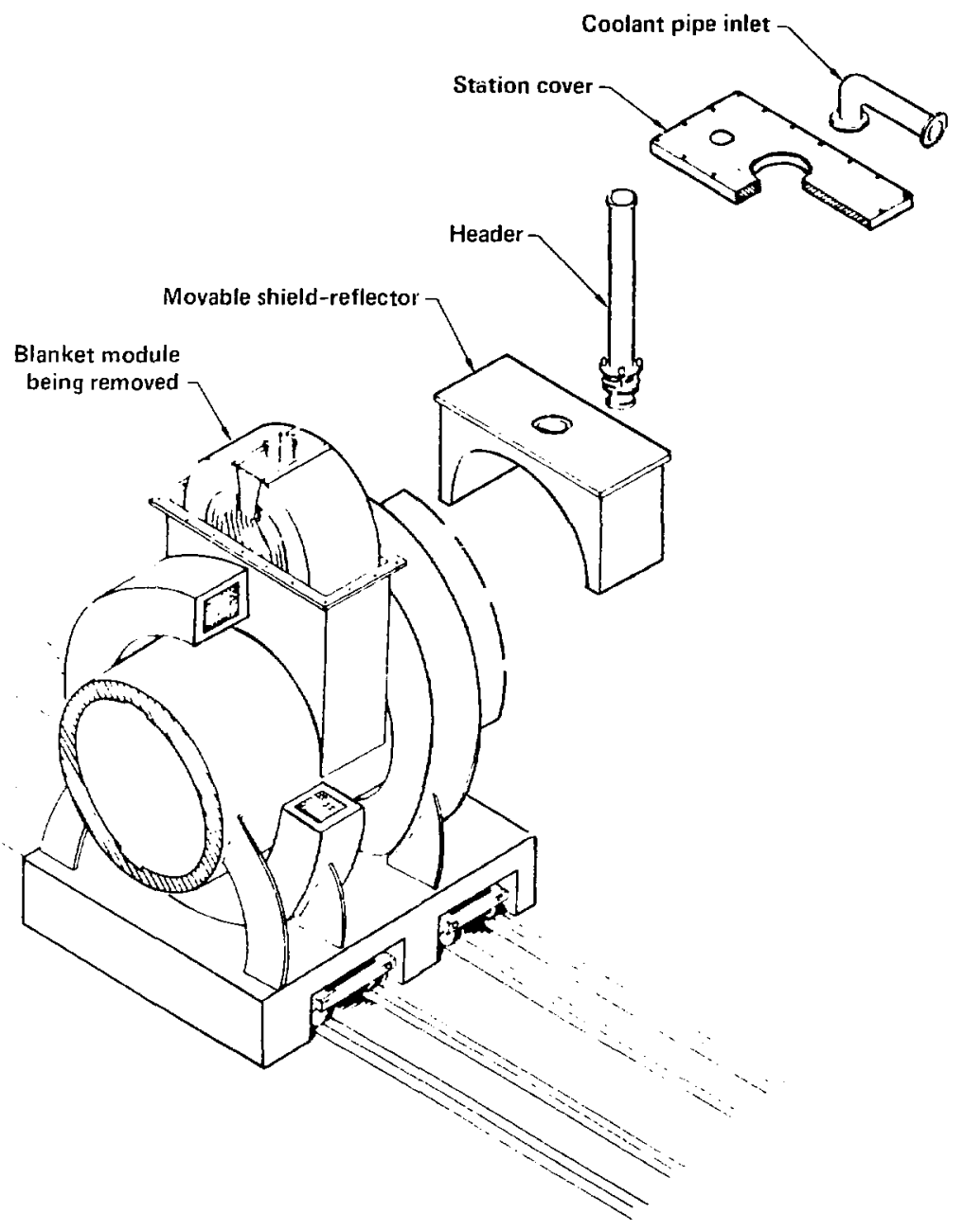

Fig. 17. Disassembly sequence of a service station during routine maintenance of the central cell. 


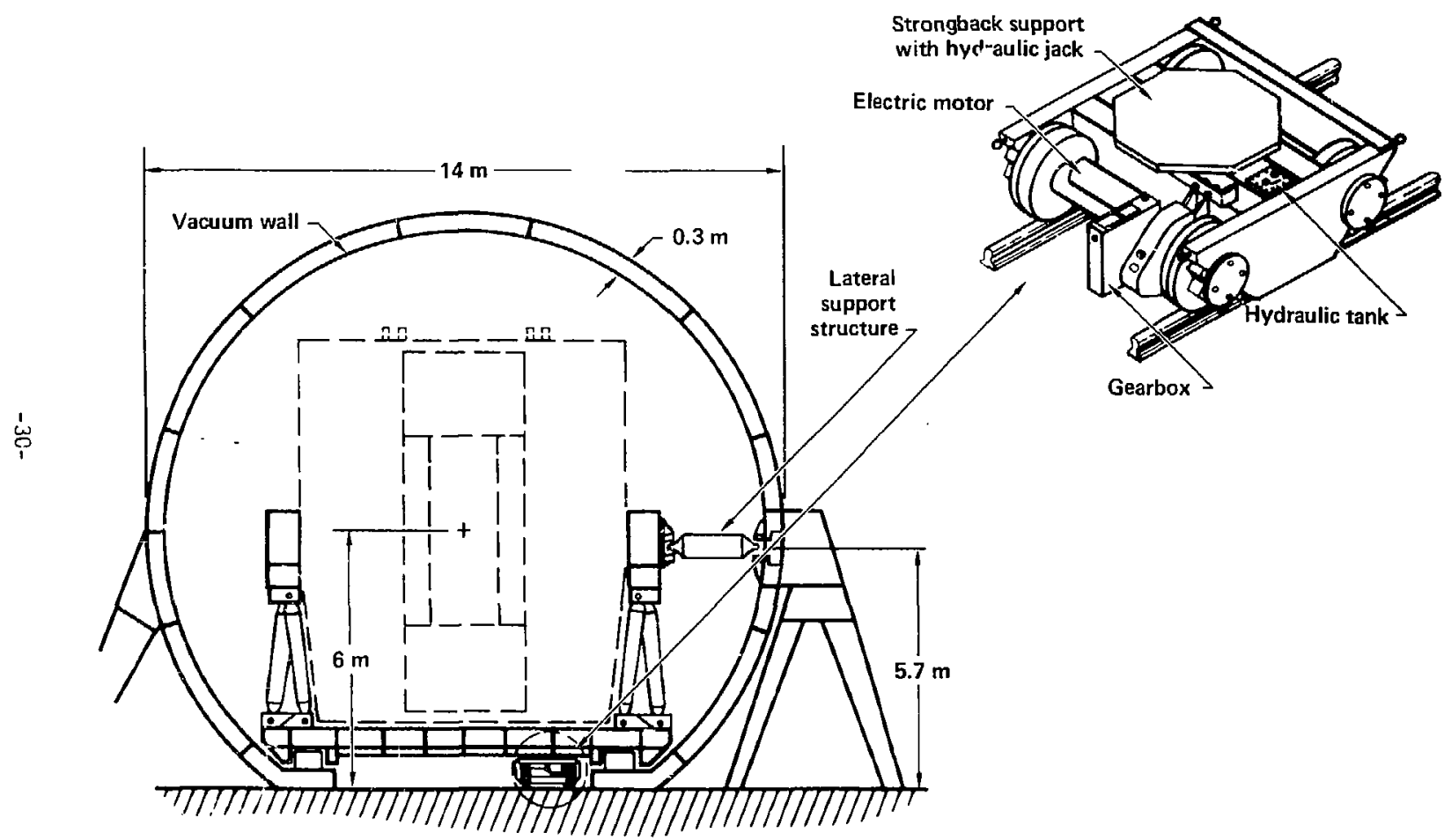

Fig. 18. Details of the magnet support and transport structure in the eno ce?l. 


\subsection{Plasma Engineering Design}

\subsubsection{Introduction}

The primary plasma engineering task for MARS was the calculation of a self-consistent set of plasma and magnetic field parameters that satisfies performance goals, physics constraints, and magnet engineering limits. The study targeted three basic performance goals (not requirements):

- The fusion power should be high enough to produce a net electrical power output comparable to Starfire. 13 At the beginning of the MARS study, the fusion power target was set at $3500 \mathrm{NW}$ (the same as Starfire). Later calculations of the net electric power indicated that the fusion power could be decreased to $2600 \mathrm{MW}$ to achieve the equivalent net electric power as Starfire (1200 MWe).

- The plasma power gain factor Q (central-cell fusion power)/(plug. plasma heating power) should exceed at least 25 to achieve reasonable recirculating electric power fractions.

- The central-cell neutron wall loading should be ir the vicinity of 4 to $5 \mathrm{MW}^{\prime \mathrm{m}^{2}}$ for blanket power densities.

In pursuit of these goals, we maintained a nominal central cell plasma radius of about $0.5 \mathrm{~m}$, and sought a piug design allowing a stable average beta $\langle\beta\rangle$ $=0.28$ at a constant central cell field $B_{C}=4.7 \mathrm{~T}$, which would produce the desired wall loading. Maintaining constant central cell radius, beta, and fielo also guaranteed a constant magnetic plasma flux connecting the central cell and plugs, and thus a constant-size aperture requirement inside the choke coil and end cell coil bores. Holding these central cell parameters nearly constant during the study permitted detailed designs of the central cell blankets, shields, and magnets to proceed while the end plug design evolved in several iterations. The main plasma engineering challenge was thus to develop a plug design that could satisfy the physics and engineering constraints and meet the prescribed performance goals for the central cell. 


\subsubsection{End Cell Design and Power Balance}

The final MARS end cell design had to simultaneously satisfy a set of plasma engineering requirements (Table 3), including piasma stability and confinement requirements as well as imporiant end cell magnet requirements affecting the plasma parameters. The most important plasma engineering requirements impacting the end ell magnet design were MHD equilibriun and stability (items 1,2 , and 4 in Table 3 ), whose simultaneous resolution required a double-ellipse plasma shape between the central cell and plug cell (as shown in Fig. 14), together with ICRH in the anchor yin-yang region to increase the $A H D$ ballooning beta limit to the required value of $\angle B_{C}>=0.28$ at $B_{C}=4.7 \mathrm{~T}$ in the central cell.

The final MARS plug design solution involved repetitive, closely coupled application of three basic plasma engineering design codes: EFFI, 21 TEBASCO, ${ }^{22}$ and TMRBAR. ${ }^{17}$ Trial values of the coil cross sections and

Table 3. MARS plasma engineering requirements.

1. MHD ballooning stability at $\left\langle\beta_{C}\right\rangle=0.28$.

2. Trapped-particle mode stability.

3. Null central-cell radial electric fields.

4. Null plasma-equilibrium currents in the central cell.

5. Circular flux tubes in the central-cell, choke coil, and direct converter.

6. Ignition via central-cell alpha-power balance.

7. Thermal alpha ash and impurity removal.

8. Mirror-mode stability in the anchor.

9. Sloshing-ion conf inement, adiabaticity, and microstability.

10. Ion-ion two-stream stability in the end cells.

11. Penetration and efficient absorption of ECRH.

12. Adequate ralo sndl, $T_{e}$ to ionize gas.

13. First-wall, end-cell magnet clearance for a one-alpha-orbit-thick halo.

14. Yin yang access for ECRH, sloshing beams, drift pumping, and shielding.

15. Maximum yin-yang conductor fields $\leq 10 \mathrm{~T}$. 
current densities were input to the magnetic field code EFFI and these were iterated to achieve both the desired plasma fields and maximum coil conductor fields ( $\leq 10 \mathrm{~T}$ on the end cell $\mathrm{C}$-shaped coils for NbTi at $1.8 \mathrm{~K}$ ). The final MARS end cell magnet dimensions and peak conductor field strengths are listed in Table 4. These magnets are illustrated in Figs. 7 and 14 . Next, the magnetic fields calculated by EFFI were input to the tandem equilibrium and stability code TEBASCO. TEBASCO then calculated central cell beta limits (Table 5) for both interchange modes and $m=1$ ballooning modes (ballooning limits stability more than interchange modes). The $m=1$ ballooning-mode beta limit depends on $S_{B}$, the gap between first wall and plasma divided by the plasma radius. For the final MARS design (Table 5), the appropriate value of $S_{B}$ is 0.22 , giving a predicted $\left\langle_{B}{ }_{c}\right.$ limit of 0.31 , which is slightly larger than the specified central cell requirement of 0.28 . Following this, beta limits calculated by TEBASCO were input to the power balance code TMRBAR, which calculates the resulting plasma parameters in the central cell (Table 6) and end cells (Table 7); required end cell ECRH, ICRH, and neutral-beaminjected powers (Table 8); and direct converter parameters (Table 9).

one sequence of EFFI, TEBASCO, and TMRBAR computations was followed by a series of checks on system parameters, including maximum conductor fields, plasma-magnet clearances, microstability, sloshing-ion confinement, heating powers, heating system access, etc. In the event that a consistericy check was not satisfied, the sequence was repeated with an appropriate change of an input parameter to TMRBAR or EFFI.

\subsubsection{Drift Pumping}

Drift pumping produces the most important plasma loss process in MARS, and therefore is the primary factor in determining power balance in the central cell (ignition), as well as in determining steady-state operation by removing trapped ions--including thermalized alpha particles and other impurities--from the transitions and thermal barriers in the end cells. Figure 19 illustrates the basic ion and electron particle flows caused by the drift-pumping process. To the left of the choke-coil mirror peak in Fig. 19 is the central cell, where the majority of ions, including 3.5-MeV alpha particles, bounce back and forth, mirror-trapped between the choke coil mirrors. The fraction of central cell ions with sufficient pitch angle to be 
Table 4. MARS magnet dimensions and fields.

\begin{tabular}{|c|c|c|c|c|c|}
\hline $\mathrm{Coil}$ & $\begin{array}{c}\text { Mean } \\
\text { diameter } \\
\text { (m) }\end{array}$ & $\begin{array}{l}\text { Central } \\
\text { field } \\
\text { (T) }\end{array}$ & $\frac{\begin{array}{c}\text { Peak } f \\
\text { inner } r a\end{array}}{\text { Major }}$ & $\begin{array}{l}\text { field } \\
\text { adius }(T) \\
\text { Minor }\end{array}$ & $\begin{array}{l}\text { Super- } \\
\text { conductor }\end{array}$ \\
\hline $\begin{array}{l}\text { Central } \\
\text { cell }\end{array}$ & 5.42 & 4.7 & 7.2 & & NbT $i$ \\
\hline $\begin{array}{l}\text { Choke- } \\
\text { background }\end{array}$ & 3.8 & 24 & 16.7 & & $\begin{array}{l}\mathrm{Nb}_{3} \mathrm{Sn}: \mathrm{Ti} \\
\mathrm{Nb}_{3} \mathrm{Sn}, \mathrm{NBT} i\end{array}$ \\
\hline Choke-insert & 1.2 & 24 & 24 & & $\begin{array}{l}\text { Copper } \\
\text { (normal- } \\
\text { conducting) }\end{array}$ \\
\hline Transition & $2.2,6.5$ & $4.1 / 7$ & 9.5 & 2.5 & NbT $i$ \\
\hline Anchor & $2.2,5.0$ & $7.3 / 3.9 / 7.3$ & $\begin{array}{l}9.9 \\
9.7\end{array}$ & $\begin{array}{l}10.5 \\
10.7\end{array}$ & $\begin{array}{l}\text { NbT i } \\
\text { NbT i }\end{array}$ \\
\hline Plug & $2.2,6.5$ & $7.2 / 3.0 / 7.5$ & $\begin{array}{l}9.2 \\
9.1\end{array}$ & $\begin{array}{l}9.8 \\
9.8\end{array}$ & $\begin{array}{l}\text { NbT i } \\
\text { NbT i }\end{array}$ \\
\hline $\begin{array}{l}\text { Recircularizer } \\
\text { C coil } \\
\text { Solenoid }\end{array}$ & $\begin{array}{c}2.2,5.0 \\
2.2\end{array}$ & $\begin{array}{l}7.5 \\
--\end{array}$ & $\begin{array}{l}9.8 \\
6.5\end{array}$ & 9.5 & $\begin{array}{l}\text { NbT i } \\
\text { NbT i }\end{array}$ \\
\hline
\end{tabular}

Table 5. MARS MHD stability parameters.

150-m-long central cel1

$6 \%$ axial field ripple on $3.16-\mathrm{m}$ pitch

$\langle\beta\rangle=0.5-i n$. anchor and plug

$\beta$ limits for flute interchange; $m=1$ ballooning:

$\frac{S_{B}^{a}}{0}$

0.14

0.65

1.0

$$
\begin{aligned}
& \frac{\beta_{c}>}{0} \mid \text { imit } \\
& 0.335 \\
& 0.316 \\
& 0.280 \\
& 0.265
\end{aligned}
$$

- $\quad$ MARS $S_{B}$ in central cell=0.22

- Predicted $\left\langle\beta_{C}\right\rangle 1$ imit $=0.31$; specified $\left\langle\beta_{C}\right\rangle=0.28$

a Note that $S_{B}=\left(r_{w}-r_{p}\right) / r_{p}$, where $r_{w}$ and $r_{p}$ are the first wal? and plasma radius, respectively. 
Table 6. MARS central cell parameters.

Fusion power (MW)

Peak DT density $\left(x 10^{14} \mathrm{~cm}^{-3}\right)$

Alpha density $\left(\times 10^{13} \mathrm{~cm}^{-3}\right)$

Ion conf inement $m_{j}\left(\times 10^{14} \mathrm{~s} / \mathrm{cm}^{3}\right)$

Electron conf inement $\mathrm{me}_{\mathrm{e}}\left(\times 10^{14} \mathrm{~s} / \mathrm{cm}^{3}\right)$

Central cell magnet ic fieig $(T)$

Neutron wall loading ( $\left.\mathrm{MW} / \mathrm{m}^{2}\right)$

$\left\langle\beta_{C}>\right.$

Plasma radius $(\mathrm{cm})$

Plasma density profile

4.3

$F$ irst wall radius $(\mathrm{cm})$

I on temperature ( $\mathrm{keV}$ )

E lectron temperature (keV)

Cold fueling current $(k A)$

0.28

49

Quartic

60

28

24

$2 . i$

Table 7. MARS end cell parameters.

\section{Choke coil}

Peak field (T)

Transition/anchor

Length (m)

Passing-ion density at field minimum $\left(\times 10^{13} \mathrm{~cm}^{-3}\right)$

13.3

DT farticle trapping current at each end $(A)$

1.7

Hot-ion density in anchor $\left(x 10^{13} \mathrm{~cm}^{-3}\right)$

800

4.2

Hot-ion energy in anchor (keV)

690

$<\beta$ anchor

0.5

Plug

Length (in)

Passing-ion density at barrier $\left(\times 10^{12} \mathrm{~cm}^{-3}\right)$

5.3

Trapped-ion density at barrier $\left(\times 10^{12}\right)$

sloshing-ion density at barrier $\left.\left(\times 10^{12} \mathrm{~cm}^{-3}\right)\right)$

4.7

8.2

Warm-electron temperature at potential peak (keV)

9.4

Hot-electron energy at barrier (keV)

124

840

$<\beta$ plug

0.5 
Table 8. MARS plasma heating requirements.

Absorbed power,

Delivered power, each end (ilW) each end $(M W)^{b}$

Anchor ICRH

Sloshing-ion neutral beam

ECRH at poing " $b$ " (thermal barrier)

5.7

2.94

38.5

3.3

50.34
6.7

4.43

38.5

3.3

Totals

Plasma puwer gain $Q=\frac{\text { plasma fusion power }}{\text { plasma heating absorbed power }}=\frac{2600}{2 \times 50.34}=26$

Startup ICRH power (total) for central cell, absorbed ${ }^{\mathrm{a}} /$ delivered $^{\mathrm{b}}$ is $10 / 12 \mathrm{MW}$

apower absorbed by plasma.

bower delivered to plasma by heating system.

Table 9. MARS direct converter parameters. ${ }^{a}$ (The energy conversion performance of this system is given later in Table 14.)

Inner halo scraper

$$
\begin{aligned}
& \text { 2.01-kA ions }-0.12-\mathrm{kA} \text { electrons }=1.89 \mathrm{kA} \\
& V=0, \mathrm{P}_{\mathrm{e}}=0, \mathrm{H}=100 \mathrm{MWth}
\end{aligned}
$$

Outer halo vented plate

$$
V=0, P_{e}=G, H=20 \text { Mwth }
$$

Outer end collector

0.03-kA ions - 0.32-kA electrons $=-0.29-k A$ net electron current $\mathrm{V}=-84 \mathrm{kV}, \mathrm{Pe}_{\mathrm{e}}=25 \mathrm{MWe}, \mathrm{H}=22 \mathrm{MWth}$

Inner ent collector

$0.15-k A$ iuns $-1.75-k A$ electrons $=-{ }^{-} .60-k A$ net electron current $V=-167 \mathrm{kV}, \mathrm{Pe}_{\mathrm{e}}=267 \mathrm{MWe}, \mathrm{H}=139 \mathrm{MWth}$

$a_{V}=$ potential, $P_{e}=$ directiy converted electric power, and $H=$ thermal power. 
(a)
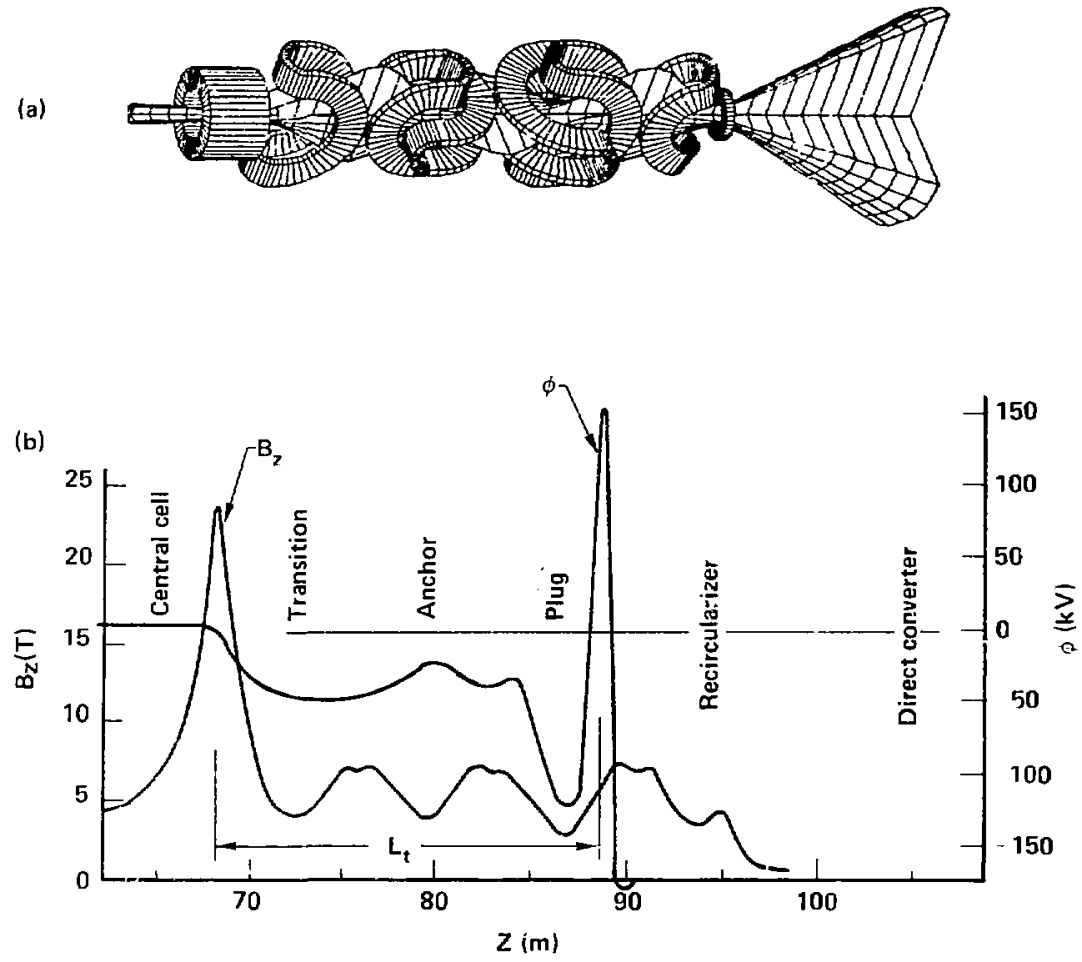

(c)

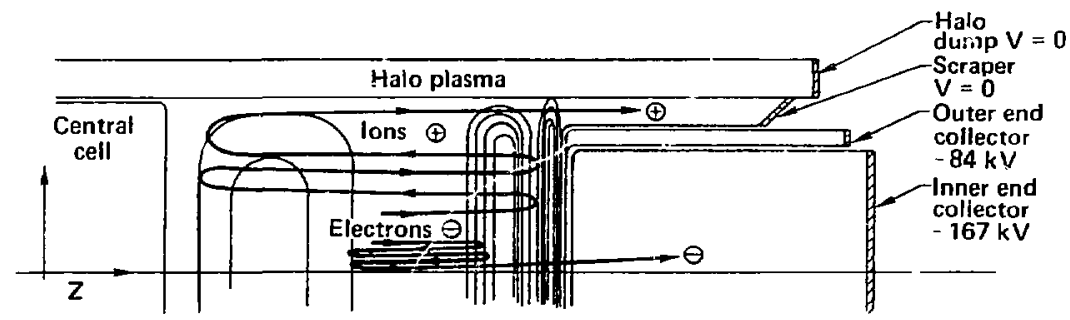

Fig. 19. Particle transport to the halo by means of drift pumping. The magnet configuration and field/potential profiles are shown on the same axial scale for reference. 
mirror-trapped is $\left(1-B_{c} / B_{c h o k e}\right)^{1 / 2}>90 \%$; thus, the choke coil mirrors hold back the majority of the axial central-cell plasma pressure.

The remaining central cell DT fuel ions pass through the choke coil mirrors, reflect off the potential peaks in the plug mirror cells (shown in Fig. 19), and return back to the central cell. Thus, the plug plasma that generates the potontial peak holds back only a small fraction of the central cell pressure. During the average deuterium or tritium ion lifetime of $1.6 \mathrm{~s}$ $\approx 2 \times 10^{4}$ bounce periods, coulomb collisions cause the average ion's pitch angle to change many times while in the high-density central cell. Collisions in the end cell cause the pitch angle of an average ion to vary onis a fraction of 90 deg during the time the ion spends in the lower density regions of the end cell, but this is still enough to trap most DT passing ions between the choke-coil mirror peak and the end plug potential peak. Without drift pumping, trapped ions would slowly accumulate in the end cell as a result of collisions, and would eventually destroy the potential barrier confining the passing ions.

Thus, one basic function of drift pumping is to induce enough radial loss of the trapped ions to match their collisional trapping rate. With drift pumping removing the trapped ions, the resulting axial density profile $n_{\text {transition }}$ in steady state then follows closely the density of the passing ions, so that approximately

$$
n_{\text {transition }}(z) \simeq n_{c} B_{\text {transition }}(z) / B_{\text {cnoke }},
$$

where $n_{c}$ is the central cell density. This transition density is maintained by a continual radial loss of trapped ions induced by the drift pump, as shown schematically in Fig. 19c. When the trapped ion diffuses to a radius just greater than the radial extent of the confining potential barrier, the trapped ions spill out the ends within a thin annulus just at the inside edge of the - alo, where they are intercepted by a halo scraper and pumped out of the reactor.

Because the drift-pump of fields are tuned to the range of ion bounce frequencies, which are much lower than electron bounce frequencies, the induced radial diffusion is selective to the ions, leaving the electrons to escape unly along the field lines. The net electron current collected by the direct converter $p l a t e s$ at the ends directly generates electric fower by forcing electron current at a legative plate potential under load. Thus, by separating ion and electron end losses, the selective ion radial diffusion 
inouced by drift pumping allows a simple form of direct energy recovery with negatively biased end wall electron collectors. Another important benefit results from the negative bias of the end walls in that radial electric fields are reduced to nearly zero in the MARS central cell (see Fig. $19 \mathrm{~b}$ and $\mathrm{c}$ ), virtually eliminating rotation as an additional contributor to MHD instability and resonant ion-transport as an additional contributor to radiai transport in the central cell. Recent evidence indicates that negatively biased end-wall plates reduce nonambipolar ion radial loss in the TMX-U central cell.23

Another essential function of drift pumping is to remove thermalized alpha ash and other impurities (item 7 in Table 3). After the mirror-trapped 3.5-MeV fusion aipha particles transfer their energy by drag to the centralcell DT ions and electrons, a majority of the alphas $(270 \%)$ end up thermalized to the DT ion temperature, at which temperature the axial electrostatic confinement time of the alphas is about 100 times longer than for the DT ions. Without radial loss, the thermalized alpha ash would build up to densities exceeding the $D T$ fuel density, causing drastic reductions in plasma gain $Q$ and wall loading $\Gamma_{n}$. The thermal alphas pass into the end cell and collisionally trap there just as the DT fuel ions do. Drift pump frequencies are therefore broadened sufficiently to pump all species of interest (trapped DT ions, trapped alphas: and plasma impurity ions). Because of the strong potential peak seen by the alphas and impurities in the core of the plasma, nearly all the alphas and impurities divert out along the haio and are removed by the vacuum punips connected to the halo end structure (Fig. 19). Figure 20 shows the location of the MARS drift pump coils at the peaks of the geodesic curvature in the transitions. There are two hairpin-shaped single-loop coils above and below each plasma fan, at each curvature peak (i.e., two sets of coils at each end of the reactor). The pair of coils on the left peak ("transition" drift pump) remove the majority of the trapped DT ions and thermal alphas, and in addition, the coil pair on the right peak is tuned to pump the sloshing ions (to maintain their double-humped axial profile) and any residual current of deeply trapped cold ions in the thermal barrier. The largest drift-pump amplitude and power requirement by $f a r$ is $f \circ r$ the transition drift-pump coil. Table 10 lists the MARS drift-pump coil parameters.

The trapping and drift pumping of DT ions in the end cells represents a major loss of particles and power from the central cell. Therefore, for fusion alpha heating to balance the central-cell plasma energy losses (ignition), the 


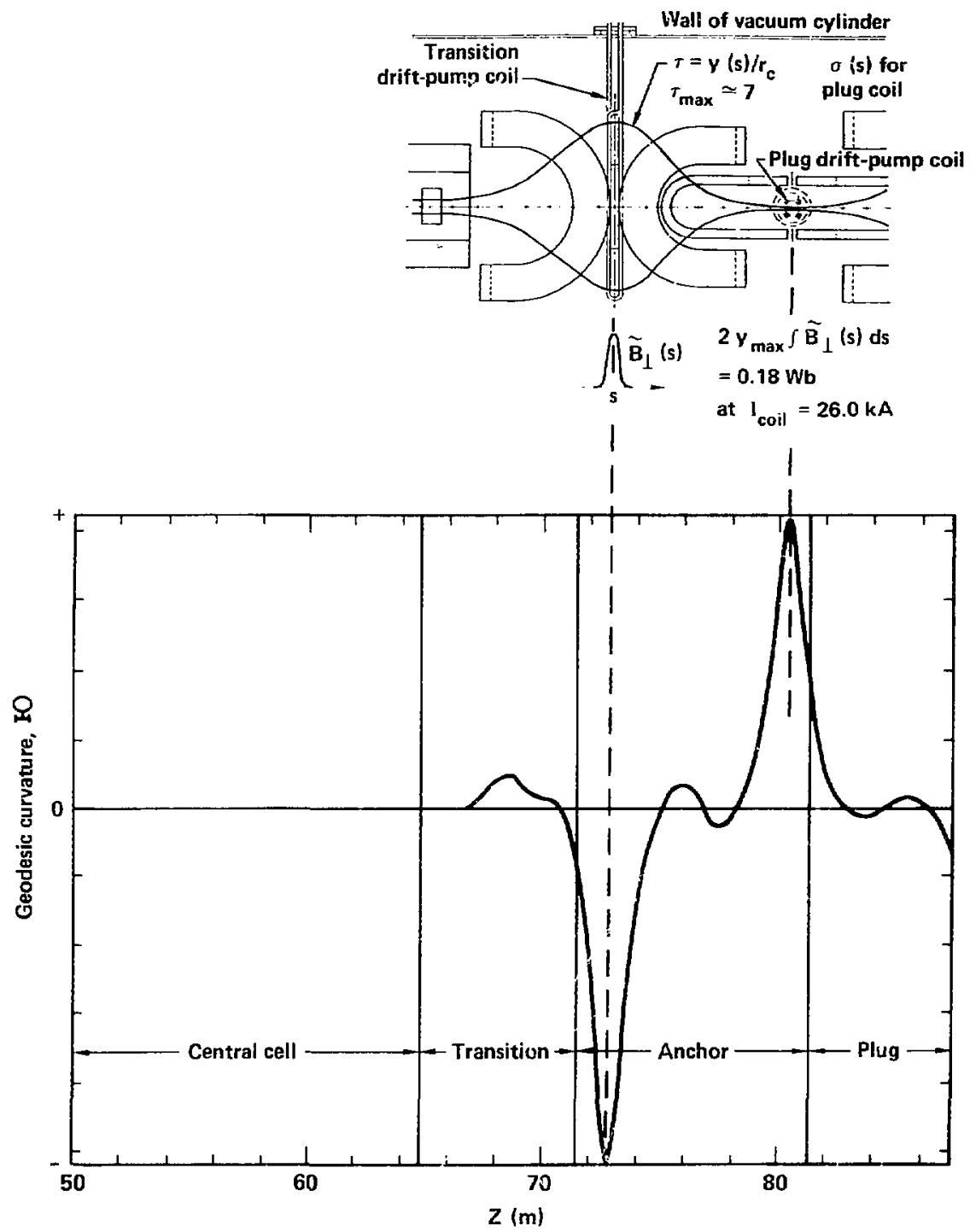

Fig. 20. Location of the transition and plug drift pump coils in tine end cell plasma ions. The axial variation of the geodesic curvature is shown for reference. 
Table 10. MARS drift-pump coil parameters.

\begin{tabular}{|c|c|c|}
\hline Parameter & $\begin{array}{c}\text { Transition drift pump } \\
\text { coil for } \\
\text { spanning DT ions } \\
\text { and thermal alphas }\end{array}$ & $\begin{array}{c}\text { Plug drift pump } \\
\text { coil for } \\
\text { sloshing and deeply } \\
\text { trapped ions }\end{array}$ \\
\hline \multirow[t]{2}{*}{ Peak rms current, each coil (A) } & 26,000 & 1,400 \\
\hline & 18,000 & 970 \\
\hline \multirow{2}{*}{ Peak rms voltage, each coil (V) } & 52,000 & 27,000 \\
\hline & 37,000 & 18,900 \\
\hline Inductance per pair $(\mu \mathrm{H})$ & 3.4 & 3.4 \\
\hline Ohmic loss per pair (MW) & 1.54 & 0.2 \\
\hline Central frequency $(\mathrm{kHz})$ & 47 & 450 \\
\hline Frequency range $\left(\frac{\Delta f}{f}\right)$ & 0.4 & 0.66 \\
\hline Perturbing flux $\widetilde{B}_{\perp}$ (T) & 0.0420 & 0.0023 \\
\hline $\begin{array}{l}\text { Number of frequencies } W_{w} \\
\text { intrinsic bandwidth }\end{array}$ & 10 & 60 \\
\hline$N_{\omega}\left(\frac{\Delta f}{f}\right)(\%)$ & 0.5 & 9 \\
\hline Dissipated power/coil (MH) & 3.4 & 1.7 \\
\hline
\end{tabular}


axial ion losses must be reduced to levels that are sinall whell compared with the drift-pump-induced losses in MARS. Small axial ion losses determine the large electrostatic plugging potentials (申 plug $-\phi_{\text {central cell }} \geq 5 \mathrm{~T}_{\text {ic }}$ ) in MARS. Since only the smaller of the two ECRH heating powers (ECRH at point " $a$ " in Table 8) controls this potential, there is not much impact on $Q$ to raise the end plug potentials to the point where the direct converter plates collect essentialiy only the plasma electrons. Since ion radial Toss then dominates over axial loss in MARS, drift-pumping then determines the MARS pellet fueling current ( $I_{\text {pellet }} \simeq I_{\text {trap,DT }}+I_{\text {burnup }} \simeq 2 \mathrm{kA}$ equivalent), and the equilibrium thermal alpha concentration $\left(n_{\alpha} / n_{D T} \approx 1 / 2 F_{b}\right)$, where the burnup fraction $\left.F_{b} \simeq 1 / 2\left(n \tau_{\text {radial }}\right)\langle\sigma v\rangle_{D T} \approx 0.14\right)$.

\subsubsection{Halo Physics and End Plasma Leakage}

The drift pumping results in approximately $2 \mathrm{kA}$ of DT ions at temperature $T_{i c} \simeq 28 \mathrm{keV}$ and about $140 \mathrm{~A}$ equivalent of therma 1 alphas at the same temperature, exhausting out the ends of MARS just inside the halo. This end loss current strikes the halo scraper and the resulting neutralized gas becomes ionized and is pumped by the surrounding halo plasma.

Figure 21 shows a schematic of this outer part of the direct converter structure. The outer halo density is sustained primarily by the gas it ionizes near the scraper and down the length of the MARS plasma column. About $3 \%$ of the fusion alpha orbits in the central cel? intercept and heat the halo electrons, maintaining the halo electron temperature high enough to ionize gas and sputtered impurities $\left(T_{\mathrm{e}} \approx 50 \mathrm{eV}\right)$. To maintain enough halo density to strongly at \pm enuate neutrals and impurities incident on it $\left(n_{j} 25 \times 10^{12} \mathrm{~cm}^{-3}\right)$, a vented plate is recessed into a reentrant annular cavity so that halo jons recycle off the vented plate an average of 20 times before being pumped through the holes of the vented plate. The number of neutral recycles and, therefore, the resulting halo density are controlled by the pressure in the plenum behind the nuter vented plate asid the number of holes in the vented plate. The inflowing halo plasma pressure allows a high plenum gas pressure of about $4 \times 10^{-2}$ Torr, sufficient to allow the MARS vacuum pumping to be achieved with mechanical pumps instead of with cryopanels.

Outside the reentrant halo cavity and the plasma halo, however, the average gas pressure is much lower $\left(\simeq 3 \times 10^{-7}\right.$ Torr $)$ because of pumping by 


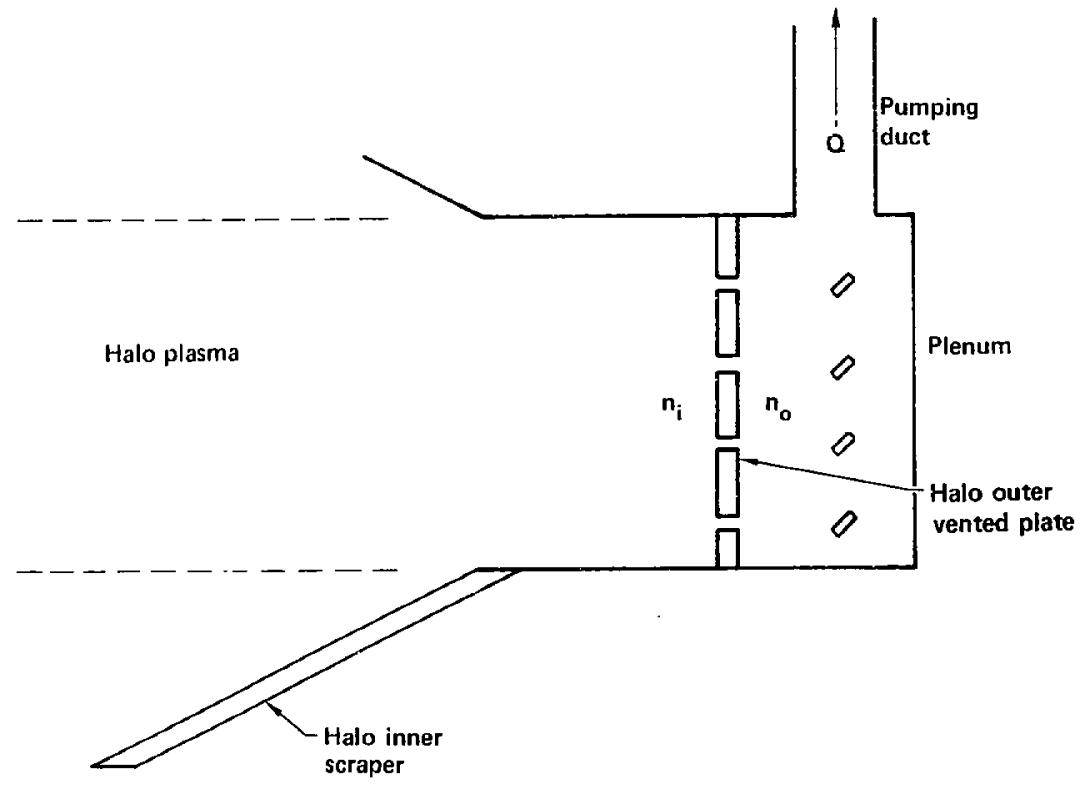

Fig. 21. Schematic of the plasma halo dump in the end cell showing the inner scraper and the outer vented plate.

ionizatior in the halo. The recycling halo in MARS is thus very similar to pumped limiters and diverter chambers being studied for some tokamaks. However, the halo ionization maintains a low neutral pressure at the first wall in the central cell, so sputtering of the first wall can be kept small, less than $0.1 \mathrm{~mm}$ per year urider pessimistic assumptions. One major feature of the "natural diverter" action of the tandem mirror halo is that first-wall. surface heat loads are very low compared with other plasma confinement concepts. In MARS, the total surface heat flux a: the first wall of the central cell is only $24.7 \mathrm{~W} / \mathrm{cm}^{2}$. The majority of this $\left(24.6 \mathrm{~W} / \mathrm{cm}^{2}\right)$ is the result of bremsstrahlung with, $20.1 \mathrm{~W} / \mathrm{cm}^{2}$ attributable to neutral and charged-particle bombardment. 


\subsection{Magnets}

The MARS magnet system is designed to use proven technology from MFTF-B (when possible) and to extend this technology when there is a strong benefit in terms of reactor system performance. The overall magnet system is depicted in Fig. 22. The long central-cell solenoids provide a nearly constant field-$5.5 \%$ ripple--along the lengt: of the central cell. Magnetic plugging of the central cell plasma is provided by the high field (24-T) choke coils. The transition coil takes the circular flux bundle to an elliptic cross section for entry into the anchor yin-yang pair. The anchor creates a minimum-B well that provides most of the MHD stability for MARS. The pligy yin-yang pair assists in providing stability. However, its principal function is to provide the location for the confining potential peak, the thermal barrier, and the sloshing-ion distribution for microstability. The final $c$ coil recircularizes the flux bundle in conjunction with a small outer solenoid coil, thus presenting a plasma of circular cross section to the direct converter. The parameters for all the coils are presented in Table 17.

The greatest extrapolation from present technology is in the high field choke coit. To create a 24-T field on axis, we use a superconducting background coil operating at $15.8 \mathrm{~T}$ and a normal conducting insert that provides an additional $8 \mathrm{~T}$ on axis and operates ac $24.8 \mathrm{~T}$. Each coil provides a significant design challenge that is further compiicated by a moderately high $\left(22.6-\mathrm{MW} / \mathrm{m}^{2}\right)$ neutron loading. We developed the design of the backgroulid coil by using three conductor regions where the material and current density were varied with the field. The high field is, of course, accompanied by high stresses. These were accommodated using a Nitronic 40 steel-reinforced conductor that limits strain to $0.35 \%$. To obtain sufficient current density in the superconductor at the high fields, we chose to use superfluid iHe II at $1.8 \mathrm{k}$ as the coolant. This also allows an increase in the heat flix, which results in about a factor of two increase in bulk current density. Because of the high cost of this coil, it is highly desirable to make it a lifetime component. Therefore, shielding must be provided to limit damage to the superconductor, insulator, and stabilizer as well as to limit nuclear heating. This shielding is illustrater in Fig. 7, which shows that the resistive insert actually ser as as part of the shield. All radiation allowables are met with this design an. no annealing of the conductor is required. 


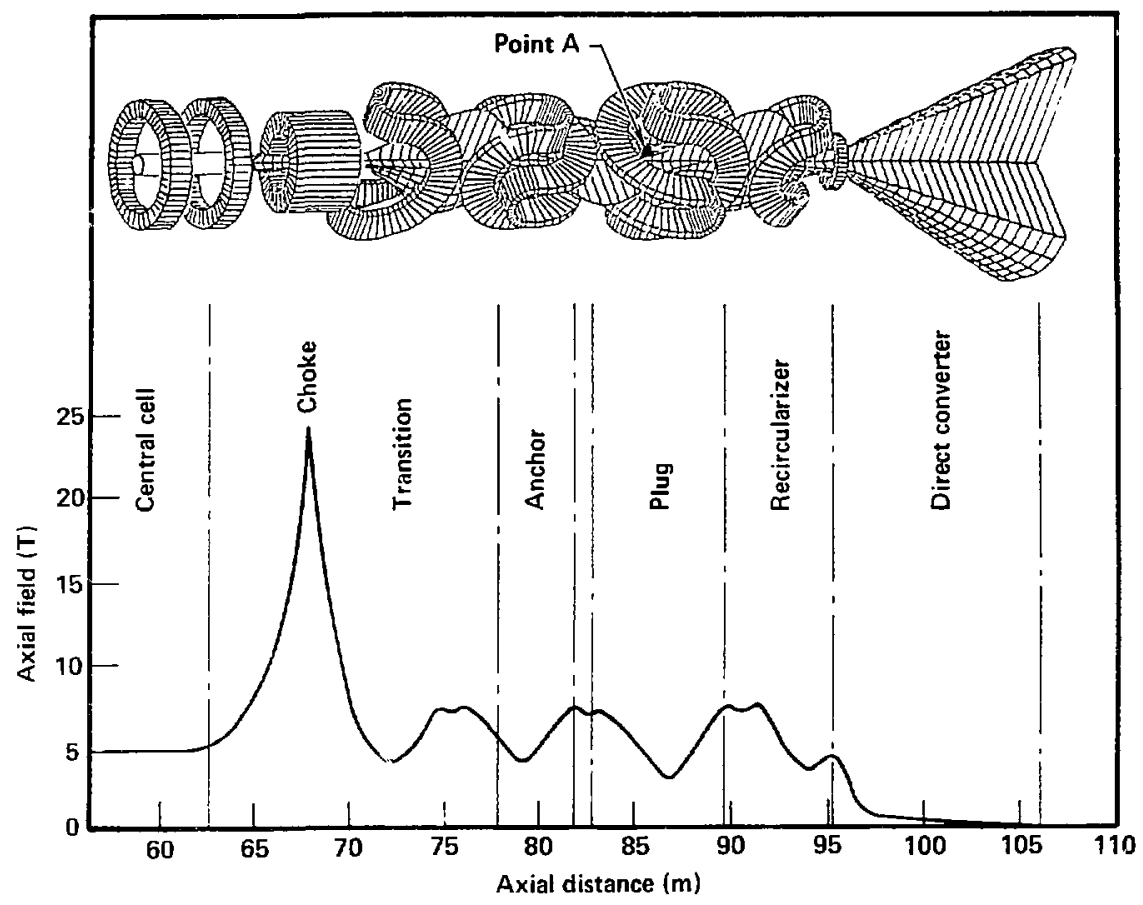

Fig. 22. The MARS magnet system and corresponding axiar magnetic field profile.

The copper insert coil must be designed to minimize power consumption (both ohmic heating and coolant pumping) while producing the required fieid, have long life in the high radiation field, and be easily replaced. After a series of trade studies, we selected an internally cooled, uniform-currentdensity coil. The principal reason fr: this selection was the need to separate the coolant from the insulation to achieve reliable operation for several years. Our baseline design is a double pancake that is machined from a single plate. The number of double pancakes determines the length of the coil. The material is the cold-worked copper alloy MZC, which has a working 
Table 11. Magnet system parameters.

\begin{tabular}{|c|c|c|c|c|c|c|c|c|c|c|}
\hline Coil & $\begin{array}{c}\text { Peak } \\
\text { on-axis } \\
\text { field } \\
\text { (T) }\end{array}$ & $\begin{array}{l}\text { Peak } \\
\text { conductor } \\
\text { field } \\
\text { (T) }\end{array}$ & Conductor & $\begin{array}{l}\text { Thner winding } \\
\text { radius } \\
\text { (m) }\end{array}$ & $\begin{array}{l}\text { Width } \\
(m)\end{array}$ & $\begin{array}{l}\text { Buiidd } \\
(\mathrm{m})\end{array}$ & $\begin{array}{l}\text { Current } \\
\text { density } \\
\left(\mathrm{A} / \mathrm{Cm}^{2}\right)\end{array}$ & $\begin{array}{l}\text { Major } \\
\text { radius } \\
\text { (m) }\end{array}$ & $\begin{array}{l}\text { Sweep } \\
\text { angle } \\
(d \in g)\end{array}$ & $\begin{array}{l}\text { Straight } \\
\text { section } \\
\text { length } \\
\text { (m) }\end{array}$ \\
\hline Central cell & 4.91 & 7.20 & $\mathrm{NbT} \mathbf{i}$ & 2.10 & 0.77 & 1.22 & $\left\{\begin{array}{r}956 \\
1206 \\
1460\end{array}\right.$ & -- & -- & -- \\
\hline $\begin{array}{l}\text { Choke } \\
\text { Superconductor }\end{array}$ & 24.0 & 16.1 & $\begin{array}{l}\mathrm{Nb}_{3} \mathrm{SnT} i \\
\mathrm{Nb}_{3}^{3 \mathrm{Sn}}\end{array}$ & 1.40 & 3.20 & 0.992 & $\left\{\begin{array}{l}1235 \\
1445\end{array}\right.$ & & & \\
\hline Insert & & 24.8 & $\begin{array}{l}\mathrm{NbT}^{3} \\
\mathrm{Cu}\end{array}$ & 0.30 & 0.858 & 0.42 & $\begin{array}{r}1830 \\
2737\end{array}$ & -- & -- & -- \\
\hline Direct converter & 4.0 & 6.46 & NbTi & 1.1 & 0.50 & 0.50 & 2000 & -- & -- & - \\
\hline Transition & 7.0 & 9.5 & NbTi & 1.1 & 1.6 & 0.40 & 2600 & 3.25 & 180 & 0 \\
\hline Inner anchor & 7.3 & 10.5 & NoTi & 1.1 & 1.6 & 0.40 & 2600 & 2.50 & 180 & 0.5 \\
\hline Outer anchor & 7.3 & 10.7 & NbTi & 1.1 & 7.6 & 0.40 & 2600 & 2.50 & 180 & 0.5 \\
\hline Inner plug & 7.2 & 9.8 & NbTi & 1.1 & 1.6 & 0.40 & 2600 & 3.25 & 180 & 0.4 \\
\hline Outer plug & 7.5 & 9.8 & NbTi & 1.1 & 1.6 & 0.40 & 2854 & 3.25 & 180 & 0.4 \\
\hline Recularizer & 7.5 & 9.8 & NbTi & 1.1 & 1.6 & 0.40 & 2946 & 2.50 & 140 & 0 \\
\hline
\end{tabular}


stress of $331 \mathrm{MPa}$ and an acceptably low resistivity. We selec :ed magnesiumaluminum oxide spinel $\left(\mathrm{MgAl}_{2} \mathrm{O}_{4}\right)$ as the insulator because of its low rate of neutroll-induced swelling and because the swelling is isotropic. The radiation effects that limit the life of the coil are resistivity increases caused by transmutations and swelling of the insulator. The latter dominates. We have selected a design tolerance of $3 \%$ volumetric swelling of the spinel as end of life, which results in a coil lifetime of more than four years. In fact, the coil will accommodate more than $3 \%$ swelling. However, this lifetime is comparable to the blanket lifetime and the insert coil can be replaced during scheduled blanket maintenance pericds. The average power dissipation over the lifetime of each resistive insert coil is $40.4 \mathrm{MW}$.

The design of the choke coil structure serves several purposes. Foremost, it holds the background coil and resistive insert in place while al lowing for easy remole removal and replacement. Second, it provides the varuum seal between the central cell and the end cell, including a gate valve to close off the end cell when the central cell is up to air during blanket replacement. Intercoil jacks ensure load continuity between the central cell and end cell. They also provide the capability to adjust the position of the choke coil.

The end cell coils are similar in design to the MFTF-B yin-yangs but are larger and have a higher peak field on the conductor. Because the peak conductor field exceeds $8 \mathrm{~T}$, a design upgrade from MFTF-B was necessary. We chose to retain NBTi because of its ductility for the difficult winding geometry. The coolant selected is superfluid LHe II to allow high current density at $10 \mathrm{~T}$. This also allows a simplified conductor design when compared with MFTF-B. The key issue for the end cell coils is radiation damage and shielding. The peak neutron wall loading in the end cell is $0.13 \mathrm{~mW} / \mathrm{m}^{2}$. he used a highly efficiert composite shield because any increase in shield thickness causes a large increase in coil volume and cost, increases peak field on the conductor (which is near the limit for NDTi technology), and lowers the achievable central cell plasma pressure. Magnet radiation alicuables were set. by the cost of heat removal at 1.8 and $4.5 \mathrm{k}$. Radiationresistant polyimide insulation was used and the stabilizer must be periodically annealed by bringing the coils to room temperature.

We selected a strongback structure for the coil supports. This reduces the bending moments, avoids interference between the structure of adjacent 
coils, allows thinner cases to accommodate more shielding, and simplifies access for supplemental heating systems. All end cell coils are removable through the direct converter end dome in the unlikely event of a coil failure.

The end cell also contains drift pump coils that modulate the magnetic field to promote radial transport of ions out of the core plasma and into the unconfined halo region. Our approach, shown in Fig. 8, uses two hairpin coils embedded in the magnet shielding at each end of MARS. The design of the coils is reasonably straightforward, but is somewhat complicated by a high radiation environmerit and the need ror a flux return path. This has been solved by using lead oxide as the magnet's radiation shield.

The central cell coils have technological requirements similar to those in the Large Coil Program technology, i.e., NbTi, pool-boiling LHe I, unreinforced conductor, peak fieid $<8 \mathrm{~T}$, low radiation levels. The design is relatively simple and the coil could be manufactured with minimal research and development (R\&D). The trade studies performed showed that the cost of the cryo plant and the cost of electricity to operate it set an economic limit that precludes making the shield thinner and making the magnets smaller, even though the other radiation levels are well below the allowables. In fact, the magnets never require annealing. In contrast to the end cell where all magnets are in a common vacuum system, each central cell magnet has its own Dewar. Because the 42 central cell magnets comprise $55 \%$ of the total magnet weight and $40 \%$ of the total magnet cost, there is incentive to examine higher performance, lower confidence designs that would operate at higher current densities to lower the cost of this system.

\subsection{Microwave Heating Systems}

MARS has two microwave plasma heating systems that use ECRH io preferentially heat electrons. The first of these creates the axial confining potential-peak in the plug. The second system creates the thermal barrier, a potential depression that decouples central cell electrons from the electrons in the region of the potential peak. The thermal barrier is at the location of the plug minimum field. The main parameters for the two ECRH systems are given in Table 12. 
Tabie 12. ECRH system parameters. Values quoted are for one end of the machine.

Potential peak Thermal barrier

\begin{tabular}{|c|c|c|}
\hline Total absorbed power (MW) & 3.3 & 38.5 \\
\hline Vacuum magnetic field (T) & 3.9 & 3. \\
\hline Axiàl locations (m) & \pm 85 & \pm 83.5 \\
\hline Vacuum frequency $(\mathrm{GHz})$ & 109 & 84 \\
\hline Peak beta & 0.574 & 0.75 \\
\hline E lectron density $\left(\times 10^{13} \mathrm{~cm}^{-3}\right)$ & 2.54 & 2.4 \\
\hline E lectron temperature (energy $\left.{ }^{a}\right)(\mathrm{keV})$ & 123 & 820 \\
\hline Range of injection angles (deg) & $77.5 \pm 3.5$ & 25 to 55 \\
\hline Axiai extent of heating zone $(\mathrm{cm})$ & \pm 28 & \pm 75 \\
\hline $\begin{array}{l}\text { Heat ing frea!'ency, } \\
\text { beta-depressed (GHz) }\end{array}$ & 71 & 60 \\
\hline Heating mooe & $\begin{array}{l}\text { Fundamental, } \\
\text { extridordinary }\end{array}$ & $\begin{array}{l}\text { Fundamental, } \\
\text { extraordinary, } \\
\text { wave trapping }\end{array}$ \\
\hline
\end{tabular}

af or the thermal barrier electron population.

Because of the large amount of required absorbed power $(83.8 \mathrm{MW})$, it was importarit to design a highly efficient, low cost system. For this reason, we have extrapolated from available technology to produce a cost-effective design. An ECRH system basically consists of the power supply, microwave source, and transmission/launching subsystems.

The source selected for the MARS ECRH system is a multimegawatt quasioptical gyrotron with a voltage-depressed collector, permitting direct energy recovery of the electron beam. This source is illustrated in Fig. 9. The potential peak system uses 1.65-MW gyrotrons at $71 \mathrm{GHz}$; the th:ies for the thermal barrier are $2.43 \mathrm{MW}$ at $60 \mathrm{GHz}$. With energy recovery, the tubes have an overall efficiency of $\backsim 80 \%$. Both tubes have about $40 \%$ frequency variability 
for plasma startup purposes. We selected the quasi-optical gyrotron over ti,e free-electron maser (FEM) and the conventional closed-cavity gyrotron. 24 The rationale for the selection included the source's potentially high efficiency, its ability to be extrapolated to large tube sizes, frequency variability, and

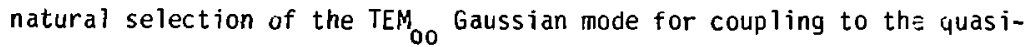
optical transmission system. The power rating of these tubes is significantly above presently achieved leveis, particularly since the quasi-optical gyrotron is in the developmental stage. However, the U.S. gyrotron development plan does call for a $2.5-\mathrm{MW}$ device abcve $100 \mathrm{GHz}$ and a $5-\mathrm{MW}$ device at $60 \mathrm{GHz}$ by 1994. The extrapolation to the MhRS design points is reasonable when compared to the rate of development in this area.

The requirements of the transmission/launching system are high efficiency, power handling capability, access constraints, and the ability to deliver the power in the proper polarization. We considered a standard overmoded waveguide system, similar to those used on current experiments, and a quasi-optical transmission system using reflective optics. We selected the quasi-optical transmission system because its excellent performance, namely, low transinission losses, high power-handling capability, and ability to operate without vacuum windows. Moreover, because of the large ture size, we were able to design a very simple transinission system that satisfied all requirements. The diverging beam from the gyrotron forms an effective colical horn. When a parabolic reflector is placed in the beam path, the beam launcher resembles a conical horn-reflector antenna. The Gaussian output mode from the gyrotron couples to the transmission system without the need for mode converters. A schematic of ihe thermal barrier ECRH transmission system is shown in Fig. 23 . The system layout considerations were dominated by the need to propagate tre beams through the $64-\mathrm{cm}$ minor radius gap in the plug coil without compromising the magnet's neutron shielding. This was accomplished with the configuration shown in $\mathrm{Fig}$. 23. In addition, two redundant ubes were added to each end of the reactor to improve ECRH system reliability.

The power supply option selected for MARS is a sinyle large supply for both ECRH systems. It is based on existing technology used in high-voltage high-power dc transmission from electrical generating stations to distribution sjstems. We chose a one-pole 12-pulse converter because of its inherent highvoltage regulation. Twelve-pulse converters are of a three-quadrupole configuration with four thyristor valves per quadrupole. There is a three-phase 


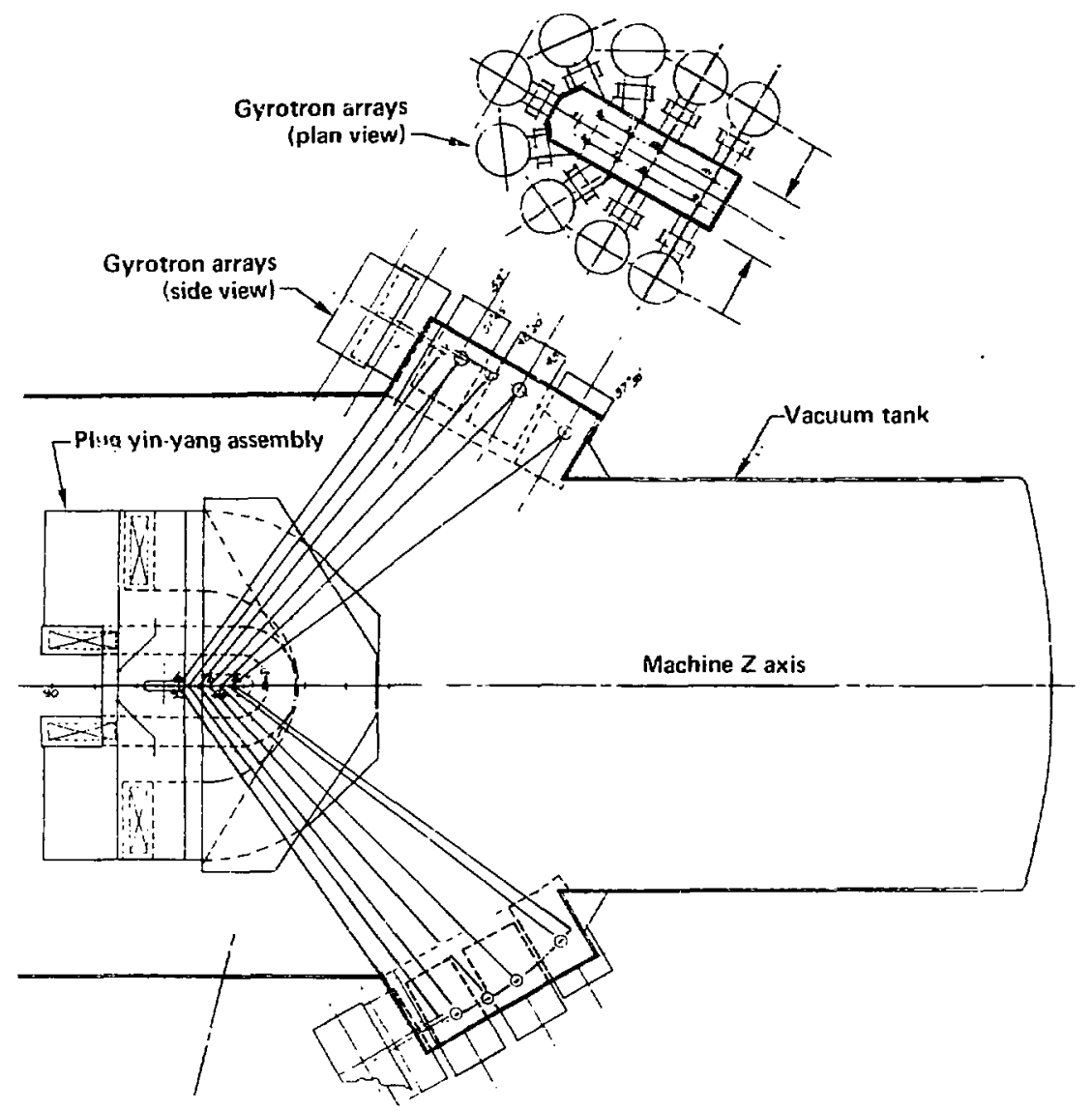

Fiq. 23. Thermal barrier ECRH system layout.

transformer for each six-pulse bridge. The large ac-to-dc converter feeds a set of parallel power regulation/isolation networks. Systems of this type are available at about $500 \mathrm{MW}$. They are presently being developed at $200 \mathrm{MW}$; the size needed for MARS. This type of system is used on the Pacific Iniertie and has demonstrated a reliability of $99.85 \%$ at full power.

The MARS ECRH system design achieves high efficiency, >70\% wal1 plug to plasma, at a low cost that is less than $50 \%$ of the cost of the ECRH systems on present experiments per watt delivered. Significint development will be required. 


\subsection{Ion-Cylotron Resonant Heating Systems}

MARS requires two ICRH systems: one for ion heating in the anchor and one for bulk heating of the centrai cell during startup.

The anchor system is required to heat the trapped-ion current to a high er.ough energy level to pruvide a peak beta of 0.75 . This requires $11.4 \mathrm{MW}$ of coupled power (total, both anchors). We have decided to heat at the second harmonic of deuterium, or $55 \mathrm{MHz}$. The system is designed to launch $13.4 \mathrm{MW}$ from eight launchers, two located in the minor radius gap of each anchor magnet (i.e., $6.7 \mathrm{MW}$ delivered to each anchor). The system consists of a coil antenna launcher, a coaxial transmission line with a three-stub tuning system, and a multistage amplifier chain.

We selected a loop antenna for the launcher, primarily because of access limitations in the anchor. The antenna is center-fed to allow an average surface power density of about $2 \mathrm{~kW} / \mathrm{cm}^{2}$. Although the nuclear radiation levels are about an order of magnitude lower than in the central cell or in a tokamak, radiation damage is still a concern. In addition, good coupling of the energy tc the plasma may require imbedding the antenna in the halo, which causes high heat fluxes and erosion. For these reasons, the antenna is designed as an easily replaceable modular unit.

The transmission system is primarily i $93 / 16-$ in. $50-\Omega$ coaxial line. The third stub provides impedance matching whereas the remaining stubs are used for VSWR control. The coax tapers to $61 / 8 \mathrm{in}$. for access through the magnet. The system is cooled with pressurized water; the most stringent requirements are for the antenna and interface at $12 \mathrm{gal} / \mathrm{min}$ and a $50^{\circ} \mathrm{C} \Delta \mathrm{T}$. The line is evacuated from the third stub to the antenna; the remainder of the line is pressure-controlled with 1 atm of dry air. Overall transmissionefficiency is $89 \%$. The transmission line-antenna interface is illustrated in Fig. 24 .

Each antenna is powered by an amplifier chain consisting of an intermediate power amplifier and driver, a low-power 90-deg hybrid splitter, two final power amplifiers (FPA), a high power combiner, a power supplier, and control and protection circuitry and monitoring. The FPA is the [imac $8974 / X-2159$ tetrode; the driver is the Eimac 4-CW, 100,000-E tetrode, both in a cathode-driven mode. 


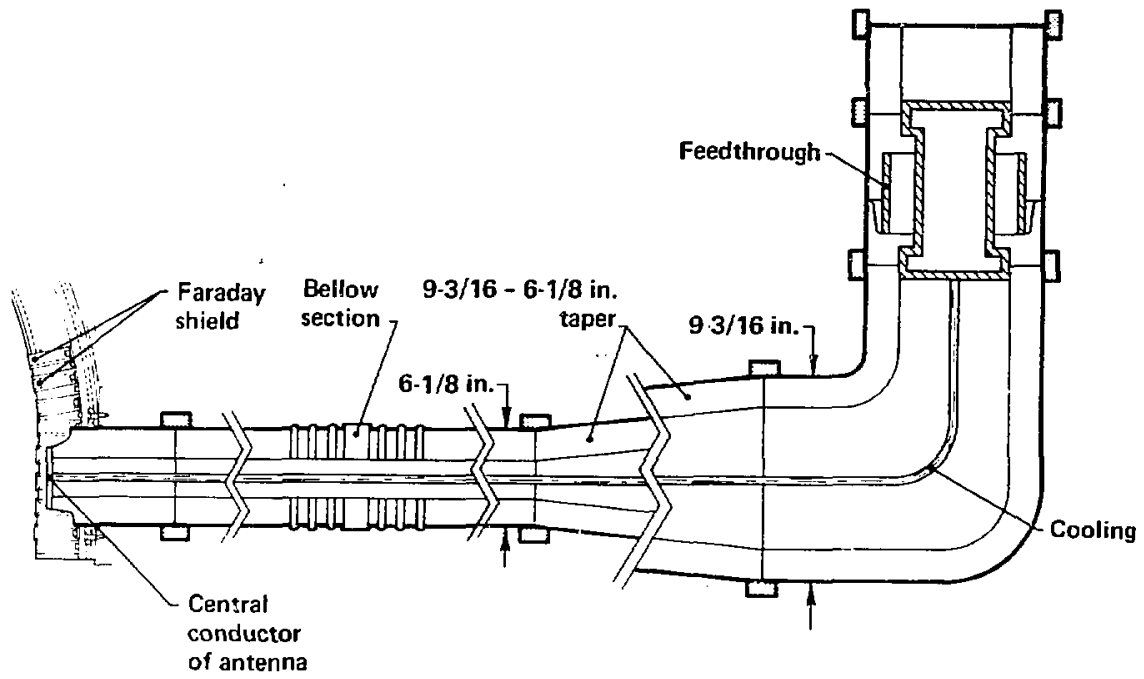

Fig. 24. Anchor ICRH transmission line antenna interface.

Overal1 system efficiency, "wall-plug" to launched power, is $54.3 \%$. We have used "off-the-shelf" hardware. A higher system efficiency could be obtained with speciaily developed tubes, but we did not make that extrapolation because of the relatively low power of the system.

The startup ICRH system heats the central cell to ignition during the reactor startup phase. It is required to deiiver 12 MW for a period of $120 \mathrm{~s}$. We heat at the second harmonic of deuterium, $112.8 \mathrm{MHz}$, at the end of the central cell where the field is higher and the beta is lower. This allows both higher frequency and a smaller change in resonance frequency during startup. The startup system differs from the one in the anchor in two respects. The higher frequency, improved access, high neutron loading, and high halo density provide a great incentive to use waveguide launchers. We use eight single-ridged waveguides arranged in spoke fashion between the last two 
central cell coils, as shown in Fig. 25. The amplifier system is of the same basic design but uses different tubes because of its higher frequency. Total system efficiency is $41.3 \%$. This could be increased by the use of more advanced tubes; however, the efficiency is not as important a consideration for the startup system.

\subsection{Neutral Beam System}

The beam system is required to delivar $4.43 \mathrm{MH}$ of neutral deuterium into each plug at an energy of $475 \mathrm{keV}$ and an angle of 70 to $80 \mathrm{deg}$. The nigh beam energy dictates that a negative ion source be used to achieve reasonable neutralization efficiency. The beam system consists of the ion source,

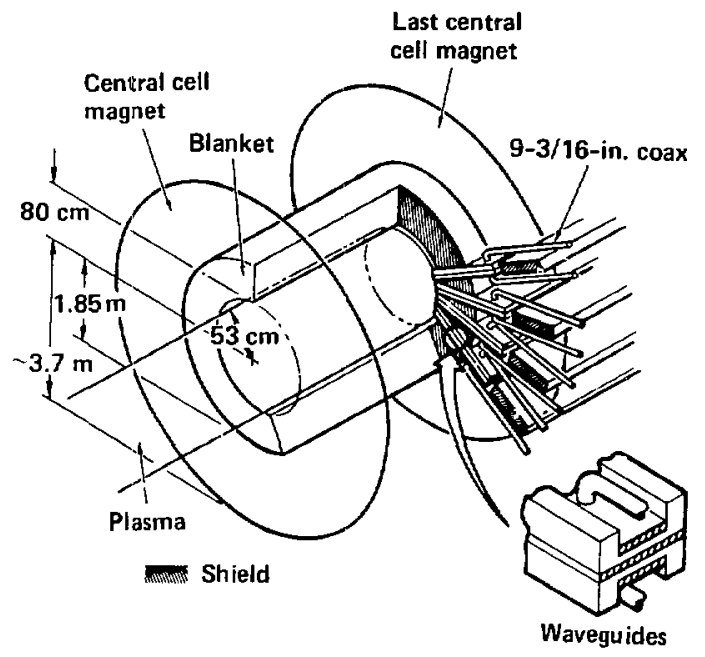

Fig. 25. Startup ICRH system in the central ce1l, located between the last two central cell coils. 
accelerator, neutralizer, ion and neutral beam dumps, cryo pumping, and magnetic shielding. The beamline and its location in the plug are shown in Fig. 10 .

We selected Lawrence Berkeley Laboratory's (LBL) self-extraction negative ion source. ${ }^{25}$ It uses a cesiated molybdenum surface to convert positive ions formed by an rf plasma generator to negative ions. Geometric shaping of the converter focuses the $0^{-}$ions into an extraction slit. Electrons are reflected from the accelerator entrance by the magnetic field produced by a set of $\mathrm{SmCO}_{5}$ magnets. The ion beam has an average current density of $47 \mathrm{~mA} / \mathrm{cm}^{2}$, which yields a source strength of $7 \mathrm{~A} / \mathrm{m}$ over a 1.5-cm-wide slot. This is a small increase in the present capability of $5 \mathrm{~A} / \mathrm{m}$. We selected a transverse field focusing (TFF) accelerator (of a type ${ }^{26}$ under development at LBL) for the beam system. The ions are first preaccelerated to $80 \mathrm{keV}$ using a standard electrostatic slot accelerator. The TFF is a type of one-dimensional strong-focusing electrostatic system used for both beam acceleration and transport. The rocusing produced by the transverse electric field causes the particles to follow circular ar's. A beam particle not on the equilibrium surface will be strongly focused by a combination of centrifugal and electrostatic forces. The IFF accelerator consists of four stages. The focus voltages are progressively increased from about $25 \mathrm{kV}$ at $80-\mathrm{keV}$ ion energy to about $50 \mathrm{kV}$ at $475-\mathrm{keV}$ ion energy. After acceleration, the beam is transported to the neutralizer using two large-radius TFF stages. This transport section allows the ion sources to be out of line-of-sight of the neutron source. The last $50 \mathrm{kV}$ of acceleration between the accelerator and the neutralizer is to inhibit electron flow from the neutralizer back to the accelerator.

The laser photodetachment neutraiizer selected for MARS can achieve more than $95 \%$ stripping of the ion beam. We use a supersonic chemical axygeniodine laser (COIL). The resonator has 40 folds and a power flux of $75 \mathrm{~kW} / \mathrm{cm}^{2}$. Cooled silicon carbide mirrors with a reflectivity greater than 0.999 are used to accommodate the high flux. A 70-kW COIL is used for each beamline. The complexity, high cost, and power consumption of the laser as compared with a gas neutralizer are completely offset by the increased electrical efficiency of the beam injection system. This allows a smaller source/accelerator system. All other beamline components are also smaller and less costly than they would be if a gas cell were used. Moreover, the internal ion dump can be designed 
for very long life because of the low unneutralized currents. Energy recovery of the unneutralized beam is not required.

One of the key issues of the neutral beam system is activation of the source, heating of the cryopanels, and radiation damage to the insulators. We used the MCNP Monte Carlo code to perform an initial analys is of the neutrons streaming through the beamline and found that radiation damage to the insulators is not life-limiting. In addition, the nuclear heating in the cryopanels, laser mirrors, and magnetic shield is low enough so that it does not affect the design. We did not calculate activation of the source; however, the flux at the source is less by eight orders of magnitude than the flux at the duct entrance. Hands-on maintenance of the source may be possible within two days after shutdown. From this analysis, we conclude that the high-energy beam transport section is effective in providing neutron shielding for critical beamline components.

The sloshing-ion neutral beam system achieves an efficiency of $71.5 \%$ from wall plug to injected power. This high efficiency is a result of using a laser phciodetachment neutralizer. Significant development is needed for both the accelerator and neutializer. Of these, the TFF accelerator is more straightforward. A gas neutralizer using present technology could be used but with the expense of a decrease in efficiency and an increase in overall' system cost.

\subsection{End Plasma Technology}

The end plasma technology systems provide the functions of particle and energy removal, direct energy conversion, continuous and startup pumping, potential control, and generation of high quality heat. The subsystems included in this system are the inner collector, outer collector, inner hato scraper, outer halo vented plate, continuous-duty mechanical vacuum pumps, cryo pumps for startup, and vacuum tanks. The particle loads on the inner and outer collectors and on the halo scraper are given in Table 13 for both ends of MARS. The collector is segmented to reduce the radial potential gradient. The thermal load on these systems of $280 \mathrm{MW}$, combined with the $730 \mathrm{MW}$ from the water-cooled reflector, led us to select a coolant temperature operating range of 280 to $320^{\circ} \mathrm{C}$. A basic tradeoff in the design is the size of the components vs the heat flux. We selected a compact design with a 5 -m radius at a peak 
Table 13. Erid tani: subsystem particle loads.

\begin{tabular}{lcccc}
\hline Subsystem & $\begin{array}{c}\text { P.jtential } \\
(\mathrm{kV})\end{array}$ & $\begin{array}{c}\text { Particle } \\
\text { type }\end{array}$ & $\begin{array}{c}\text { Current } \\
(\mathrm{A})\end{array}$ & $\begin{array}{c}\text { Average particle } \\
\text { energy (keV) }\end{array}$ \\
\hline Inner collector & -167 & $\mathrm{e}$ & 1754 & 23.7 \\
& $\alpha$ (prompt) & 20.6 & 3862 \\
& $\alpha$ (scattered) & 50.6 & 942 \\
& D (sloshing) & 9.6 & 800 \\
& DT (end loss) & 73.8 & 353
\end{tabular}

Uuter collector $\quad-84$

$\begin{array}{crc}\mathrm{e} & 322 & 23.7 \\ \alpha \text { (prompt) } & 3.8 & 3691 \\ \alpha \text { (scattered) } & 9.4 & 771 \\ \text { D (sioshing) } & 1.8 & 762 \\ \text { DT (end loss) } & 13.6 & 191\end{array}$

Halo scraper

0

$\begin{array}{ccr}\text { e } & 116 & 74 \\ \alpha \text { (prompt) } & 1.4 & 3528 \\ \alpha \text { (scattered) } & 3.4 & 608 \\ \alpha \text { (drift pump) } & 208 & 50 \\ \text { DT (neoc lassical) } & 78.3 & 46 \\ \text { DT (drift pump) } & 1714 & 46 \\ \text { DT (end 1oss) } & 4.9 & 107\end{array}$

heat flux of $2.96 \mathrm{MW} / \mathrm{m}^{2}$. This is illustrated in Fig. 4. Because of the high heat flux, temperature, and associated pressure, we selected the moiybdenum alloy TZM as the best material to resist the thermal and pressure-induced stresses in the particle collectors and halo dumps. 
The inner collector is designed for a peak heat flux of $2.96 \mathrm{MW} / \mathrm{m}^{2}$. It is basically a TZM plate with a fully cooled back. It has five vertical 1.2-m-wide sectors in each end with 140 parallel coolant channels per sector. We chose a front plate thickness of $3 \mathrm{~mm}$ and a coolas: channel width and depth of 6 and $8 \mathrm{~mm}$, respectively, based on an overall stress minimization analysis. We use standard nonboiling, turbulent coolant flow at a velocity of $11.2 \mathrm{~m} / \mathrm{s}$. Pumping power is less than $0.5 \%$ of the heat removed. Stresses are less than $50 \%$ of the conservative ASME Boiler Code ailowable. Material loss from sputtering is less than $0.5 \mathrm{~mm}$ for the reactor lifetime.

The requirements on the outer collector are less severe. The peak heat flux is $1.90 \mathrm{MW} / \mathrm{m}^{2}$. The coolant routing is changed to have five coolant channels in series. Water velocity is reduced to $5.9 \mathrm{~m} / \mathrm{s}$ and pump power is less than $0.25 \%$ of the heat removed.

If the inner halo scraper were normal to the plasma, the peak heat flux would be $8.79 \mathrm{MW} / \mathrm{m}^{2}$. In our case it is inclined at more than $70 \%$ to reduce the peak heat flux to $2.52 \mathrm{MW} / \mathrm{m}^{2}$. This simplifies the heat transfer and deflects particles toward collection ports for pumping; however, it also significantly increases sputtering. Because sputtering would severely 1 imit the lifetime of a bare TZM plate, we have added thick beryllium tiles to the scraper. We have limited the peak beryllium temperature to $70 \%$ of its melting point, which-sets the tile thickness at $2.1 \mathrm{~cm}$, We obtain a scraper lifetime, set by beryllium sputtering, equal to half the reactor lifetime. Thus, the scraper is designed for periodic replacement. The TZM structure is cooled in much the same manner as the collector plates: three coolant channels are placed in saries, the maximum velocity is $14.6 \mathrm{~m} / \mathrm{s}$, and the pumping power is about $1 \%$ of the heat removed. The outer halo vented plate is subject to much lower heat fluxes and particle loads. The heat flux is $0.47 \mathrm{MW} / \mathrm{m}^{2}$. No protective coating is needed; however, the front plate has a maximum thickness of $1.4 \mathrm{~cm}$ to allow for $1 \mathrm{~cm}$ of TZM erosion over the life of the reactor. The plate has a $5 \%$ open area tha: allows a portion of the plasma flux to enter the pumping plenum. The vacuum system provides pumping to a base pressure of $10^{-7}$ Torr for startup and continuous removal of the plasma exhaust. A major change in MARS from previous tandem mirror designs is tine elimination of a large, continuous, cryopumping system for plasma exhaust. Because of the halo design, the pressure in the plenum is $4 \times 10^{-2}$ Torr, 
which is consistent with mechanical pumps. The vacuuin system is integrated with a roughing/backing section and a high vacuum section; both are used for startup. The roughing/backing section includes four compound booster pumps, each rated at $4300 \mathrm{ft}^{3} / \mathrm{min}$ at $4 \times 10^{-2}$ Torr, and each consisting of a mechanical pump and a roots blower. This system provides a base pressure of $10^{-3}$ Torr for startup and all steady-state pumping. The $10^{-7}$-Torr base pressure for startup is provided by two cryopumps, each with a speed of 55,000 liters/s. The pumping surface is double-sided with an area of $1.1 \mathrm{~m}^{2}$ per side and is thermally protected by liquid-nitrogen-cooled shields. The cryopumps are isolated from the vacuum vessel during normal operation. This vacuum system design has substantially reduced the size of the end tank and the costs of the components.

The thermal and electrical performance of the end plasma system is given above in Table 9. The overall energy conversion performance is given in Table 14.

We $c$ an see that $68 \%$ of the power entering the system is converted to electricity. If the heat were not used in the thermal cycle, thus eliminating the high pressure and TZM structure, $51 \%$ efficiency would still be achieved.

Table 14. Energy conversion performance of the end plasma system.

\begin{tabular}{ll}
\hline Core plasma power leakage, $P_{1}(M W)$ & 453 \\
Halo plasma power leakage, $P_{2}(M W)$ & 120 \\
Directly converted power, $E_{1}(M W)$ & 292 \\
Thermally converted power, $E_{2}(M W)$ & 06 \\
$\left.\begin{array}{ll}\text { Direct conversion efficiency }\left(E_{1} / P_{1}\right) \\
\text { Net direct conversion efficiency }\left(\frac{E_{1}}{P_{1}+P_{2}}\right)\end{array}\right)$ & 0.51 \\
& 0.64 \\
$\begin{array}{l}\text { Overall electrical } \\
\text { conversion efficiency }\end{array}$ & 0.68 \\
\hline
\end{tabular}


The major R\&D areas for the end plasma are in TZM brazing and machining of large size panels, sputtering and blistering of surfaces, and halo scraper performance.

\subsection{Pellet Injector}

The MARS fueling requirements of pellet velocities in the range of 2 to $10 \mathrm{~km} / \mathrm{s}$ at an injection rate of more than $6.5 \mathrm{~Hz}$ for cylindrical pellets $5 \mathrm{~mm}$ in diameter and $5 \mathrm{~mm}$ long (i.e., 10\% of the plasma ion content) are beyond the present state of the art, and significant develooments are needed. We have reviewed alternative techniques, primarily the use of centrifugal accelerators, pneumatic gun injectors, and rajlgun injectors. Of these, railguns offer the best potential for exceeding $2 \mathrm{~km} / \mathrm{s}$. We have developed a haseline conceptual railgun system.

A medium-speed centrifugal or pneumatic injector would be used as a preaccelerator for a railgun located at one end of the central cell. For optimum pellei penetration, it is desirable to inject as close to the 24-T point as possible to reduce the velocity requirement because the central cell plasma approaches a minimum radius here. A key issue in the system design is the acceleration strength of the pellet. If we limit the propulsive stress to $3 \mathrm{MPa}$, based on the tensile strength of frozen DT, we get a launcher length of $21 \mathrm{~m}$ for a velocity of $10 \mathrm{~km} / \mathrm{s}$. If we assume that a high-strength sabot can take up acceleration stresses and be separated from the pellet before injection, we get a launcher lergth of on 1 y $0.57 \mathrm{~m}$ at $300 \mathrm{MPa}$ of propulsive stress. The latter case produces severe rail heating and an optimum would be expected at an intermediate acceleration.

\subsection{Blanket, Reflector, and Shield}

The MARS blanket and reflector breed tritjum and convert nuc iear energy to useful heat. Our objectives in designing them were to minimize the cost of electricity, develop a simple maintenance system, minimize long-term radioactive waste, provide a passive safety system, and allow hands-on maintenance at the back of the shield within two days after shutdown. We aid achieve these objectives in the MARS design. 
We selected Li-Pb as the coolant/breeder. This material has a high tritium breeding potential, permits the design of thin blankets, and affords a high energy multiplication, all of which contribute to a lower cost of electricity. Moreover, the design can be geometrically simple, which helps maintenance and lowers fabrication costs. For the blanket structural materiai, we chose HT-9 ferritic steel because of its radiation resistance for long life at the high wall loading of MARS, low long-term radioactivity that allows b? ankets to be disposed of as low-leve? Llass $C$, nuclear waste, and resistance to liquid metal corrosion. The blariket has two radial zones, as is shown in Figs. 3 and 16. The front, or tube, zone has two rows of Li-Pb-filled tubes. This configuration resists interna $i$ pressurization better and $c$ an accommodate the surface heat flux and high nuclear heating as well as a thin wall. The rear, or beam, zone has a high steel fraction to enhance energy multiplication, and a low void fraction for good space utilization.

The reflector is water-cooled austenitic stainless steel with an outiet temperature of $320^{\circ} \mathrm{C}$. It is dasigned as a lifetime structure, although we have provided for its replacement in the event of failure. A reflector life $>24$ full power jears is possible because the shielding provided by the blanket reduces radiation damage to the reflector structure.

The central ceil shield is designed to protect the magnets from permanent damage and minimize the cryogenic heat load. It is composed of three regions: the innermost layer is steel and water, the middle layer is water-cooled boron carbide with a steel structure, and the outermost layer is water-cooled lead with a steel structure. An additional 15-cm-thick tiological shield between the magnets allows hands-on maintenance at the back of the shield within two days after shutdown.

An isometric view of the central cell module is shown in Fig. 26; a list of performance and design paraineters is presented in Table 15. Key issues in the design are the overall mainterance approach, blanket thermal/hydraulics (including MHO effects), liquid metal corrosion, blanket lifetime, safety under accident conditions, and waste disposal.

The overall layout takes advantage of the linear geometry of the tandem mirror to simplify the fabrication and maintenance approach. Thus, the blanket, reflector, and shield are concentric cylinders. We constrained the design by requiring that the blanket modules be light enough to handle easily by remote control and that no magnets be moved for blanket module replacement. 
These considerations resulted in the design shown in Fig. 3, 16, and 26 . The central cell has ten service stations: eight of these stations service seven modules; the stations at the ends of the central cell service eight modules each. The modules are translated axially until they are under the service station access hatch and are then removed by a simple vertical lift with an overhead crane (see Fig. 17).

Liquid metal flow and heat transfer in a tandem mirror blanket are dominated by magnetic effects that suppress turbulence, create a flat velocity profile across the tube, and cause the heat transfer to be primarily by conduction. Because the surface heat flux on the MARS first wall is low, $3.8 \mathrm{~W} / \mathrm{cm}^{2}$, the heat transfer can be accommodated. However, it is the cause of the $50^{\circ} \mathrm{C}$ difference between the bulk coolant outlet temperature and the maximum structure temperature. In addition, there is an increase in flow resistance when a conducting fluid is moved perpendicular to the magnetic field. We calculated the MHD pressure drop in the blanket to be $1.57 \mathrm{MPa}$;

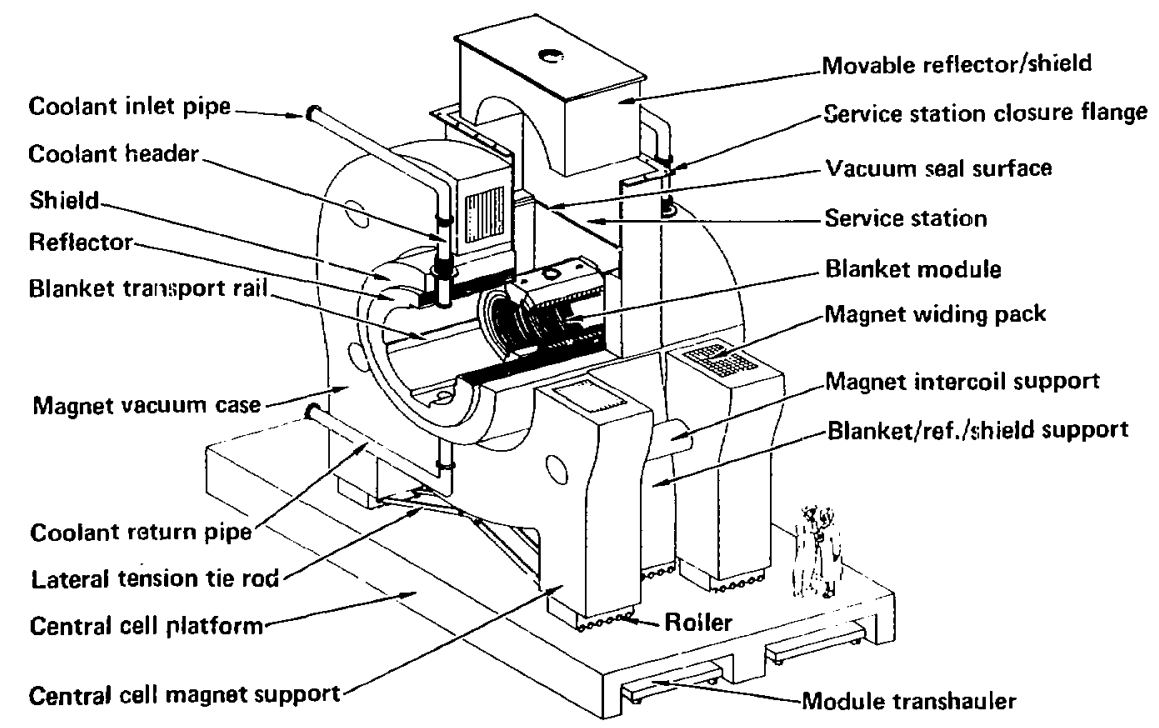

Fig. 26. Isometric view of MARS central cell section. 
Table 15. Blanket, reflector, and shield parameters.

\section{Blanket}

Extracted power (MW)

Coolant inlet/out let temperature $\left({ }^{\circ} \mathrm{C}\right)$

2081

Minimum/maximum structural temperature $\left({ }^{\circ} \mathrm{C}\right)$

$350 / 500$

Coolant velocity $(\mathrm{m} / \mathrm{s})$

$350 / 550$

First wall radius (m)

Neutron wall loading $\left(\mathrm{MH} / \mathrm{m}^{2}\right)$

0.17

0.6

Tritium breeding ratio

Tube zone thickness $(\mathrm{cm})$

4.3

$1.15^{b} / 1.12^{c}$

Beam zone thickness (cm)

19.2

19.0

Tube outer diameter $(\mathrm{cm})$

10.14

Tube wall thickness (cp)

0.23

Maximum opa rate $\left(\mathrm{FPY}^{-}\right)^{\mathrm{a}}$

61

Maximum He production rate (appm/FPy)

482

Module mass, drained $(\mathrm{kg})$

$2.73 \times 10^{3}$

Module mass, filled $(\mathrm{kg})$

$2.95 \times 10^{4}$

Reflector

Extracted power (MW)

Coolant inlet/outlet temperature $\left({ }^{\circ} \mathrm{C}\right)$

730

Minimum/maximum structural temperature $\left({ }^{\circ} \mathrm{C}\right)$

$280 / 320$

$280 / 340$

Coolant velocity $(\mathrm{m} / \mathrm{s})$

1.03

Thickness (m)

0.43

Coolant pressure (MPa)

13.8

B lanket/ref lector

Energy multiplication

1.362

Shield

Absorbed power (MW)

22

Thickness $(\mathrm{m})$

0.41

Peak nuclear heating in magnet winding pack $\left(\mu W / \mathrm{cm}^{3}\right)$

63

Peak damage rate in $\mathrm{Cu}$ stabilizer (dpa/FPY)

Lifetime thermal insuiator peak dose (rad)

$1.6 \times 10^{-5}$

Lifetime electrical insulator peak dose (rad)

Peak neutron fluence in $\mathrm{NbT} i, \mathrm{n} / \mathrm{cm}^{2}>0.1 \mathrm{MeV}$

$2.7 \times 10^{9}$

$1.4 \times 10^{9}$

$4 \times 10^{17}$

afull power year.

$b_{B}$ lanket local tritium breeding ratio.

$\mathrm{C}_{0 \text { vera }} 1$ reactor tritium breeding ratio.

this internal pressurization is a principal coniributor to blanket stresses. The maximum pressure at the first wall is $0.73 \mathrm{MPa}$. About 20 MWe are required for primary loop pumping. In the inlet and exit piping, the pipe walls are of a sandwich construction with an electrical insulator between two metallic walls. The inner wall provides a thin conducting liner that limits return 
currents, whereas the outer wall takes up the coolant pressure. Insulators are not used inside the blanket where the radiation levels are high.

We have esiimated the lifetime of the blanket to be more than 4 full power years based on stresses caused by void swelling and strain induced by irradiation creep. Because the ability to predict lifetime is very tenuous, we have scheduled replacement of modules every five calendar years, which is about 3.6 full power years. The maximum damage to the first wall is about 220 dpa at this lifetime. This high allowable value results from the use of HT-9 with its low swelling and relaxation of stresses by irradiation creep.

A key issue in the viability of the blanket concept is liquid meta' corrosion. The data on HT-9 corrosion by $\mathrm{Li}_{17} \mathrm{~Pb}_{83}$ are sparse and specir $\mathrm{c}$ to the experimental conditions. Therefore, we had to extrapolate to MARS conditions. At MARS temperatures, the corrosion rates are low enough so that wall thinning is not a concern. The critical questicn is whether we can prevent coolant passages from becoming blocked by corrosion product deposition. We have specified a cold trap system to localize deposition and to keep the primary loop below saturation at the coldest point. In addition, our analysis of corrosion product transport and deposition does not identify any egions where blocking or plugging appear to be a serious concern. Although they are not included in our present design, the use of corrosion inhibitors could potentially reduce corrosion products to insignificant. levels. In addition, desigr shanges could lower the maximum interface temperature at the expense of a small pressure increase. We believe that the corrosion product deposition problems are tractable at the present design temperature values of the MARS blanket and that methods are available to reduce the magnitude of the effects if necessary. However, this remains an area where additional data are needed.

Inherent reactor safety is a critical area for fusion that must be exploited in designs. The MARS blanket/reflector is the first design with a metallic structure that cannot melt in the event of loss of coolant and/or loss of flow accidents. The worst case is for the simultaneous loss of flow in the blanket and loss of flow or coolant in the reflector. This could occur because of a loss of site power and a failure of the emergency diesel generator. The first-wall temperature excursion is shown in Fig. 27 for this case and for loss of flow in the blanket, with flow maintained in the reflector. The melting point of $\mathrm{HT}-9\left(1420^{\circ} \mathrm{C}\right)$ cannot be reached. If blanket cooling can be resumed within 3 to 4 hours, which will keep the structure below $800^{\circ} \mathrm{C}$, 


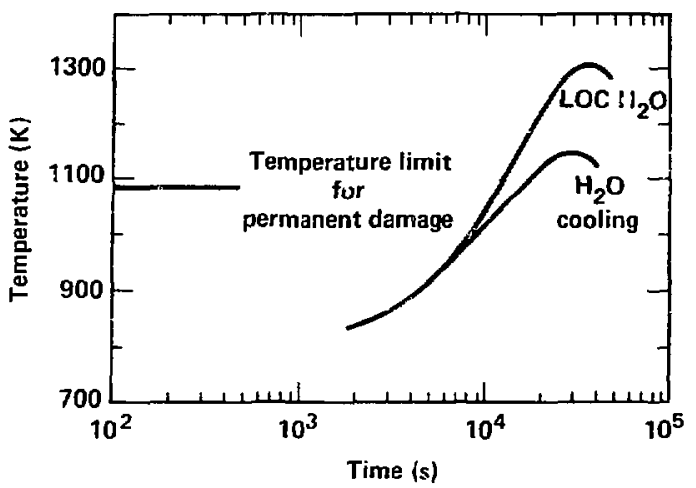

Fig. 27. Temperature response of the MARS first wall to loss of coolant and loss of flow.

the metal will not be permanently damaged and operation can be resumed. This pessive safety feature in fusion reactor designs is unique to MARS.

The MARS blanket, shield, and reflector have satisfied all design objectives and are consistent with a high-efficiency thermal conversion system. The combination of high thermal efficiency and high energy multiplication allows a reduction in fusion power and cost of the fusion island for a given electrical output. The raiio of gross electric output to fusion power is almost $60 \%$ in MARS as compared with just over $40 \%$ in a standaro tokamak reactor. Much of this is a result of blanket performance.

\subsection{Heat Transport and Energy Conversion}

The heat transport and energy conversion system includes the three primary loops: blanket L.i-Pb loop, reflector water loop, and end tank water loop. An optimization of cost-per-unit of electric power generation led to a decision to have two independent cycles. The Li-Pb loop couples to a superhi ated, single-reheat, extraction steam cycle. The water ioops drive a saturated steam cycle similar to that for a pressurized water reactor. This system includes piping, pumps, economizers, steam generators, superheaters, reheaters, cold traps, tritium removal system, and drainage/melting tanks for the Li-pt loop. The water loop includes piping, pumps, economizers, steam generators, the pressurizer, and water cleanup systems. 
The key feature in this system is the use of double-walled heat exchangers for tritium isolation between the Li-Pb and secondary water loops. The tube construction, shown in Fig. 28, has two tubes in close contact. A heiium purge flow with 1 Torr of oxygen flows between the tubes to create self-healing oxide barriers to tritium permeation through the tube walls. The tritium that diffuses into the gap is oxidized to $T_{2} 0$ to prevent further permeation. The effectiveness of the system depends on rapid oxidation of $T_{2}$ to $T_{2} 0$ in the gap or on keeping the partial pressure of $T_{2}$ in the $\mathrm{Li}-\mathrm{Pb}$ very low. Validation of the double-walled heat exchanger for tritium isolation needs an experimental basis, as does the heat transfer for this design. Methods to validate tritium pressure control in the Li-Pb also need experimenta? validation.

\subsection{Tritium Systems}

The tritium systems comprise a wide range of functions that include separating tritium from the Li-Pb breeder and plasma exhaust gases, purifying it for reinjection into the plasma, and ensuring that tritium does not leak into the environment. An overview of the fueling system giving tritium and

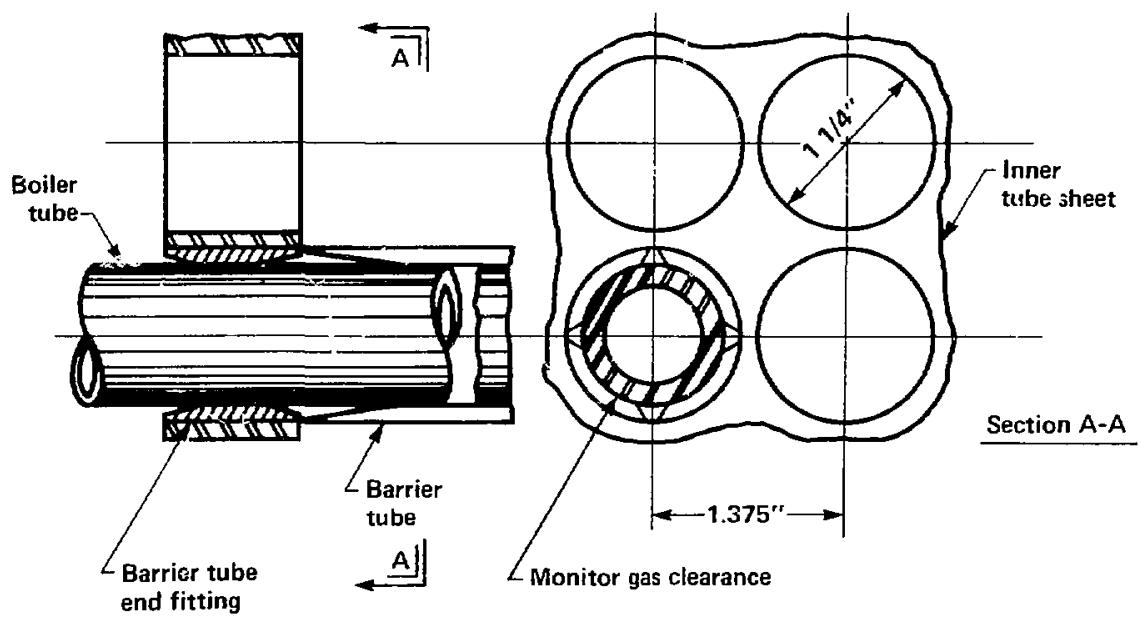

Fig. 28. Tube construction for the double-walled heat exchanger. 
deuterium flow rates is presented in Fig. 29. The principal parameters of the system are given in Table 16.

The system that removes tritium from the $\mathrm{Li}-\mathrm{Pb}$ is important because of its potentially high cost and the need to keep the partial pressure of tritium in the Li-Pb very low. Based on an optimization study, we selected vacuum degassing of a droplet spray for the tritium removal system (TRS). Twenty percent of the coolant mass $f$ low is diverted to the TRS; the removal system is $53 \%$ efficient. The equilibrium tritium concentration entering the steam generator is $4.56 \times 10^{-4}$ wpm and the resultant tritium partial pressure is $8 \times 10^{-5}$ Toir. This is conjistent with an effective barrier in the double-walled heat exchangers of about $3 \times 10^{4}$.

The fuel processing system includes the pellet injector, plasma exhaust pumps, fuel cleanup unit, isotope separation system, tritium waste treatment, fuel blender, and fuel storage, as shown in Fig. 29. These systems contain most of the tritium inventory in the plant and are important because of safety, cost, and performance. The fuel cleanup (FCU) system separates

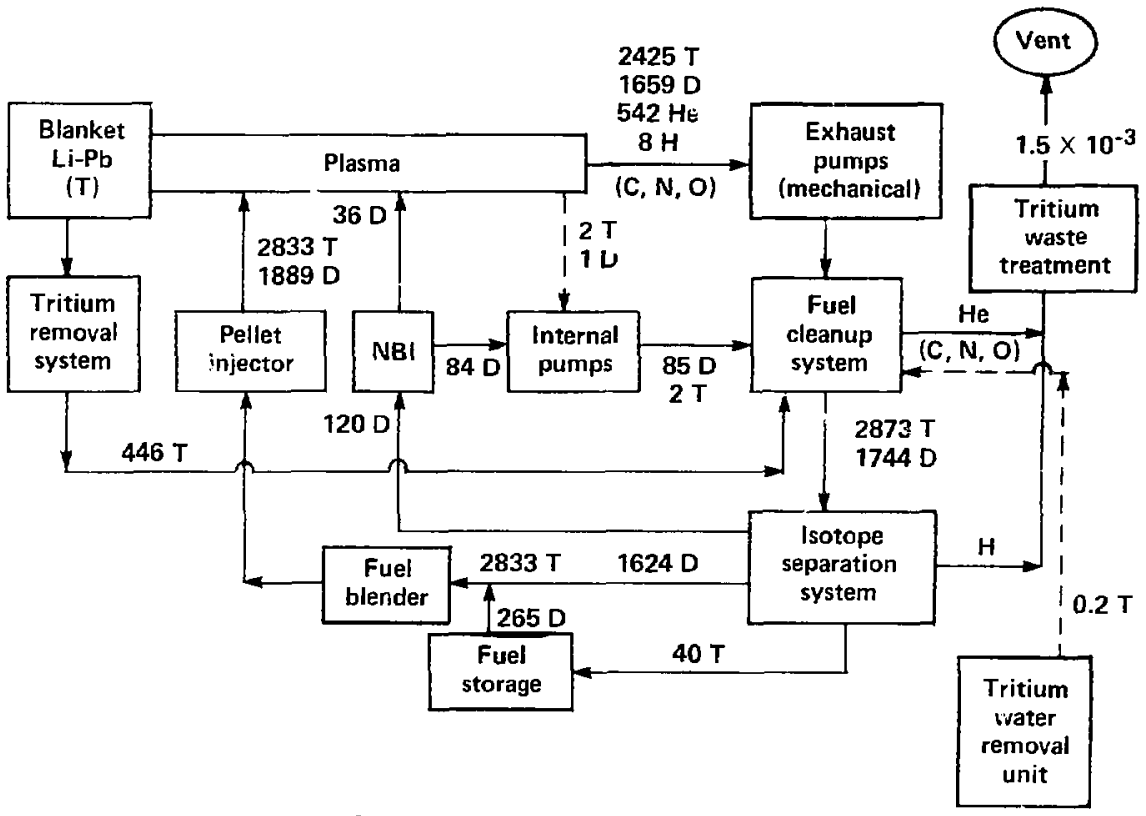

Fig. 29. MARS tritium flow. 
Table 16. Principal tritium parameters far MARS.

Fusion power (MW)

Tritium burn rate ( $\mathrm{g} /$ day)

Tritium injection rate ( $\mathrm{g} /$ day)

Burn fraction (\%)

Blanket breeding ratio

Tritium inventory in blanket $(g)$

Total tritium inventery in primary loop (g)

T, itium partia: pressure (Torr)

Extraction method

Sidestream fraction (\%)

Tritium recovered (\%)

Heat exchange containilent method

Barrier factor

Total site inventory $(\mathrm{g})$

Vulrarable site inventory ( $g$ )

Tritium release to environment ( $\mathrm{C}$ i/day)
2600

400

2833

14

1.15

1.0

7.5

$8 \times 10^{-5}$

Vacuum degassing of droplet spray 20

53

Double-walled with $\mathrm{He} / \mathrm{O}_{2}$ purge

$10^{5}$

3087

$<50$

15

hydrogen isotopes from the plasma exhaust. The entire stream is passed to the $\mathrm{FCl}$, which is designed to remove impurity molecules containing carbon, nitrogen, oxvgen, heavy metals, and most of the helium. It also decomposes compounds containing tritium, such as $\mathrm{CT}_{4}$ and $\mathrm{NT}_{3}$. The $\mathrm{FCU}$ design is based on technology being developed at the Tritium System Test Assembly (TSTA) at Los Alamos National Laboratory, Los Alamos, NM, using type $5 \mathrm{~A}$ molecular sieves. The last stage of the FCU separates helium from hydrogen. This is currently envisioned as being by evaporation from a falling liquid film.

The isotope separation system (ISS) uses cryogenic distillation to prepare three product streams: a pure OT stream for direct supply to the injector, a nearly pure $T_{2}$ stream to the fuel biender, and a nearly pure $\mathrm{D}_{2}$ stream for the neutral beam and fuel blender. The ISS design is also based on TSTA technology.

The fuel blender mixes deuterium and tritium to achieve an atomic ratio of unity. The blending tanks contain agitators for good mixing and an online mass spectrometer to verify the composition. 
The tritium waste treatment system removes tritium from FCU and ISS effluents by catalytic oxidation. Its primary function is to iimit the tritium loss to the environment.

The fuel storage vault contains tritium as $U T_{3}$ on metallic beds. Our baseline for a one-day supply is $2.8 \mathrm{~kg}$ in the beds.

It is necessary to remove tritium that permeates into end-tank cooling water to keep the concentration below $\mathrm{I} \mathrm{Ci} / \mathrm{kg}$. It is also necessary to remove tritium from the condensate in the atmospheric detritiation system. Other sources of water that may need tritium removal are the reflector coolant and double-walled heat exchanger purge system. Several techniques were evaluated for the tritiated water removal unit. Based on cost and power consumption, we selected a front-end electrolysis process followed by cryogenic distillation. This system requires only $420 \mathrm{~kW}$ of auxiliary power for the electrolys is unit and $100 \mathrm{~kW}$ for the cryogenic unit.

Removal of tritium from the building atmosphere is a continuous process that is needed to minimize tritium loss to the environment. The system is sized to keep the steady-state concentration at $50 \mu \mathrm{Ci} / \mathrm{m}^{3}$. This leve 1 requires workers to be protected by bubble suits. The atmospheric detritiation system is also used to clean up the reactor hall atmosphere in the event of a spill. All six units would be used to bring the level to $500 \mu \mathrm{Ci} / \mathrm{m}^{3}$ within 2.4 days after a release of $2 \times 10^{5} \mathrm{Ci}$ (the inventory of the pellet fueler). MARS has a very low vulnerable tritium inventory because $0^{\circ}$ the selection of a Li-Pb breeder and the use of mechanical pumps for plasma exhaust. The plant inventory is presented in Table 17. The total inventory outside the storage vault is $254 \mathrm{~g}$. Of this, we estimate less than $50 \mathrm{~g}$ is vulnerable and the maximum credible release is about $20 \mathrm{~g}$.

\subsection{Cryogenic System}

The cryogenic system is designed to accommodate all startup and steadystate loads for the reactor. The cryogenic loads are given in iable 18; we have sized the systems to allow $20 \%$ over capacity. Cooling and liquid production are performed simultaneously. Neutron-induced heating of the coils is a major contributor to the helium loads, and accourits for $63 \%$ of the LHe I load and $y 0 \%$ of the LHe II load. The cryoplant design for the LHe $I$ and $L N_{2}$ systems is based on the plant being built for MFTF-B. It has an efficiency of $430 \mathrm{~W} / \mathrm{W}$ for LHe 1 and $12 \mathrm{~W} / \mathrm{W}$ for $L N_{2}$. Little data exist on 
large LHe II plants. We have based the MARS plant on a design for the Stanford Linear Acceierator Center. To minimize the distribution losses at $1.8 \mathrm{~K}$, the final heat exchangers are placed in the magret service stacks. The estimated system efficiency is $1720 \mathrm{~W} / \mathrm{W}$.

Tabie 17. MARS tritium inventory.

$\begin{array}{cc}\text { Suissystem } & \text { System } \\ \text { inventory } & \text { inventory } \\ (\mathrm{g}) & (\mathrm{g})\end{array}$

\begin{tabular}{lr} 
Reacior hall and steam generator building & \\
\cline { 1 - 2 } Fuel pellet injector & 20.4 \\
Keactor exhaust pumps & 0.1 \\
Li-Pb coolant/breeder & 7.5 \\
Water coolant (1 C $\mathrm{i} / 1$ iter & 21.6 \\
Neutral beam injector cryopanels & 1.0 \\
End cell structure & 18.0 \\
Central cell structure & 0.8 \\
Reactor plasma & 0.1
\end{tabular}

Tritium process building

Fuel cleanup unit.

22.4

Isotope separation system

162.0

69.5

0.4

7.5

1.6

1.0

0.8

0.1

Storage vault (1-day supply) 2833

$\begin{array}{ll}\text { Total on-site inventory } & 3087\end{array}$

Table 18. Cryoplant requirements.

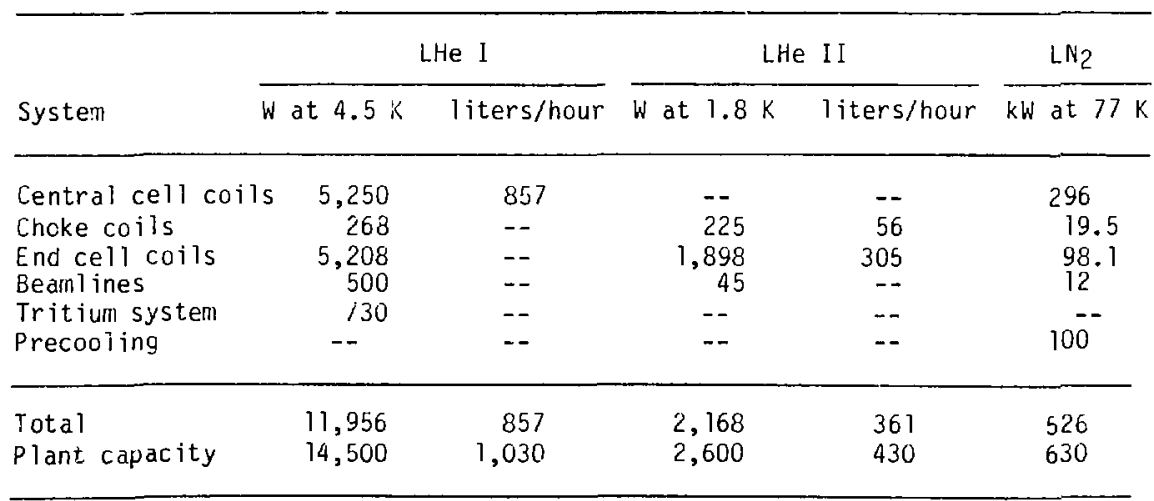




\section{Balance of Plant}

An artist's conception of the MARS power plant is shown in Fig. 1. The plant systems are essentially conventional. However, the general arrangement of buildings and functions takes into account the linear nature of the tandem mirror and uses the open access to advantage. One side of the central cell contains all facilities for new, replacement, and spent equipment, whereas the other side contains the energy conversion systems. The site selected for MARS is "Middletown," U.S.A. and, for the purposes of labor statistics, it is assuned to be near Kansas City, Missouri. The site is within Uniform Building Code (UBC) Seismic Zone 2; this provides criteria for seismic design of the ctructures. The single unique feature of the balance of plant is the use of two independent power cycles, as discussed in Sec. 4.10. The superheated steam cycle is designated Unit 1 while the saturated steam cycle is called Unit 2. The MARS plot plan is shown in Fig. 30.

We have separated the MARS facility buildings into two groups: those that are safety-relicted and those that are not. The safety-related buildings are designed using a stringent set of codes that encompass NRC regulations and sustain earthquake forces, tornado-generated forces and missiles, accident temperatures and pressures, and operating loads. The e builitings are the reactor hall, steam generator hall, hot cell, spent blanket pool, tritium building, control building, and diesel generator building.

The reactor building has $60-\mathrm{cm}-$ thick reinforced concrete walls and roof, stiffened with concrete frames $180 \mathrm{~cm}$ deep and $100 \mathrm{~cm}$ thick, spaced on 10-m centers. The steam generator and tritium buildings have a 70-cm-thick roof, 60-cnl-thick walls, and a structural steel interior framing. The floors and surrounding walls of these buildings are steel lined to a height of $60 \mathrm{~cm}$. The building's interior surfaces are sealed with epoxy paint against tritium leakage and are operated at a subatmospheric pressure of $-5 \mathrm{~cm}$ of water. We were able to reduce the load conditions on the reactor hall because of a low internal overpressurization under accident conditions.

The secondary loop energy conversion cycles convert the steam generated in the heat transport system to elnctric power. The Unit I system consists of high-pressure, intermediate-pressure, and three low-pressure steam turbine cylinders and a hydrogen-cooled electric generator arranged in tandem. There is a single, reheat between the high- and intermediate-pressure turbines. All turbines have nozzles for bleeding extraction steam to feedwater heaters and stean generator feed pumps. The Unit 2 system has high and low pressure 

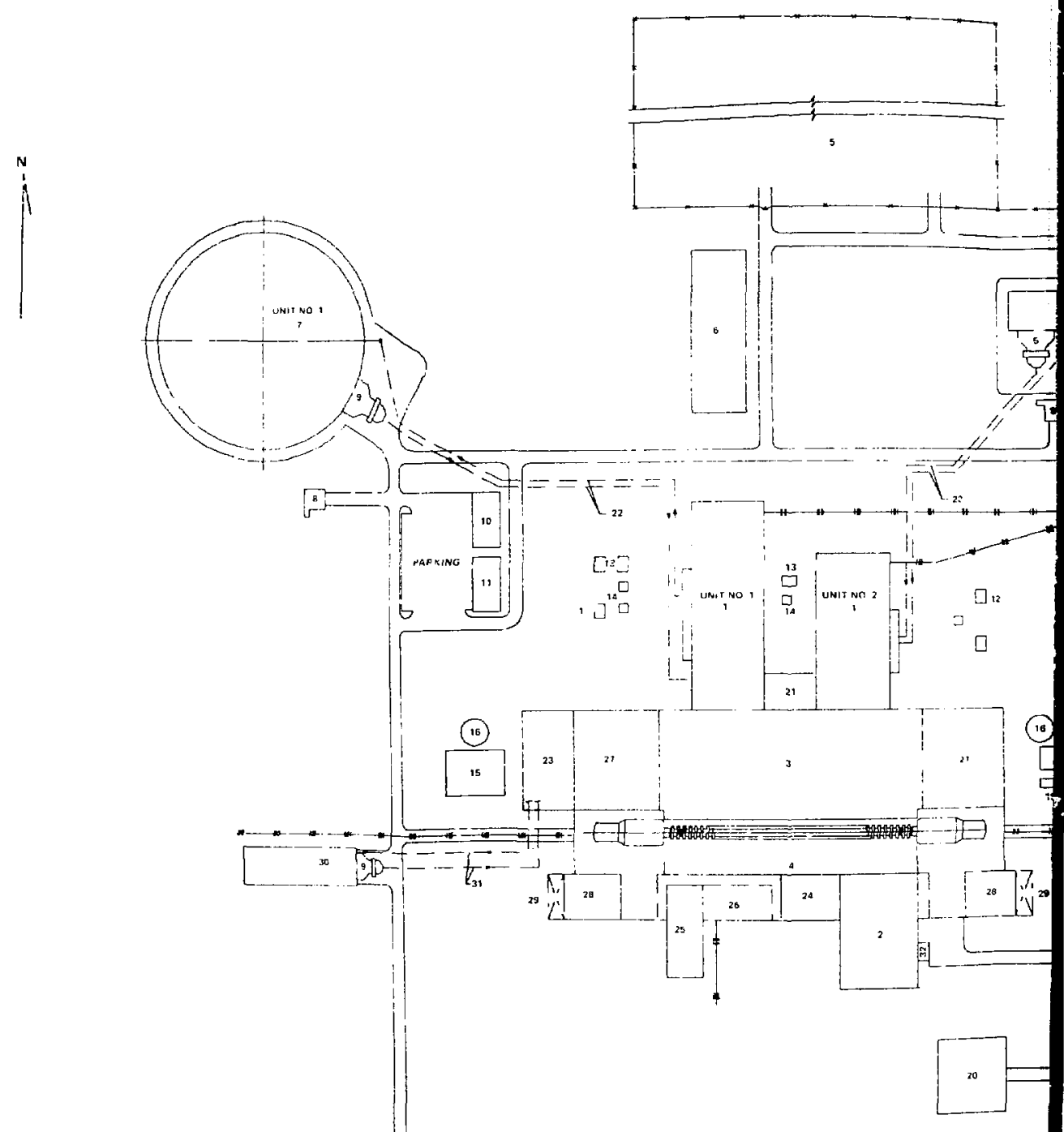

Fig. 30. Maks plot plan. 

turbines connected in tandem to a hydrogen-cooled electric generator. There is a moisture-separator-reheater between the two turbines. Steam extraction is used for feedwater heating. The performance of the turbine-generator systems is presented in Table 19. Overall efficiency of the combined system is about $40 \%$.

Heat rejection from the cycles is from cooling towers. A hyperbolic ratural draft tower is used for Unit 1 and a mechanical draft tower for Unit 2.

The MARS electrical systems are designed to interface the two generators with the electric utility grid, to provide the auxiliary power for startup and normal operation, and to provide standby emergency power. The recirculating power requirements for normal operation are presented in Table 20 . The

Table 19. MARS turbine generator performance.

\begin{tabular}{llc}
\hline & $\begin{array}{c}\text { Superheat } \\
\text { cycle } \\
\text { Unit } 1\end{array}$ & $\begin{array}{c}\text { Saturated } \\
\text { cycle }\end{array}$ \\
\hline Unit 2 \\
Throttle flow $\left(\mathrm{kg} /\right.$ hour $\left.\times 10^{6}\right)$ & 3.15 & 1.83 \\
Throttle temperature $\left({ }^{\circ} \mathrm{C}\right)$ & 479.4 & 277 \\
Throttle pressure $(\mathrm{MPa})$ & 16.65 & 6.21 \\
Reheat temperature $\left({ }^{\circ} \mathrm{C}\right)$ & 482 & 346.9 \\
Gross generation $(\mathrm{MWe})$ & 892.8 & 33.83 \\
Gross efficiency $(\%)$ & 42.04 & 10642.1 \\
ivet turbine heat $\mathrm{rate}(\mathrm{kJ} / \mathrm{kWh})$ & 8563 & \\
\hline
\end{tabular}

Table 20. MARS recirculating power.

Equipment description Operating load (HiW)

ECRH-B power converter ELRH-A power converter Neutral beam injection Anchor ICRH

Magnets

Drift pumips

Helium I compressor

Helium II compressor

Nitrogen reliquifiers

-i-Pb pumis

other plant auxiliaries
106.2

9.1

14.1

28.8

81.5

20.0

5.2

3.7

6.7

21.0

38.2 
dominant contributors to the $334 \mathrm{MW}$ of recirculating power are the supplemental heating systems $(158 \mathrm{MW})$ and the resistive magnets, including drift pumps (101 MW).

\section{Plant Construction}

The design of clie MARS plant is amenable to a rapid construction schedule. We have developed an optimistic schedu? site work to first commercial operation. We have assumed that the site is lever to gently rolling, within UBC Seismic Zone 2, with adequate water available for make-up, and located close to existing major access roads, rail lines, and an inland waterway. Construction schedule durations have heen based on construction and procurement lead times in the nuclear power industry. We also assume multishift operations and maximum use of preassembled components, either on site or at vendor shops. The schedule does not include site selection or acquisition, nor do environmental studies and licensing constrain the construction schedule.

The critical path for construction is the reactor building, which requires 33 months of initial work before the reactor can be assembled. Reactor installation begins when construction of the reactor building has progressed to a point where the roof is completed. The building requires 24 months to complete. We use parallel assembly of the central cell and end celis. This approach is consistent with the linear nature nf MARS and the layout of the reactor building. Subsystem testing will be initiated in the fourth year of construction both at vendor locations and at the reirtor site as the equipment arrives. There is a total of 24 months of subsystem anit startup testing before commerical operation. The last 12 months are devoied to fully integrated testing of the reactor. A top-level construction schedui? is presented in Fig. 31 .

\section{Plant Operations}

Plant operations include maintenance, plant operation, and normal startup and availability modeling. 


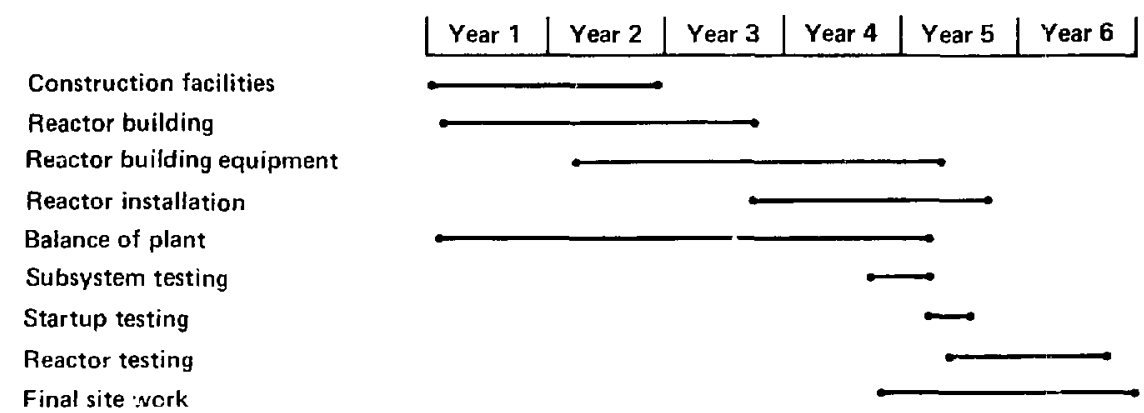

Fig. 31. Sirmplified MARS construction schedule.

\subsection{Maintenance}

The maintenarice design for MARS has three basic objectives:

- Capability for totaliy remote maintenance, but with sutficient shielding for hands-on operations;

2. Minimized downtime for schediled maintenance;

3. Capability to replace any reactor component in the event of an unexpected failure without excessive downtime. The central cell and end cell are separated by gate valves and temporary shielding to allow persornel in the end coll area when the central cell is upened.

The two major systems that require periodic replacement aro the blanket modules and choke coil resistive inserts. We have developec detailed timelines for servicing these systems.

Each year the blanket moaules at two or triree service stations will be reflaced. Parallel operations are planned for each service station and sufficient equipuent is providea for three parallel operations. The timeline for this is presented in $\mathrm{Fig}, 32$, which shows a requirement for 10.3 days from shutdown to the beginning of startup. The first 2.5 days are for reactor silutdown, during which time the magnets are deenergized and the blanket mcdules are couled and drained. After this time the headers and vacuum cover are removed; radiatiun levels are low encough to pernit manual assistance. 


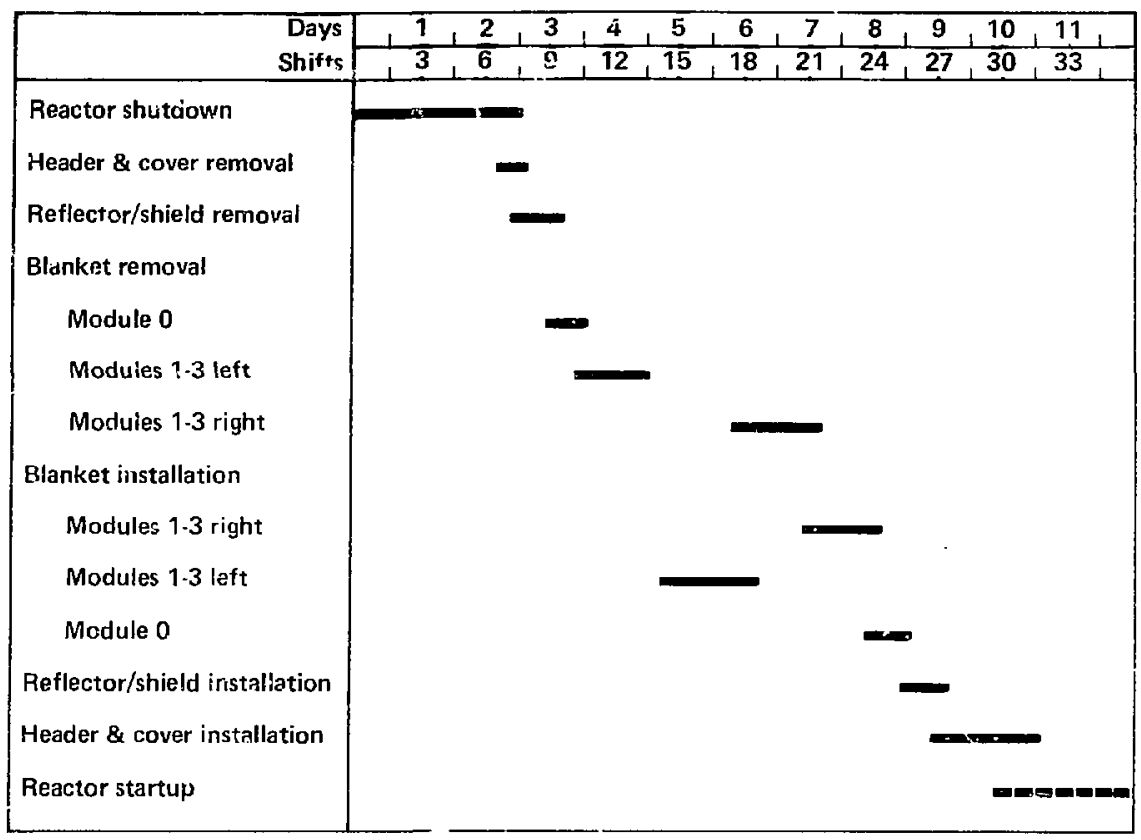

Fig. 32. Blanket moduie replacement timeline.

The reflector and shield plug in the service station are removed by a simple vertical lift. In a sinilar fashion, blanket module 0 , which is directly under the access port, is removed. The modules to the side of the service station are translated axially using a worm screw actuator and are then lifted vertically out of the reactor. The leverse process is used for module installation.

We performed a similar analys is and developed a procedure for replaciriy the choke-coil normal-magnet insert. The entire choke coil assembly is rolled aut on rails. The insert is removed and a new insert installed using a floormounted remote machine. This operation can be accomplished in less than two 
days. However, the insert would be replaced in conjunction with blanket replacement because their lifetimes are similar. An increase ir change-out time would not affect overall performance.

In the unilikely event of a failure of a central cell, end cell cuil, or other major lifetime component, we have designed the system to accommodate remote change-out of any damaged component. Tr.e central cell contains segmentation points where a section containing two magnets and the associated blanket: reflector, and shield modules can be removed. A spare central cell segmint is included in the MARS equipment list. The central cell module is removed on permanent rails anbedded in the floor; end cell magnets are removed through the direct converter end dome using the same transiiaulers used during machine fabrication.

\subsection{Reactor Operation}

The operation of MARS as a power plant involves several issues in addition to steady-state operation. These include pre-operational testing, initial commissioning, startup procedures, operation and testiny at fractions of full power, and shutdown. After pre-operational tesing and initial commissioning, the four phases of operation will be repeated over the reactor life. Startup may be ejther from a cold shutdown mode (Plase IA) when the blankets are drained, the coolant stored, and the mayreis deenergized and warmed; or from a hot shutdown mode (Phase IB) when power conversion components and their coolants are maintained near their operating tenperatures and pressures. Phase 11 includes system testing, plasma initiation, and a standby power mode at typically less than $5 \%$ of raieo power. In Phase III, staged power ascension tests are conducted at several levels. These are typically 0 to $20 \%$ of full power, $20 \%, 50 \%, 80 \%$ and $100 \%$. This phase is expected to take 6 nonths for initial startup. Phase IV is rated power operation.

Because MARS has a liquid metal blanket, special startup procedures are necessary to avoid thermal shock and stress to the system. For cold startup, ve use a helium gas preheat system to condition the primary loop to a uniform temperature of $350^{\circ} \mathrm{C}$. This requires about 30 hours. After conditioning, $\mathrm{L}$ i-PD is pumped from the storage tank and the primary loop is filled. We 
first fill half of the primary loop, then the blanket from bottom to top, and finally the remaining half of the piping. The temperature in the loop is held constant by pump heat and resistance strap heaters. In startup from hot shutdown, the time period is expected to be much shorter.

In Phase II, much of the activity will be associated with plasma and plasma systems, including supplemeital heating, arift pumping, and direct converter testing. This will be done at as low a power level as possible. During staged power operation--Phase ill--three tests will be performed at each power lever. These are turbine trip, loss of load, and loss of flow. The purpose of the testing is to validate safety analysis models and to collect data on performance under thes transient conditions. During the tests, flow conditions are monitored in both the frimary and secondary loops and strain gauge measurements ior $i$ atigue and vibration analysis are taken. At the 20\% power plateau, the illitial turbine roll is established and steam cycle performance is validated. At each plateau level, coolant chemistry, primary coolant radioactivity, neutron leakage, and corrosion data wie monitored in detail. At the $50 \%$ level, offsite power is removed by isolating the startup transformers. The turbine is tripped and blackout conditions are maintained for 30 minutes. All emergency power systems are tested. The ability to respond to a load decrease is validated at the plateaus and a full loss-of-load transiel. is initiated at 100\% power.

The startup of the MARS power plant is similar to nther fossil and nuclear systems with the exception of the plasma systems and the liquid metal blanket. The only additional system needed for the blarket is the helium preheater.

\subsection{Availability}

The availability of the MARS plant has been assessed to determine which subsystems and components have the largest effect on availability, to evaluate how installed component redundancy ca.i improve availability, to deternine where minimizing component reazir or replacement times will improve reliability, and to support computation of the cost of electricity. All systems in MARS were designed for a lifetime consistent with $80 \%$ availability, specifically, 24 full power years. We performed a bot.toms-up estimate of availability for 
the system. For each major component, the system designer estimated the mean time between failure (MTBF) and mean time to repair ( $M:{ }^{r} R$ ); and the project team reviewed the estimates for consistency. A standard availabiliiy analysis was then performed under the assumption that all failures were uncorrelated and that no credit would be taken for planned outages to improve availability. This analys is also includes failures in the supplemental heating systems that degrade system performance.

The resu. is of the analysis indicate a best-estimate availability of $73 \%$ with a 30-day annual scheduled maintenance outage. If the annual shutdown could be recuced to 20 days, the availability would increase to $75 \%$. The analysis alco showed that installed redundancy in the neutral beam and ECRH system:s is necessary to achieve adequate availability. This provision has been included in the design. The five subsystem groups that have the largest effect or availability are presented in Table 21 . Even with redundancy, supplemental heating is stil? the largest contributor in the reactor systems. An Estimate of MARS availability based on component reliability and repair times indicates the potential for an excellent system, with a computed availability factor of 73 to $75 \%$. With additional work on subsystem designs, we believe the $80 \%$ goal could be reached.

Table 21. Factors affecting reactor avajlability.

Subsysten' group

Supplemental heating systems

Turbine and generator

- lectrical equipment

cryogenics

B lanket, reflector, and

service station

Normal conducting magnets
Unavailability effect

(\%) 


\section{Environment and Safety}

MARS has been designed to minimize adverse effects on the environment through normal releases of radioactivity, exposure to workers, releases under accident conditions, and waste management. In addition, we nave developed a design that has high inherent safety. That is, minimal active measures are required to ensure safe operation of MARS. The materials and operational parameters have been selected to achieve this safety goal.

\subsection{Radioactivity}

We have addressed several issues under the general title of radioactivity in MARS. These include blanket, reflector, and shield activation to quantify afterheat, coolant activation, biological dose at the back of the central cell shield and the end ceil shield, and radioactive waste manangement.

The afterheat in the central cell is the principal source of energy that must be removed in the event of loss of coolant or loss of flow accidents, discussed in Sec. 4.9. Our analysis showed that the blanket cannot melt from: the worst case combination of these causes. Initial afterheat from the structure is about $4 \%$ of the steady-state, centril-cell thermal puwer. It is dominated by ${ }^{56} \mathrm{Mn}$ with a 2.58 -hour half-life, ant drops to about $0.06 \%$ of the steady state one day after shutdown.

We evaluated activation of the coolant as a contributor to central cell afterheat, for long-term waste disposal, and as a source of 210 po. polonium-2lu is an energetic alpha emitter $\left(E_{\alpha}=5.3 \mathrm{MeV}\right)$ and has a relatively short half-life $\left(t_{1 / 2}=138.88\right.$ days $)$. It is also highly volatile in air and thus could pose a significant hazard if it is released to the environment. Poloniull-2lo is produced from lead and from bismuth impurities in lead by the following reactions:

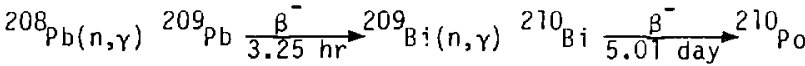

$$
\begin{aligned}
& { }^{209} \mathrm{Bi}(n, \gamma){ }^{210} \mathrm{Bi} \underset{5.01 \mathrm{day}}{\stackrel{\beta^{-}}{2}}{ }^{10} \mathrm{Po} \text {. }
\end{aligned}
$$

The initial production rate from the bismuth impurity 10.0042 wt\% for electrolytic lead) is about $6 \mathrm{mCi} / \mathrm{s}$. This rate increases linearly with time, 
doubling in about 8 to 9 years, from tie double capture reaction. Because of the hazard, we continuously remove 210 po from the coolant in the tritium recovery system. This is possible because the vapor pressure of 210 po at $500^{\circ} \mathrm{C}$ is 2 Torr. The equilibrium activity of $210_{\mathrm{Po}}$ in the coolant near tine beginning of 1 ife is estimated to 1 ie between 90 and $20,000 \mathrm{Ci}$, depending on the chemical activity of polonium in $L i-P b$. This value will increase in proportion to the production rate.

The central cell shield is designed for nands-on access at the rack of the shield within 1.5 days after shutdown. We evaluated several shielding criteria that are consistent with hands-on maintenance and selected a requirement that a maintenance worker receive no more than 100 mrem in a standard week that commences 1.5 days after shutdown. This is within present NRC 10CFR2U regulations, ailows prompt access to the shie?d, and causes minimal cost pendties for the shield. However, because of this restriction, the final biological shield is of aluminum construction.

We collputed the dose at the wall of the eid cell vacuum tank for two conditions: (1) behind the majnets and structure and (2) where there are line-of-sight paths to the vessal without intercepting a magnet. In the former case, the cose is low enough to allow access at shutdown. In regions corresponding to the seccond case, $65 \mathrm{~cm}$ of concrete shielding was added to a) low access in within 2 days.

we paid particular attention to radioactive waste management with the goal of achieving near-surface disposal of all compunents according to NRR regulations (IUCFR61). We evaluated the tlankets, choke coil insert, direct converter, and coolant. The ferritic steel blanket structure has severa? dovantayes relative to standard austenitic steels for waste management because of its lower llolybdenum fraction, very low nickel fraction, and no intentional use of niobium. We performed a detailed analysis of blanket activation and requirements for disposal. The MARS blarket can be disposed of as $c l a s s ~ C$ low-level waste by encasing it in concrete after a short period of cooling in the reactor spent-blanket pool. As an alternative, we also investigated low-cust isotopic tailoring of the molybdenum to be used in HT-9. We found that, for a $13 \%$ increase in blanket cost, we could dispose of a compacted blanket structure as Class $C$ waste without concrete encasement. This allows a 14-fold reduction in the volume of the waste. The MARS design is the only steel blanket to date that achieves this degree of low activation. 
The direct converter TZM structures, taken together, would qualify as Class $A$ waste. The inner collector alone would be $C$ lass $C$; however, compacting and mixing all of the TZM yields Class $A$ waste.

The coolant, as extracted from the reactor, would qualify for Class $C$ providing that processing is used to reduce radioactive silver and bismuth contents by a factor of 27 . Because the coolant is a large capital investment, it is likely to be used in subsequent plants and not be discarded at the enc uf plant life.

Because neutron transmistations of copper in the choke coil insert produce ${ }^{53} \mathrm{Ni}$, the coil is not suitable for near-surface burial. There are three aptions for disposing of the choke coil: (1) deep geologic burial, which is economically acceptable because of the low volume; (2) dilution by a factor of 6 to 12 between 5 and 300 years after removal from the reactor; or (3) interim storage for about 360 years at which time it qualifies for Class C (700 years for Class A).

We conclude that the radioactive waste requirements for MARS can DE made to fall into either Class $C$ or Class A catagories. Deep geologic burial may be used for some selected components for economic reasons, but it is not required.

\subsection{Normal Radioactivity Releases}

There are three sources of ncrmal radioactivity release from MARS. Two of these are associated with tritium. The rormal release up the stack is less than $15 \mathrm{Ci} /$ day, as discussed in $\mathrm{Sec} .4 .11$. The loss through the double-walled heat exchangers is less than $10 \mathrm{Ci} /$ day, assuming oxidation of $T_{2}$ in the "3p between the tubes. The tritium that gets into the secondary loop is not directly lost to the environment. The thiru source of no:mal radioactivity r lease is direct radiaticn when the plant is operating. MARj has been designed to meet present NRC site boundary dose regulations. The expected levels are innocuous.

\subsection{Satety}

We performed a safety analys is of MARS under certain chosen accident conditions, in which we found that the radiation releases were far below NRC accident limits because the design includes safety systems and barriers. The accident conditions considered were: (1) release of activated struct.ure; 
(2) release of activated corrosion products; (3) release of the activated coolant; and (4) release of tritium. For these arialyses we pcstulated releases into the containment building and evaluated the effect of iraech of containment. In many cases. te could not identify any credible mechanisms that wi!ld lead to these releases. The reslittant doses have been caiculated in the everit that a credible release ncchanism can be pristulated.

The results of these aidi:;es ar.. shown in Tuble 22 . The column titled "Containment failurg" inplies tizat the pirticle filters and atmospheric tritium removal systems are inoperative at the time the release occurs. With the contaiment building intact and saficy systems operating, the site boundary doses are very low. Ever if the fiitering systems fail, we are still well below the present NRC g!ujeline of 25 rem fur fission plants. We conclude that MARS is an inherently soffe plant.

iabie 22 . Site youndary doses urider worst-case accident conditions.

\begin{tabular}{|c|c|c|}
\hline \multirow[b]{2}{*}{ Occurrence } & \multicolumn{2}{|c|}{ Site boundary dose (rem) } \\
\hline & Containment intact & Containment failure \\
\hline $\begin{array}{l}\text { Release of activater structure } \\
\text { Full blanket } \\
\text { One nodule }\end{array}$ & $\begin{array}{l}3.2 \times 10-5 \\
1.2 \times 10^{-6}\end{array}$ & $\begin{array}{l}0.1 \\
4.6 \times 10^{-3}\end{array}$ \\
\hline $\begin{array}{l}\text { Retease of activateo corrosin } \\
\text { products. }\end{array}$ & $8 \times 10^{4}$ & 2.6 \\
\hline $\begin{array}{l}\text { R+lease of } T_{2} \text { in } \\
\text { pellet injector }\end{array}$ & $6 \times 10^{-5}$ & 0.016 \\
\hline Releast of coolant activation & -- & 0.024 \\
\hline
\end{tabular}

\section{Economic Analysis}

The MARS cast and economic analyses provide a etailed breakdown of the capital and operating costs for a tandem-mirror commercial power plant and the resultant cost if electricity. These have been developed consistent with t? 
1978 DOE guidelines, ${ }^{27}$ which facilitate comparisons with other fusion reactor studies. We have also used methods of establishing time-rolated costing that are closer to present utility practices.

The direct capital costs were developed for a first-of-a-kind commercial reactor. This assumes that the equipment research and development costs are not included in the capital costs, but are borne by the demonstration reactor or auxiliary programs. The final costs for MARS are for a tenth-of-a-kind capital cost estimate througl the application of learning curves tiat were applied on the subsystem or component level. These curves quantity a reduction in unit cost of a product as the number of manufactured units increases. The degree of learning, and thus cost reduction, is largest for systems or aperations that are labor-intensive in their production, e..., magnet winding. We have been quite conservative in our use of learning-curves. Thus, the reduction in cost from the first plant to the tenth plant is not as large as has been seell in other reactor design studies. Direct capital cosis are presented in 1983 dollars. These are shown in Table 23 for major elements in the code of accounts. The cost estimates for both first- and tirth-of-a-kind plants are given. The direct capital cost for MARS is $\$ 2,365$ billion, or $\$ 1,971 / k$ we. The largest difference between first- and tenth-of-a-k. ind plant custs occurs in Account 26, special materials, which is primarily the cost of $L i-P b$ that is $90 \%$ enriched in ${ }^{6} L i$. The reduction stems from a lowering ut enrichment costs based on a high product throughput.

The total capital cost is the sum of the direct capital cost and indirect capital costs for construction equif ent, facilities, and services (Account 91), engineering and construction management services (Account 92), and other costs including insurance, taxes, and owner's genera? and administritive: expenses (Account 93). These costs are specified in Table 24.

Account 91 is based on a detailed estimate derived from recent light water reactor experience. It is slightly more than the $10 \%$ of total direct cost used in many other reactor studies. Account 92 is $8 \%$ of direct costs and Account 93 is $5 \%$ as spec if ied by the Pacif ic Northwest Laborateit $y$ (PNL). 27 The tutal capital cost is $\$ 2.912$ billion, or $\$ 2,427 / \mathrm{kWe}$.

The final contributors to the total capital investment are th? time-related costs during the 5.75-year construction period and payout schedule discussed in Sec. 6. During this time the utility will pay interest on the funds already expended or intere. I ouring construction (IOC). :n 
Table 23. MARS direct capital costs.

\begin{tabular}{|c|c|c|c|}
\hline $\begin{array}{l}\text { Account } \\
\text { number }\end{array}$ & $\begin{array}{c}\text { Account } \\
\text { title }\end{array}$ & $\begin{array}{l}\text { First-of-a-kind } \\
\text { rost } \\
(M \$)^{\mathrm{a}}\end{array}$ & $\begin{array}{l}\text { Tenth-of-a-kind } \\
\text { cost } \\
\text { (M\$) }\end{array}$ \\
\hline 20 & Land and land rights & 5.0 & 5.0 \\
\hline 23 & Builaings and structures & 264.8 & 249.8 \\
\hline 22 & Reactor plant equipment & $1,879.4$ & $1,517.3$ \\
\hline 22.01 .01 & Blanket and first wall & 101.0 & 71.2 \\
\hline 22.01 .02 & Shield & 97.1 & 75.0 \\
\hline 22.01 .03 & Magnets & 576.5 & 493.0 \\
\hline 22.01 .04 & Supplemental heating & 135.2 & 101.3 \\
\hline 22.01 .05 & Prinary structure arid support & 67.1 & 54.6 \\
\hline 22.01 .06 & Vacuum systems & 8.2 & 7.0 \\
\hline 22.01 .07 & Power supplies & 72.3 & 63.4 \\
\hline 22.01 .08 & Orift pump coils & 5.6 & 4.7 \\
\hline $22.01 .0 y$ & Dirert converter & 25.5 & 22.8 \\
\hline $2 \% .02$ & Wain heat transport & 292.4 & 236.6 \\
\hline 22.03 & Auxiliary cooling system & 61.7 & 50.2 \\
\hline 22.04 & Radiuactive waste tredtment & 14.3 & 11.5 \\
\hline 22.05 & Fuel handling and storage & 65.1 & 45.9 \\
\hline 22.46 & other reactor plant equipment & 40.5 & 30.5 \\
\hline 22.07 & Instrumentation and control & 35.2 & 24.8 \\
\hline 2.96 & Spares & 42.0 & 32.0 \\
\hline 22.99 & Cont ingency & 239.7 & 193.0 \\
\hline 23 & Turbine generator plarit & 299.7 & 275.0 \\
\hline 24 & Electrical plant & 180.0 & 160.0 \\
\hline$\Leftrightarrow$ & Miscellaneous plant equipment & 36.1 & 33.2 \\
\hline \multirow[t]{2}{*}{$z b$} & Special materials & 177.3 & 124.9 \\
\hline & Total & $2,842.3$ & $2,365.2$ \\
\hline
\end{tabular}

Millions of dollars. 
Table 24. Indirect capital costs.

\begin{tabular}{|c|c|c|}
\hline Account & Account title & $\begin{array}{l}\text { Cost } \\
(M \$)^{\mathrm{a}}\end{array}$ \\
\hline & Total direct capital cost & $2,365.2$ \\
\hline 91 & Construcition facilities, equipment, and services & 240.0 \\
\hline 92 & Engineering and construction management & 189.0 \\
\hline 93 & Other & 118.0 \\
\hline & Total capital cost & $2,912.2$ \\
\hline
\end{tabular}

amillions of dellars.

addition, if there is an underlying inflation rate during the construction period tron the cost of construction yet to be completed will rise at this rate. This represents an escalation during construction (EDC). We have developed the total capital investment for the four cases given in Table 25 . Cases 1 and 2 present costs in "constant 1983 dollars." This assumes that there is no inflation. Case 1 has interest at $5 \%$ above the inflation rate (PNL guifeline) while Case 2 assumes trat the interest rate is $10 \%$ above general inflation (non-nuclear utility practice). Cases 3 and 4 present costs in "then current dollars," which account for the underiying inflation rate during construction. Cases 3 and 4 assume 5 and $8 \%$ escalation, respect.ively. The IDC for Case 3 is $10 \%$, or $5 \%$ above inflation (PNL guideline). Case 4 shows the effect of a higher escalation rate.

The cost of electricity (COE) is computed from the fixed carrying charge on the total plant investmant $\left(C_{A C}\right)$ plus the annual operating and maintenance costs $\left(C_{O \& M}\right)$, annual scheduled component replacement costs $\left(C_{S C R}\right)$, annual fuel costs $\left(C_{F}\right)$, the plant availability factor (PAF), plant capacity $(P C)$, escalation rate $\{5$ ! , and construction period ( $P$ ). The COE is given by

$$
C O E=\frac{C_{A C}+\left(C_{0 \& M}+C_{S C R}+C_{F}\right)(1+E)^{P}}{P C(. A F)(8760)},
$$


where $C_{A C}$ is given by the rroduct of the fixed charge: rate (FCR) and the tatal rapital investment.

We have derived a fixed-charge rate based on financing for an investor-uwned ut $i$ lity with $55 \%$ debt financing and $45 \%$ equity financing. We assumed strai. it-line depreciation for book purposes, while the sum of the digits is usec or income tax purposes on a flow-through basis. The plant life is 30 yea: with zero net salvage value; this implies that the actual salvage value is equal to the cost of decomissioning. We derive a fixedcharge rate of 0.14913 using these assumptions and use 0.15 in most of the COE computations.

Operations and maintenance costs, scheduled component replacement costs, and fuel costs are $\$ 20.2,5.3$, and 2.8 million per year, respectively, in 1983 dollars.

We compute the cost of electricity for the same four cases given in Table 25. These cases are shown in Table 26. For case 1, we use a $10 \%$ fixej-charge rate in accordance with PNL guidelines. For the other three cases, we use 15\%. The plant capazity is $1200 \mathrm{MW}$ and the availahility is 75\%, as discussed in Sec. 7. We can see that the busbar cost of electricity varies frcill 46.2 to $98.6 \mathrm{mil} / \mathrm{kWh}$, depending on the economic assumptions used. Cases 1 and 3 are Egivivalent to the two cases presented in the Starfire study. If costs are normalized to the same ycar and if we use the availability goals of 80 and $75 \%$ for MARS and Star? ire, respectively, then the MARS COE is about $4 \%$ iess than that of Starfire. The difference is well within the uncertainty of the estimates.

The costs presented are within the range of costs for new generation capacily to be insialled in the late eighties, and aro the uoper end of that range. Significant cost reductions can be gained by improved engineering designs without changes in the physics. The areas where the largest reductions can be attained are in the magnets, heat traisport systen, and electrical system. These, coupled with improved subsystem efficiencies, could result in a 20 to $23 \%$ reduction in capital cost per unit of output $(\$ / k W e)$. In addition, new physics concepts that allow a reduction in end cell costs can illprove the plant cost even further. Both of these can be done without sacrificing the environmentāl, safety, and maintainability advantages inherent in the MARS design. 


\begin{tabular}{|c|c|c|c|c|}
\hline \multirow[b]{3}{*}{ Cost element } & \multicolumn{2}{|c|}{ Constant 1983 dollars } & Then-current & 1989 dollars \\
\hline & Case 1 & Case 2 & Case 3 & Case 4 \\
\hline & $\begin{array}{l}1 D C^{a}=5 \% \\
E D C^{b}=0\end{array}$ & $\begin{array}{l}I D C=10 \% \\
E D C=C\end{array}$ & $\begin{array}{l}1 D C=10 \% \\
E D C=5 \%\end{array}$ & $\begin{array}{l}I D C=10 \% \\
E D C=8 \%\end{array}$ \\
\hline $\begin{array}{l}\text { Total capital cost }(M S)^{C} \\
\text { IDC } \\
\text { EDC }\end{array}$ & $\begin{array}{c}2912.1 \\
354.1 \\
0\end{array}$ & $\begin{array}{c}2912.1 \\
705.3 \\
\mathrm{u}\end{array}$ & $\begin{array}{r}2912.2 \\
863.2 \\
521.7\end{array}$ & $\begin{array}{r}2972.2 \\
67.8 \\
938.9\end{array}$ \\
\hline $\begin{array}{l}\text { Total capital } \\
\text { investment (MS) }\end{array}$ & 3266.3 & 3620.5 & 4257.1 & 4748.9 \\
\hline $\begin{array}{l}\text { Cost per unit } \\
\text { generated power }(\$ / k w e)\end{array}$ & 2722 & 3017 & 3581 & 3957 \\
\hline
\end{tabular}

Table 26. Cost of electricity (in $\mathrm{mil} / \mathrm{kWh}$ ).

\begin{tabular}{|c|c|c|c|c|}
\hline \multirow[b]{3}{*}{ Cost element } & \multicolumn{2}{|c|}{ Constant 198j dollars } & Then-current & 1989 dollars \\
\hline & Case 1 & Case 2 & Case 3 & Case 4 \\
\hline & $\begin{array}{l}I D C^{a}=5 \% \\
E D C^{b}=0 \\
F C R^{C}=10 \%\end{array}$ & $\begin{array}{l}I D C=10 \% \\
E D C=0 \\
F C R=15 \%\end{array}$ & $\begin{array}{l}I D C=10 \% \\
E D C=5 \% \\
F C R=15 \%\end{array}$ & $\begin{array}{l}I D C=10 \% \\
E D C=8 \% \\
F C R=15 \%\end{array}$ \\
\hline $\begin{array}{c}\text { Annual fixed charge } \\
\text { Annual } 0 \& M \text {, SCK, fuel } \\
\text { Tota? }\end{array}$ & $\begin{array}{r}42.56 \\
3.68 \\
46.2\end{array}$ & $\begin{array}{c}70.77 \\
3.68 \\
74.5\end{array}$ & $\begin{array}{r}84.00 \\
.38 \\
88.9\end{array}$ & $\begin{array}{l}92.83 \\
5.73 \\
98.6\end{array}$ \\
\hline
\end{tabular}

$a_{I D C}=$ interest during construction.

${ }_{E E D C}=$ escalation during construction.

$C_{F C R}=$ fixed-charge rate. 


\section{Power Flow and Cost Scaling}

The MARS plant makes very efficient use of the fusion energy it produces because of the following performance factors: (1) high neutron energy multiplication in the blanket; (2) direct conversion of end plasma losses; high-efficiency thermal conversion; (4) high plasma gain; and (5) highefficiency supplementary heating. These features are illustrated in Fig. 33 with a simplified power flow diagram. The definitions of the quantities in this figure are given in Table 27. We start from the supplemental heating power absorted by the plasma of $100.6 \mathrm{MW}$. The plasma gain (Q) of 26 yielas a fusion power of $2618 \mathrm{MW}$. The energy multiplication in the blanket and reflector increases the total thermal power to $3466 \mathrm{MW}$. Some of the power is lost (PL) before reaching the enerav conversion system as a result of synchrotron lusses from the plug anu neutrons that r.o not enter the blanket. The useful power is Givided among the blanket (PBL), reflector (PREF), and end ce? I (PEC). The blanket power is converter in a superheat cycle to produce $892.8 \mathrm{MW}$ (PESH) of electricity. A portion of the end cell power is directly converted to electricity (PDC), producing $292 \mathrm{MW}$. The remainder is obtuined as qiality heat (PECT) and is combined with the reflector power for con:ersion in a saturated stean cycle to produce $346.9 \mathrm{MW}$ of electricity (PESAT!. Thus, the gross electric jeneration in MARS (PG) is 1531.7. The reactor tequires $334.2 \mathrm{MW}$ of recirculating fower (PREC). The choke coil resistive inserts anu drift. pump coils require $: 01.5 \mathrm{MW}$ (PMAG). The four supplemental heating system.5-- chermal barrier ECRH, potential peak ECRH, anchor ICRH, and sloshingion neutral beams--require $158.3 \mathrm{MW}$ tctal (PPHW). The rest of plant, including primary loop pumps, cryo plant, reject cooling pumping, and other auxiliaries, 1EQuir(.5 14.4 MW (PAUX). This results in a not generation of $1197.5 \mathrm{MW}$ (PNET).

Thert aro several areas where the power balance could be improved. More officient lCRH lransmitters basec on developmental tubes could save about $6 \mathrm{MW}$. Juruasing the "ield in the superconducting portion of the choke coil to $18 \mathrm{~T}$ wuld reduce the magnet power by more than $20 \mathrm{MW}$. Improved efficiency of the cryo plant based on newer designs could save abolt $3 \mathrm{MW}$. Finally, changing the power split to increase the fraction of energy in the blanket could generate an additional $30 \mathrm{MW}$ of electricity. Thus, without any changes in the 


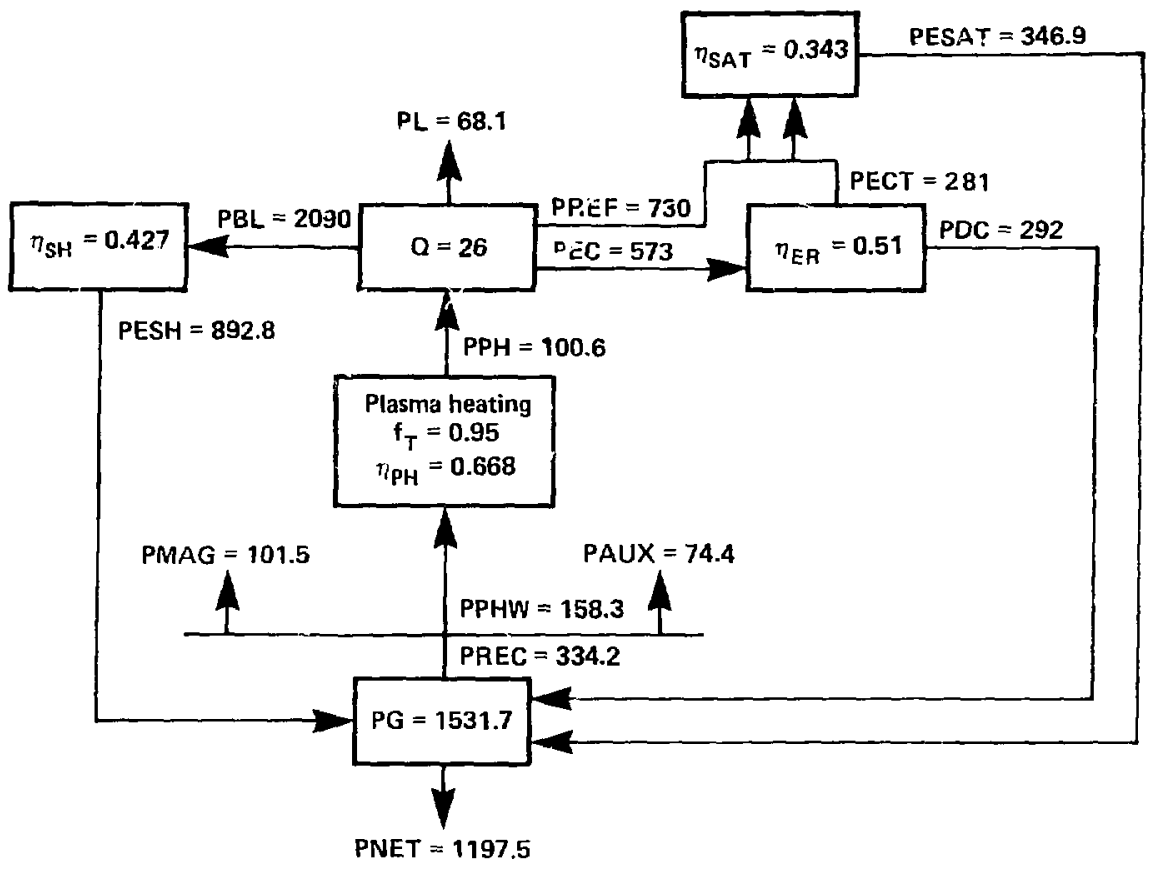

Fig. 33. A simplified model for the MARS power flow system.

physics, plasma configuration, and most subsystems, an aoditionai $60 \mathrm{MW}$ of electricity could be generated.

The unit rating of MARS and the cost of the plant size are closely related. Originally, we sized MARS for $3500 \mathrm{MW}$ of fusion power. Because of the efficient use of fusion power, this resulted in a net generation of about 1700 MW of electricity. We discussed this plant with representatives of the utility industry and decided to reduce the net electric ou.put to $1200 \mathrm{MW}$ to be consistent with recent utility practices. This lower plant size also simplifies comparisons with other fusion reactor studies and standard fission plant designs. 
Table 27. Power flow definitions.

Q Plasma gain, ratio of fusion power to power absorbed by the plasma

PL. Unusable power (synchrotron raoiation in the plug and neutrons in the central cell that do not enter tre blanket)

PEC End-: 211 charged-particle power on the inner and outer collectors, halo scraper, and halo dump

PREF Ref lictor power in water coolant

PBL Blanket power in Li-Pb coolant, including losses to the corrosion product cold trap

nER End-region direct-conversion efficiency

PECT Therma] power from the end cell in water coolant

ISAT Thermal efficiency of the saturated steam cycle

PESAT Electric power from the saturated steam cycle

POC Directly converteo $\epsilon$ lectric power

nst Thermal efficiency of the superheated steam cycie

PESH Electric power from the superheated steam cycle

PPH Absorbed plasma heating power from ECRH/barrier, ECRH/potential peak, $\mathrm{ICRH}$, and sloshing-jon beam

fT Average trapping fraction of plasma heating systems

npH combined efficiency of ?lasma heating systems

PMAG Recirculating power for choke coil resistive inserts and drift pump coils

PPHW Recirculating power for plasma heating systems

PAUX Recirculating power for primary loop pumping, secondary loop pumping, miscellaneous cooling, cryo plant, cooling tower fans, tritium plant, and electrical systems

PREL Total iecirculating power

PG Gross electric power

PNFT liet electric power 
The tandem mirror reactor has a unique feature that gives it a strong economy of scale: whereas the fision power increases line ${ }^{-m}$ ly with the length of the central cell, the end cell cost and the majority of the recirculating power remain approximately constant as the central cell length varies. The total capital cost for a MARS-type tandem mirror reactor as a function of net electric output is presented in Fig. 34. The MARS baseline design point of 1200 MWe and $\$ 2.912$ billion is indicated. The cost of a 1700-MWe plant is only $14 \%$ above that of the baseline. Of more importance is the cost per unit of net electric power, which is shown in Fig. 35. The unit cost is closely related to the cost of electricity. We can see the very strong economy of scale. The unit cost for a 1700-MWe plant is 19\% lower than the unit cost of the baseline; the unit cost of a 2000-MWe plant is $25 \%$ less. If cost of the tandem mirror reactor scaled at the 0.8 power, as do many power piants, the reductions at 1700 and 2000 MWe would only be 6.7 and $9 \%$, respectively. We chose to accept these cost penalties to produce a plant design that is within the range of present plant sizes. Today there is a strong desire to build plants smaller tlian the MARS baseline. Based on the scaling shown in Figs. 34 and 35 , the cost of a small reactor obtained by shortering the central cell length in MARS is prohibitive. Therefore, we are currently pursuing alternative design concepts with compact plugs for plants of less than 750 MWe net output.

The baseline MARS design was optinized for a large size plant. The cost of electricity could be reduced significantly if the plant sice were increased even further. For small-size tandem mirror reactors, a different sesign concept for the plugs is indicated and is now being explored.

\section{Conclusions of the MARS Study}

\subsection{Accomplishments}

The two-year MARS study produced the most complete and detailed tandem mirror reactor design to date, with self-consistent physics and engineering elements. It gives a fairly clear picture of what a commercial tandem mirror reactor would look like based on the type of thermal barrier plugs in TMX-U at LLNL, and on the plasma/magnet configuration to be tested in MFTF-B (a]so

at LLNL). The MARS study showed that safe, efficient, technically sound 

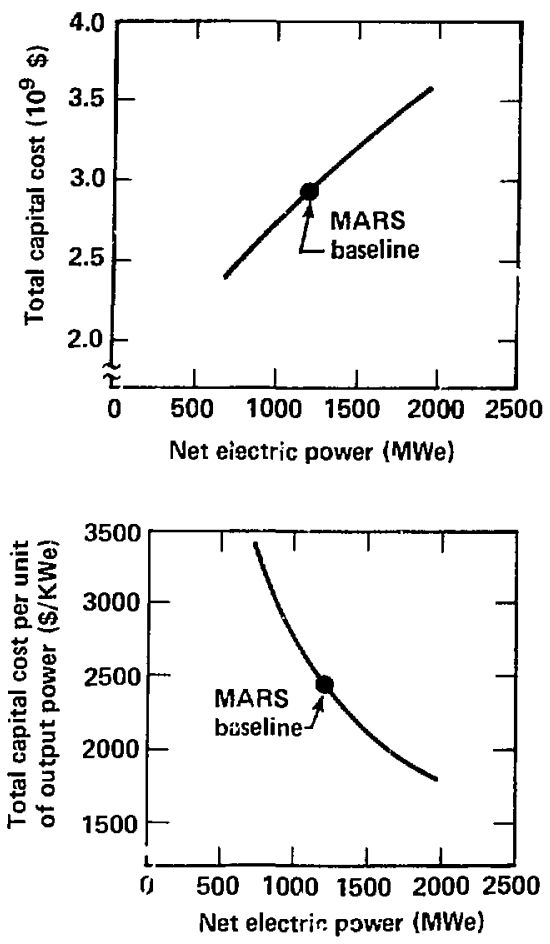

Fig. 34. Capital cost scaling for a tandem mirror reactor as a function of net electric power.
Fig. 35. Unit cost scaling for a tandem mirror reactor as a function of net electric power.

commercial reactors for the production of both electricity and synfuels can be designed based on these plasma confinement concepts. The MARS concept has many characteristics conducive to an attractive central-station fusion plant-high fusion power density, inherent steady-state operation, linear geometry, and direct conversion of plasma energy to electricity. The capital costs of the MARS electricity and synfuel plants are relatively high and thus we would expect the MARS reactor to be 1 imited to large, baseload central power plants. However, improvements in MARS reactor economics can be envisioned by evolut ion and maturation of fusion technology, and future $d i$ : coveries in physics can be expected to lead to both simplifications in the design, smaller unit sizes, and, therefore, even lower costs. 
The MARS design incorporates the key advances in mirror physics achieved in TMX-U--thermal barrier plugs with enhanced pocential plugging using ECRH, and enhanced microstabiiity using sloshing ions. The MARS study has also developed new physics concepts needed for improved reactor performance, such as śrift pumping of alpha ash and impurities, vacuum pumping by recycling halo plasmas, and radial-potential reduction by negatively biased end wall plat:zs. Many of these reactor improvement concepts have stimulated similar improvements to be incorporated into TMX-U and into the MFTF-B design. These improved plasma corfinement ideas fostered by both experiments and reactor design have enabled MARS to meet its performance goals of high plasma power gain $(Q \simeq 25)$ and high first-wall loading $\left(T=4.3 \mathrm{MW} / \mathrm{m}^{2}\right)$.

In addition to improved plasma design concepts, the MARS study also produced higher performance blanket designs, notably a high hlanket-energy multiplication $(M=1.36)$ in $\mathrm{d}$ Li-Pb blanket for electricity production, and a high-temperature, helium-cooled silicon-carbide pebble bed bianket $\left(T_{H E}\right.$ max $=1000^{\circ} \mathrm{C}$ ) for efficient synfueis production. These blankets, coupled with direct conversion of the plasma exhaust, have made it possible for MARS to achieve an impressive overall efficiency of fusion energy conversion to net electricity production equal to $46 \%$ of the DT fusion power, and liquid methanol svafiel energy production equivalent to $50 \%$ of the DT fusion power in a separate synfuel plani design.

Anticipating that superconducting magnets are a key fusion technology requirement far MARS and that they are one of the larger cost items in the reactor plant, the MARS magnet design adheres as closely as possible to MFTF-B magnet technology and cost data. Except for key portions of the magnet system, such as the high-field choke ccils, which require extensive development for MARS, the majority of the MARS magnets require only modest extrapolations in present state-of-the-art superconducting magnet size, fields, and technology. Aggressive magnet design in terms of both increased stored energy per unit mass and radiation tolerance is one future area whe. . we would expect to see big payoffs in terms of system ecollomics.

The MARS study also pioneered several new ideas to exploit inherent fusion possibilities in improved waste disposal and safety. We showed that practical ferritic structural steels could meet NRC ruies (10CFR61) for nearsurface burial as Class-C low-level waste; and we designed simple, i ightweight 
blanket modules to meet those requirements with a minimum of processing and transportation. We showed that passive radiation and conduction cooling in the MARS blanket would prevent meltdown in all conceivatle loss-of-coolant and loss-of-flow accidents. Reactor vault overpressures in worst-case accidents would not exceed even a small fraction nf an atmosphere, reducing containment building complexity and cost.

\subsection{MARS R\&D Needs}

\subsubsection{Introduction.}

Table 28 identifies some critical technology requirements that are particularly vital in order for us to achieve our performance goals for MARS. The requirements 7 isted in Table 28 need extensive additional R\&D, but are not a total 7ist. We also require further data on the effects of corrosion and neutron damage on the constituent materials of most of these technology components (see Table 29). Major areas in which we can define R\&D needs are described in the following sections.

\section{2 .2 Negative-I on-Based Neutral Beams}

Develupment of negative ion technology is essential to the formation of energetic sloshing ions in the MARS thermal barriers. While the greater neutralization efficiencies and single species characteristics of negative-ionbasea necitral beams would be useful everywhere on a mirror reactor, the $475-\mathrm{kV}$ 10-A requirements for the MARS reactor appear to necessitate the negative ion approach. Presently, negative ion sources in tre $1-A$ range are operating in a continuous mode. Also, initial experiments with single-aperture, large-area, multiple-beamlet electrostatic quadrupole accelerators have been performed. However, there is an immediate need for an enhanced negative ion program to complete source development and construct a proof-of-principle accelerator and neutralizer assembly. In addition, photodetachmert using lasers merits development to provide the high neutralization efficiencies desired in mirror reactors. 
Table 28. MARS critical technology R\&D needs.

Technology

sequirement

Negative ion beam

$475 \mathrm{kV}, 10 \mathrm{~A}, 0.1 \mathrm{~A} / \mathrm{cm}^{2}$

High-field hybrid magnet

$24 \mathrm{~T}, 60-\mathrm{cm}$ bore, $\mathrm{Cu}+\mathrm{Nb}_{2} \mathrm{Sn}+\mathrm{NbT} \mathrm{i}$

Drift pumping

$18 \mathrm{kA}, 47 \mathrm{kHz}, \Delta f / f=0.4$

Direct conversion, plasma

$3-\mathrm{MW} / \mathrm{m}^{2}$ gricless direct converters compatible exhaust with radial potential control; high recycling halo dumps for 2-kA DT and He pumping

$20 \mathrm{~km} / \mathrm{s}, 6.5 \mathrm{~Hz}, \mathrm{r}=2 \pi \mathrm{m}$

High-speed DT pellet injectors

Quasi-optical ECRH systems

$42 \mathrm{NW}, 60 \mathrm{GHz}, 2.5-\mathrm{MH}$ gyrotron tubes

Li-Pb blankets

$T_{\max }=500^{\circ} \mathrm{C}, \mathrm{S}_{\mathrm{W}}=5 \mathrm{~W} \mathrm{~cm}^{-2}, 0.1-\mathrm{mm} /$ year erosion, $\Gamma>4 \mathrm{MW} / \mathrm{m}^{2}$, corrosion product cold traps

Double-walled heat exchangers $10^{-4}$ attenuation of $T_{2}$ from the $L i-P b$ side to the steam side

High temperature synfue 1 $T_{\text {max }}=1000^{\circ} \mathrm{C}, P=80 \mathrm{~atm}, \Gamma=4 \mathrm{MW} / \mathrm{m}^{2}$, blankets $S_{w}=5 \mathrm{w} / \mathrm{cm}^{2}, 0.1-\mathrm{mm} /$ year erosion

$\mathrm{High}$ temperature $\mathrm{SO}_{3}$ $P=80 \mathrm{~atm}, T_{\max }=960^{\circ} \mathrm{C}$, corrosionresistant decomposer 
Table 29. MARS critical material data needs.

Blanket and coolant

- Enu-of-life radiation damage effects in HT-9 ferritic steel (i.e., swelling, radiation creep, changes in QBTT, etc.) for first-wall neutron fluences in the range of 5 to $25 \mathrm{MW} \cdot \mathrm{yr} / \mathrm{m}^{2}$

- Li-Pb/HT-9 corrosion data:

- Corrosion rates for interface temperatures of 2500 to $550^{\circ} \mathrm{C}$, flow velocities of 20.1 to $2 \mathrm{~m} / \mathrm{s}$ and magnetic fields of several teslas

- Deposition characteristics of corrosion products in turbulent flow regions and cold traps

- Performance of additives as corrosion inhibitors

- Performance testing of $L i-P b$ as a self-sealing material for remote joint technology

Superconducting magnets

- Radiation damage properties of organic insulators under stress condicions (shear and compressive) relevant to magnet operation

- Definirion of radiation-induced critical-current degradation in NbTi and Nb3sn superconductors

- Quantification of radiation-induced resistivity increases in copper stabilizers

- Ongoing development of general radiation-resistant magnet materials for high-field, high-current-density applications

No mal conducting magnets

- Development of high-yield-strength high-conductivity copper alloys for normal-conducting magnet applications

- Radiation drilage effects in high sirength copper alloys under elevated $14-\mathrm{MeV}$ neutron fluences $>10^{26} \mathrm{n} \mathrm{m}^{-2}$

- Characterizatjon of ceramic insulator damage under elevated 14-MeV neutron fluences $>10^{26} \mathrm{n} \mathrm{m}^{-2}$

- Radiolytic dissociation effects in cooiant water

Direct converter materials

- High-heat-flux, high-yield-strength, low-sputtering materials for direct converter and halo scraper surfaces

- Brazing and machining of large-size TZM molybdenum alloy panels

- Experimental determination of diffusion properties of implanted tritium through proposed direct converter materials 


\subsubsection{Magnet Development}

The peak field levels--10 T--and size of the yin-yang maynets in MaRS are nearly the same as those recently demonstrated in the MFTF-B magnet system. In addition, 7-T 5-m-bore central solenoid magnets are easily within the reach of existing technology. However, these magnets dominate the cost of the reactor and further development is desired to reduce these costs. The 24-T hylrid-choke-coil magnets require considerably more development. A normal copper hybrid coil producing about $8 \mathrm{~T}$ augments a background superconduct ing coil field of $16 \mathrm{~T}$. The development of 12- $T$ magiets is currently being pursued in the High Field Test Facility at LLNL, and a 13.5-T solenoid is planned for MFTF-B. Future superconducting magnet development plans will include ternary additions, such as titanium, to niobium-tin to reach fields of 15 to $16 \mathrm{~T}$. In addition, development of organic insulators with higher rar'iztion-damage tolerance is certainly required here.

However, a new ingredient in the magnet development plan is normal copper insert coils producing field increments of $9 \mathrm{~T}$ in a $60-\mathrm{cm}$ inside bore. The 24-T field produces very high tensile stresses in a high neutron radiation environment. New ceramic insulators must be examined and new coil winding techniques must be developed. Experience with water-cooled Bitter coils indicates that this type of coil is unlikely to be applicable in its present state of deve?opment because of short coil lifetimes attributable to shorting and arcing. By contrast, internally cooled MgO-insulated magnets used in the Los Alamos Meson Production Facility (LAMPF) exhibit good lifetimes but low current densities. At a minimum, conductor configuration, insulation, joining, and coil winding techniques need to be demonstrated as a proof-of-principle. Later, small-scale coil tests to full field will be necessary.

\subsubsection{Particle Fueling, Exhaust, and Energy Recovery}

Steady-state operation in MARS will require $2 \mathrm{KA}$ of DT particles throughput, with repetitive high-velocity pellet injection, radial drif $t$ pumping, and exhaust into a halo diverter plasma (see Table 28). The required pellet velocities are estimated to be well beyond the 1-to-2-km/s speeds presently available with centrifugal or pneumatic drives. Linear electromagnetic railguns are the most promising method to achieve the factor of 10 in velocity, and have been achieved with small plastic pellets. Tests of railguns 
with hydrogen ice peliets are needed. The key challenge with drift pumps is to obtain $r f$ drivers that can suppiy the large reactive $r f$ currents at several simultaneous frequencies with low loss (circuit $Q>200$ ). The halo dump that receives the drift-pumped DT fuel and alpha ash must trap the resulting nautralized gas in a reentrant cavity with a high recycling coefficient $(>10$ to ?0) and at a useful plenum pressure ( $5 \mu$ or higher). The sputtering lifetime lust be usefully long--a minimum lifetime of several years is desirable. Tritium loss into the cocling water must be much less than $1 \%$ of the tritiun bred in the blanket. The electron exhaust, which is separated from the ion current by the drift-pumping process, must be collected on negatively biased plates with in the annular halo dump. The electron collector potentials $(-167 \mathrm{kV}$ maximum) must be appropriately graded to keep the central cell plasma near ground potential. Peak collector heat fluxes of $3 \mathrm{MW} / \mathrm{m}^{2}$ are required for compact direct converters.

\section{$11.2 .5 \quad$ Li-PD B Banket}

The use of $\mathrm{Li}-\mathrm{Pb}$ as the blanket r:olant/breedom $: 1$ lows high performance in terms of themal efficiency, tritium breeding, and energy multiplication, coupled with long life and simplicity of design. One key issue for the blanket is the upper temperature limit set by liquid metal corrosion. Additional data are needed on corrosion rate as a function of temperature and velocity. No data exist on the effect of the magnet ic $f i_{t}$ un corrosion, which could change the results markedly. Most importantly, no work has been períormed on methods to reduce the corrosion rate through the use of inhibitors or on the design of the primary loop to accommodate large corrosion rates. The use of traps to avoid plugging of passages indicates great promise. If material thinning is determined to be the only life-limiting corrosion effect, then long blanket life at high $\left(>500^{\circ} \mathrm{C}\right)$ temperatures $\mathrm{can}$ be attained. One of the principal causes of stress in the blanket is the internal pressurization of the coolant to overcome the MHO-induced pressure drop. More R\&D on pumping conducting liquids through a magnetic field is needed. Of particular importance are entrance and exit effects, flow constrictions and expansions, flow striations, and the overall effect on heat transfer. Other fruitful blanket R\&D areas would be to investigate relaxation of stresses by radiation-induced creep, 
radiation-induced change in the ductile-to-brittie transition temperature, swelling at high displacement-per-atom levels, and design for total deformation as a life-limiting mechanism.

\subsubsection{Heat Transfer Components}

The primary loop, because of the high density of the Li-Pb coolant, requires component development. Moreover, the size of components is 1 imited due to weight restrictions. Development is needed in heat exchanger design (particularly double-walled heat exchangers), piping supports, and pumps. The c'esign of self-soldering Li-Pb seals used for remote disconnection of the piping needs to be tested.

\subsubsection{Tritium Control}

Because of the low solubility of tritium in Li-Pb, tritium control in the plant is difficult. We have designed a baseline doubli-walled steam generator with an active, $\mathrm{O}_{2} / \mathrm{He}$ tritium purge to provice a barrier of $10^{4}$ to $10^{5}$ between the primary and secondary loops. The effectiveness of this barrier relies on oxidizing the tritium to $\mathrm{T}_{2} \mathrm{O}$ in the gap to preclude further permeation, and 0,7 providing a self-healing oxide coating on the tube walls. Tests of this coniept are needed to prove its effectiveness as a tritium barrier and for heat transfer. Methods to enhance the oxidation in the gap need development. The method of removing tritium from Li-Pb is important because we desire an equilibrium pressure of $T_{2}$ in Li-Pb of less than $10^{4}$ Torr. Further work is desirable to explore the most economic and effective method of implementing this recovery.

\subsection{Future Directions}

Although MARS represents a significant advance in tandem mirror reactor design, it is important to realize that MARS, like other fusion reactor designs at this early stage of conceptual development, will continue to evolve and improve as new experiments and better ideas are brought to bear. We likely have not yet fully exploited all the intrinsic characteristics of tandem mirrors (see Sec. 1) to achieve an optimum design in terms of reli bility and 
economics. The tandem mirror reactor concept is still relatively new and has received limited study relative to the tokamak. The simultaneous solution of the large number of physics and engineering requirements that formed the MARS point design commanided almost all of the two years of the MARS study. Now, at the conclusion of the study, we can already see new opportunities for future improvement and optimization of $t$ andem mirror reactors.

We can foresee at least four general areas in which to seek these future improvements:

- We can probably find a better optimization in the tradeoff between central cell field, wall loading, and end cell heating power requirements. In MARS, we prescribed a maxilitum wall loading $\left(\Gamma_{n}>4 \mathrm{MW} / \mathrm{m}^{2}\right)$ consistent with the maximum MHD-stable plas:na pressure. This maximum wall loading required high plug betas as well as high anchor betas in the MARS end cell, resulting in high synchrotron radiation losses and ECRH power. Some of our recent post-MARS analyses incicate that reducing the wall loading by a factor of two (and central cell field from 4.7 to 3.3 T) could virtually eliminate synchrotron radiation and reduce total plug power by a factor of 4 (which doubles $Q$ to 50 ). This tradeoff needs further exploration.

- We could obtain a large reduction in magnet weight and cost if we could design superconducting magnets to withstand greater neutron fluence, so that the shields could be thinner until cryoplant cost and power become the fundaniental tradeoffs with magnet size and cost. Figure 36 shows the present dominance of magnet costs in the MARS reactor plant equipment (Account 22). Preliminary investigations by Henning et al. ${ }^{28}$ indicate that neutron fluence effects that could be tolerated by superconducting magnets--dpa-induced resistivity in the copper stabilizer, compressive strength loss in polyimide insulators, and reductions in superconductor-critical current density--could be increased by factors of 100 with proper design allowance in the magnet design parameters. In many cases, particularly in the end cell magnets, shield thicknesses could be reduced by 20 to $40 \%$, and corresponding geometric reductions in magnet volume, stored energy, weight, and cost could be decrea ed by factors of 2 to 3 compared with MARS. 


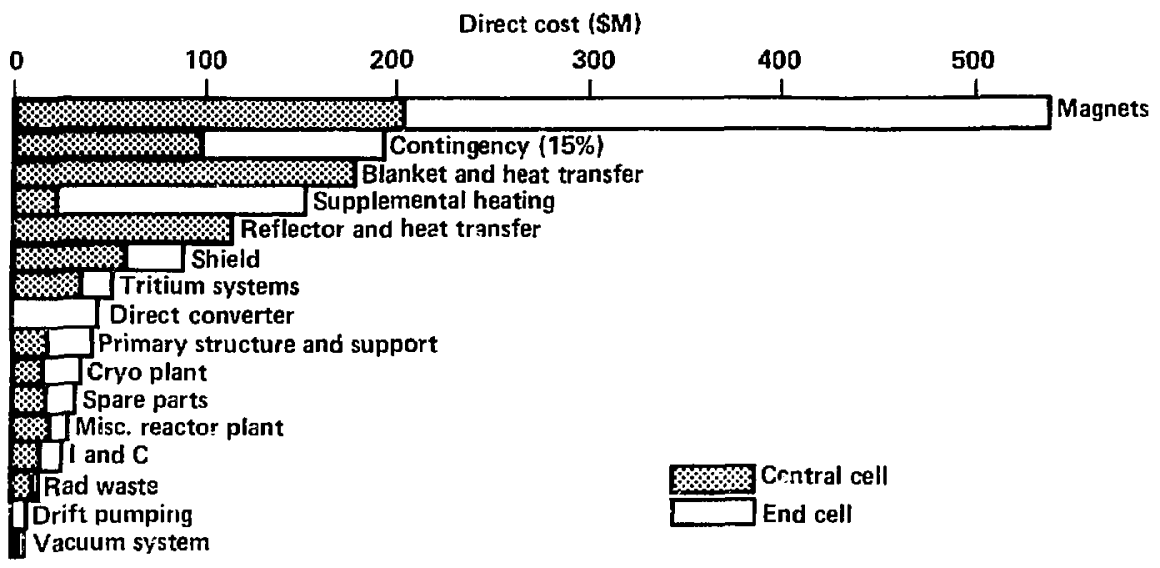

\%का Li-Pb coolant

Fig. 36. Histographic representation ur tae MARS reactor plant equipment costs. The cost of the Li-Pb coolarit (classified as "special materials") is shown for comparison.

- We could simplify the MARS main heat transfer system and balance of plant if we could avoid using two coolants in the MARS blankets without losing performance $\left(M=1.36, n_{T H}=0.40\right)$. This could allow the heat exchangers to be located closer to the reactur vault, ecunomics in piping, and more economical common steam turbines. Coolants other than water should also be investigated for conversion of the thermal friction of the end loss power. Also, we need to reduce the lithium enrichmeni to reduce the inventory costs of $\mathrm{Li}-\mathrm{Pb}$ ( $\mathrm{Fig} .36$ ).

- Finally, by the end of the MARS study we more fully understood the relationship between the physics requirements for equilibrium, stability, and transport and the resulting size and cost of the MARS end plugs. Figure 36 shows that if the plug rosts (unshaded portion of the bars) could be greatly reduced by new design 
approaches to solve the physics requirements, then potential reductions in MARS reactor plant equipment of up to 40 te $50 \%$ would occur if the central cell became the fundamental lower limit to the costs. Theoretical efforts are presentiy underway at LLNL, and other laboratories are investigating use of higher-order multipole fields, ElMo-type hot electron rin:ss, and $r f$ ponderomotive forces to stabilize just the outer boundary of "flat" radial-pressure profile plugs, which is the only area that requires stabilization as pradicted by theory. The result would be that the plasma core--the central cell--could be plugged with essertially sirgle mirror cells 7 ml long on each end, compared with the $30-m$ length of the MARS end cells.

Although for future improvement most of the above four areas (and others) will be vigorously pursued. there are many physics and engineering concepts usad in the MARS design that will likeiy endure in future tandem mirror reactor designs. These include the central cell with its engineering simplicity and high-performance blankets, the high-field choke coils, drift pumping, slosining-ion tirermal barriers, quasi-optical ECRH systems, and negatively biased direci r.onverters. The real value of MARS, like all reactor studies before it, lies in its probleni-solving role and in the new concepts fostered by the study as an invaluable educational process in the design of commercial fusion power plants. 


\section{References}

1. T. C. Simonen, D. E. Baldwin, S. !. Allen $e^{+}$al., "TMX Tardem Mirror Experiments and Thermal Barrier Treoreticai Studies," in Proc. of the Ninth International Conference on Plasma Physics and Cont. ol led Nuc lear Fusion Research, Baltimore, MD, 1982, Vol. 1, p. 519.

2. R. R. Borchers and C. M. Van Atta, The National Mirror Fusion Program Pian, Lawrence Livermore National Lahoratory, Livermar a, CA, UCAR $\cdot 10042-80(1980)$.

3. E. G. Logan et al., Mirrur Advanced Reactor Study (MARS)--Final Report (Vols. 1-A, 1-B, and 2), Lawrence Livermore National Labcratory, Livermore, CA, UCRL-53480 (1984).

4. G. I. Cimov, V. V. Zak i jakov, anc it. E. Kishinevsky, Fiz. Plasmy 2, 597 (1976) [Sov. J. Plasma Phys. 2, $320(1976)$ ], in Proc. of the Sixth International Confer ince on Plasma Physics and Controlled ivuc lear Fusion Research, Berchtesgaden, West Germany, 1976 (International Atomir. Energy Agency, Vienna, 1977), Paper No. C4.

5. T. K. Fowler aru B. G. Logaii, Lomments Plasma Phys. Controlled Fusion 2, $167(197 i)$.

6. T. C. Simonen, Editor Summary of TMX Result,s--Executive Summary, Lawrence Livermore Naticnal Laboratory, Livermore, CA, UCRL -53120 (1981). See also, T. C. Simonen, C. A. Anderson, T. A. Casper et al., Plasma Conf inement Experiments in the TMX $T$ andem Mirror," in Proc. Int l. Conf. Plasma Physics and Controlled Nucl. Fusion Research, 8th, Brussels, 1980 (T'EA-CN-38/F-1, Vienna, 1981). 
7. T. C. Simonen, S. L. Allen, L. Berzins et al.' Initial TMX-U Thermal Barrier Experiments, Lawrence Livermore National Laboratory, Livermore, CA, UCID-19872 (1983). See also D. P. Grubb, S. L. Allen, T. A. Casper et a1., Thermal Barrier Production and Indent if ication in a Tandem Mirror, Lawrence Livermore National Laboratory, Livermore, CA, UCRL-905JE (1984).

8. D. E. Baldwin, R. H. Cohen, T. B. Kaiser at al., "Studies in Tandem Mirror Theory," in Proc. of 8th Int. Conf. on Plasma Phys. and Cont. Nuclear Fusion Research, IAEA, Brussels 1980, Vol. I, p. 133.

9. R. H. Bulmer, T. B. Kaiser, W. M. Nevins et al., "Gyrokinetic Equilibrium and Stability in Quadrupole Tandem Mirrors," (IAEA-CN-41/G-2) in Proc. of 9th Int. Conf. on Plasma Phys. and Cont. Nuc. Fus. Research, IAEA Balitmore, MD 1982, Vol. 1, p. 531.

10. G. L. Kulcinski et al., "A Commercial Tandem Mirror Reactor Design with Thermal Barriers-WITAMIR I," UWFDM-375, Univ. of Wisconsin, Madison, WS, in Proc. of 4 th ANS Topical Meeting on the Technology of Controlled Nuclear Fusion, King of Prussia, PA, Oct. 14-17, 1980.

11. G. A. Carlson, W. L. Barr, B. M. Baghosian et al., Comparative End-Plug Study for Iandem Mirror Reactors, Lawrence Livermore National Laboratory, Livermore, CA, UCID-19271 (1981).

12. D. E. Baldwin and B. G. Logan, Editors Physics Basis for an Axicell Gesign for the End Plugs of MFTF-B, Lawrence Livermore National L aboratory, Livermare, CA, UC1D-19359 (1982).

13. C. C. Baker et al., Starfire--A Commercial Tokamak Fusion Power P lant Study, Argonne Nationa) Laboratory, Argonne, IL, ANL/FPP-80-1 (two volumes), (Sept. 1980).

14. 0. E. Baldwin, Bullet in Am. Phys. Soc. 26, p. 1021 (1981). See also, B. G. Logan, Mirror Advanced Reactor Study Interim Report, Lawrence Livermore Nationil Laboratory, Livermore, CA, UCRL-53333, p. 2-359 $(1983)$. 
75. W. L. Barr and B. G. Logan, "A New Direct Converter for Tandem Mirror Reactors," Cumments Plasma Phys. Controlled Fusion 8 (j), pp. 103-107 (1984).

76. B. G. Logan et a1., "High-Beta Gas-Stabilized Mirror-Confined Plasma," Phys. Rev. Lett. 37,1468 (1976).

17. R. B. Campbe 11, TMRBAR--A Code to Calculate Plasma Parameters for Tandem Mirror Reactors Dperating in the MARS Mode, Lawrence Livermore National Laborator y, Livermore, CA, UCID-19875 (1983).

18. M. N. Rosenbluth, H. L. Berk, H. V. Wong et a1., "Fast-Growing Trapped Particle Modes in Tandem Mirrors," in Proc. of 1982 Sherwood Meeting, Annual Controlled Fusion Theory Conference, Santa Fe, NM, April 25-28, 1982.

19. L. D. Pearlstein, D. E. Baldwin, R. H. Cohen et al., "Stabilization of Tandem Mirror Trapped Particle Modes by Incomplete Cancellation of Trapped Particle Drifts," in Proc. of 1982 Sherwood Meeting, Annual Controlled Fusion Theory Conference, Santa Fe, NM. Apri ? 25-28, 1982.

20. J. Kesner, R. S. Post, B. D. McVey, and D. K. Smith, A Tandem Mirror with Axisymmetric Central Cell Ion Confinement, Massachusetts Institute of Technology, Cambridge, MA, Report PFC/JA81-11 (1981).

21. S. J. Sackett, EFFI-A Code for Calculating the Electromagnetic Field, Force and Inductance in Coil Systems of Arbitrary Geometry, Lawrence $L$ ivermore National Laboratory, Livermore, CA, UCRL-52402 (1978); see also Users Manual, Lawrence Livermore National Laboratory, Livermore, CA, UCID- 17621 (1977).

22. L. D. Pearlstein, T.B. Kaiser, L. LoDestro et al.. IEBASCO User's Guide, Lawrence Livermore National Laboratory, Livermore, CA, UCID-19869 $(1983)$. 
23. E. B. Hooper, Jr., Plasma Potential Control--Initial Results from TMX-U, Lawrence Livermore National Laboratory, Livermore, CA, UCID-20025 (1984).

24. M. E. Read, "NRL Multimegawatt Program," in Proc of U.S. DOE Office of Fusion Energy-Gyrotron User/Developer Meeing, Germantown, MD, P.pril 12-13, 1982, 170.

25. K. N. Leung and K. W. Ehlers, Rev. Sci. Instrum. 53, 803 and 1423, (1982).

26. 0. A. Anderson, "Transverse-F ield Focusing Accelerator" in Proc. of Third International Symp. on Production and Neutralization of Negative Ions and Beams, Brookhaven National Laboratory, American Institute of Physics, AIP Conference Proceedings. No. 111, p. 473 (1983).

27. S. C. Schulte, T. L. Willke, and J. R. Young, Fusion Reactor Design Studies--Standard Accounts for Cost Est imates, prepared for the U.S. Department of Energy by Pacific Northwest Laboratory, PliL-2648 (May 1978).

28. C. D. Henning, E. N. C. Dalder, J. R. Miller, and L. J. Perkins, Superconducting Radiation Hardened Magnets for Mirror Fusion Devices, Lawrence Livermore National Laboratory, Livermore, CA, UCRL-90092 (1983). 